Universidad de Lima

Facultad de Ingeniería Industrial

Carrera de Ingeniería Industrial

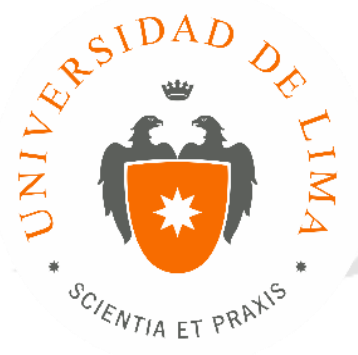

\title{
ESTUDIO DE PREFACTIBILIDAD PARA LA IMPLEMENTACIÓN DE UNA PLANTA DE PRODUCCIÓN DE ACEITE DE SACHA INCHI (Plukenetia volubilis)
}

Trabajo de investigación para optar el título profesional de Ingeniero Industrial

Lourdes Gómez de la Torre Cateriano

Código 20072340

Diego Lazo Cánepa

Código 20071580

\author{
Asesor \\ Edmundo Arroyo Benites
}

Lima - Perú

Noviembre de 2015 


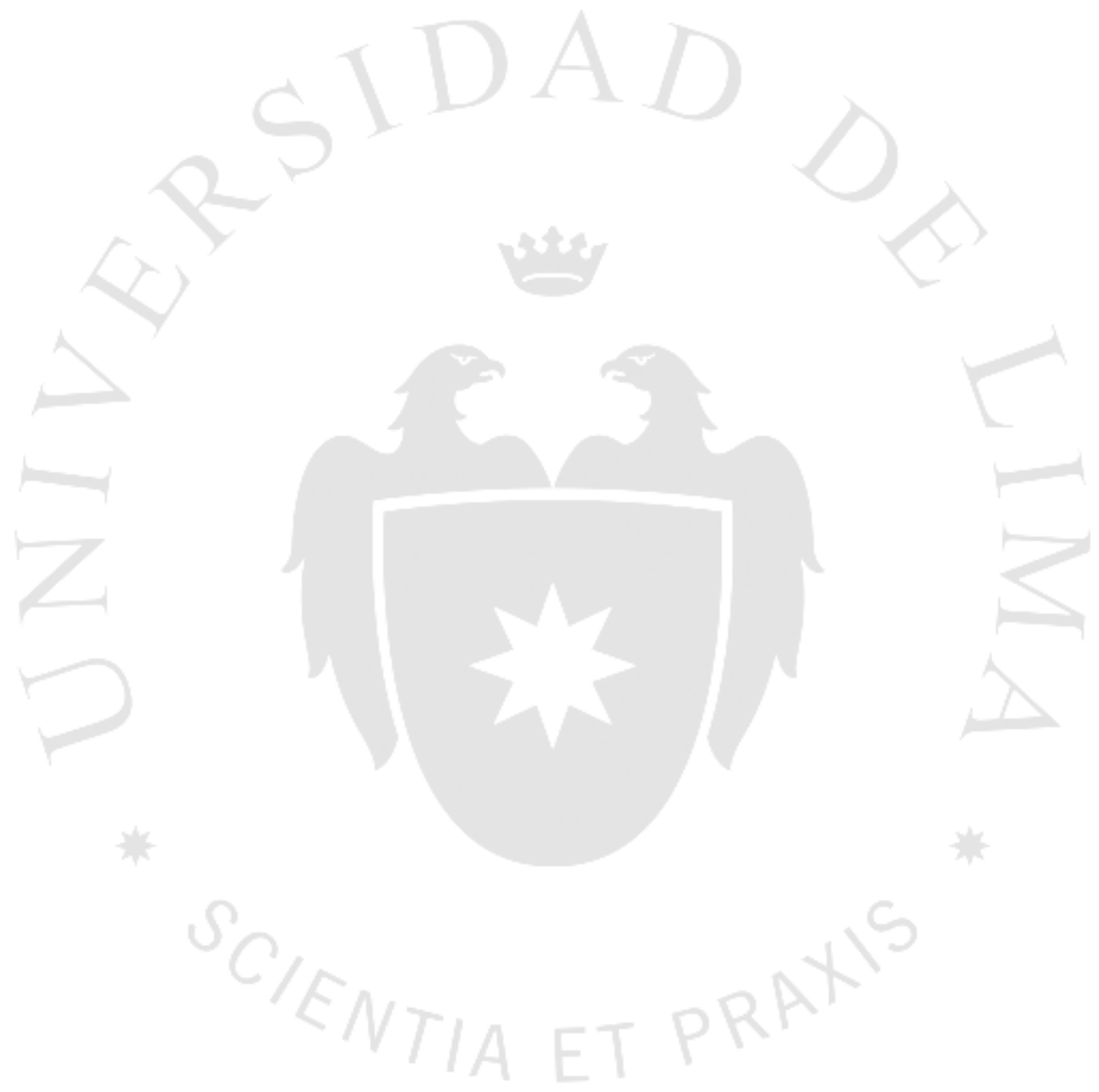




\section{ESTUDIO DE PREFACTIBILIDAD PARA LA IMPLEMENTACIÓN DE UNA PLANTA DE PRODUCCIÓN DE ACEITE DE SACHA INCHI (Plukenetia volubilis)}




\section{TABLA DE CONTENIDOS}

Resumen ejecutivo...................................................................16

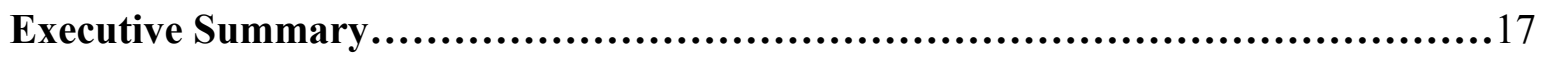

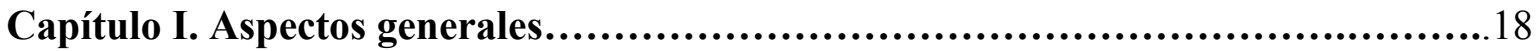

1. Objetivo general........................................................ 18

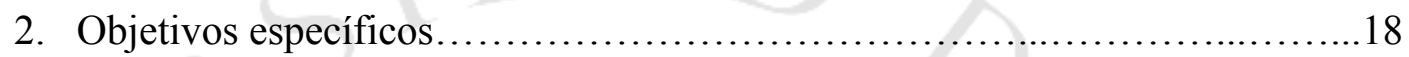

3. Justificación de la investigación........................................... 18

1. Social........................................................ 18

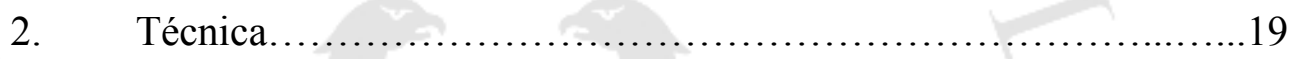

3. Económica.....................................................

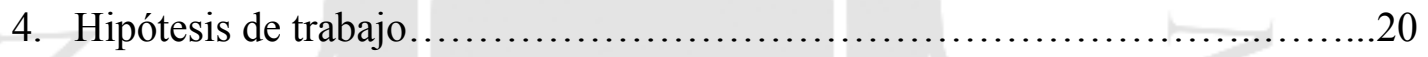

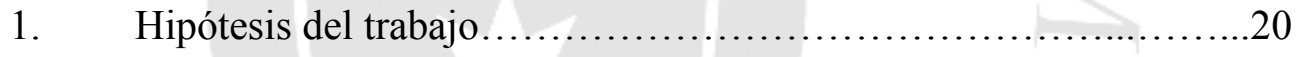

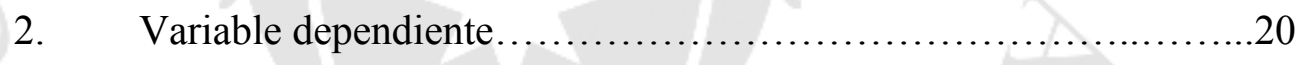

3. Variable Independiente......................................20

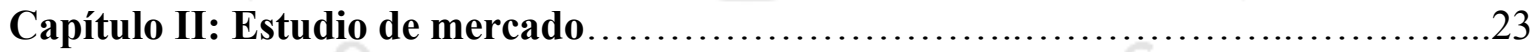

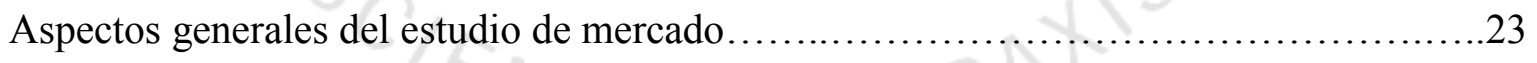

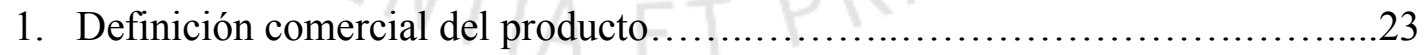

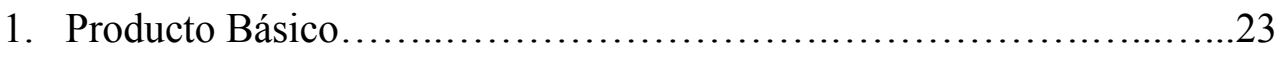

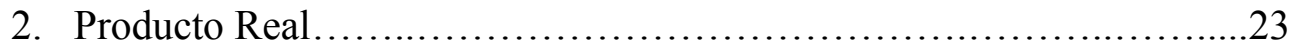

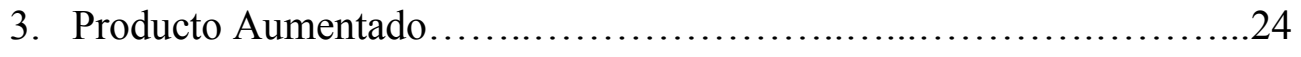

2. Principales características del producto.....................................24

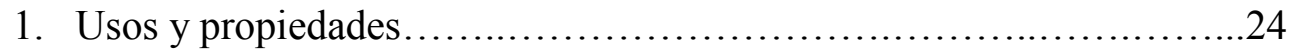




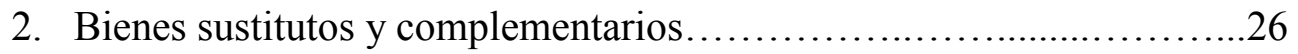

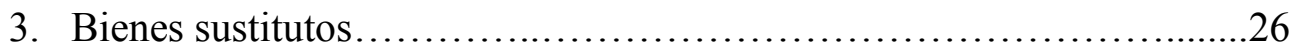

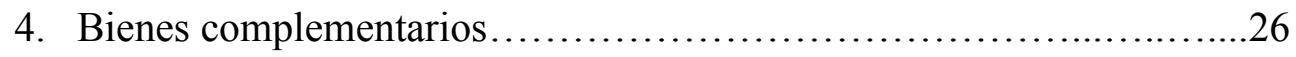

3. Determinación del área geográfica que abarcará el estudio......................27

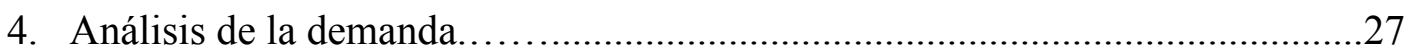

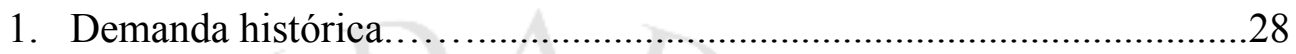

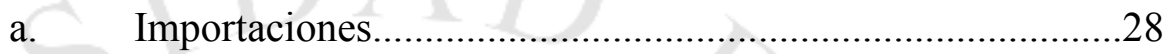

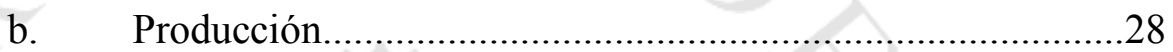

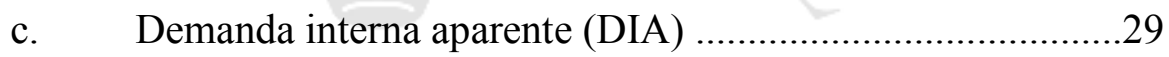

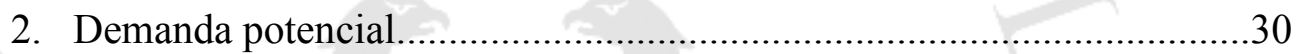

a. Patrones de consumo...............................................................

b. Determinación de la demanda potencial................................32

3. Proyección de la demanda y metodología del análisis...............................33

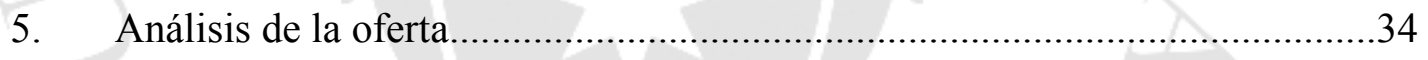

1. Empresas productoras, importadoras y comercializadoras......................34

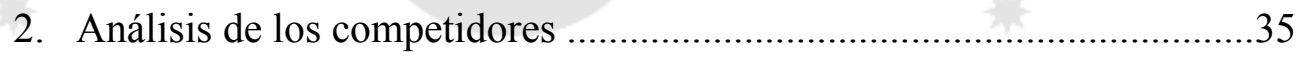

a. $\quad$ Poder de negociación de los proveedores.................................36

b. Amenaza de nuevos competidores..............................................

c. Poder de negociación de los clientes.........................................36

d. Amenaza de productos sustitutos...............................36

e. Rivalidad entre los competidores existentes...........................37

f. Principal competidor.............................................................

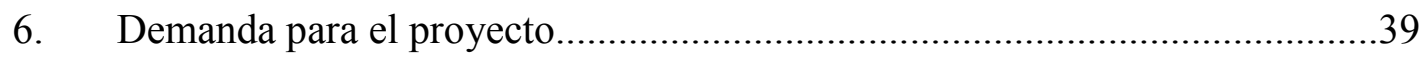


1. Segmentación del mercado

2. Selección del mercado meta.................................................................

3. Determinación de la demanda para el proyecto........................................41

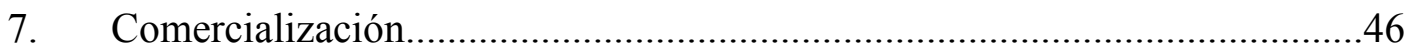

1. Políticas de comercialización y distribución................................46

a. Producto........................................................ 46

b. Plaza..........................................................

c. Precio......................................................... 47

2. Publicidad y promoción.................................................47

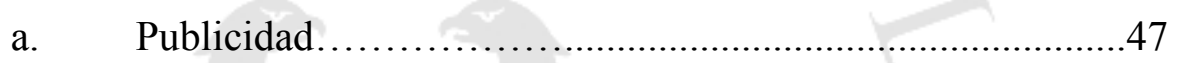

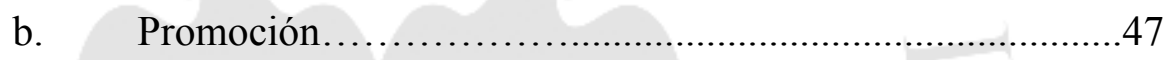

3. Análisis de precios.................................................48

a. Tendencia histórica de los precios...........................48

b. Precios actuales........................................................... 48

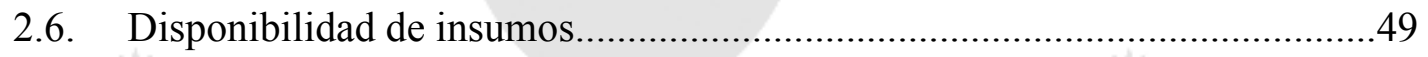

1. Características principales de la materia prima...................................49

2. Potencialidad del recurso en la zona de influencia del proyecto.....50

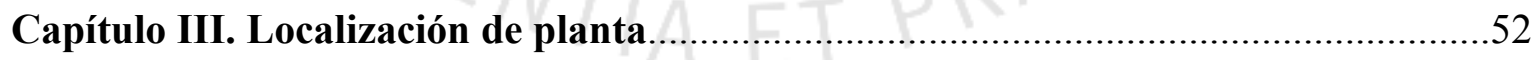

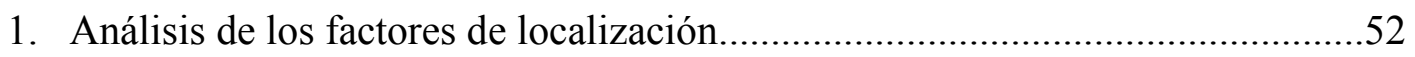

1. Disponibilidad De Materia Prima......................................................53

2. Proximidad al Mercado.................................................................

3. Proximidad De Mano De Obra Calificada...........................................54

4. Disponibilidad de energía eléctrica.....................................................54 


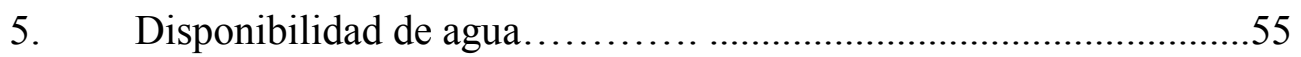

6. Costo de terreno e instalación de planta...............................................55

2. Posibles ubicaciones de acuerdo a factores predominantes...............................56

3. Evaluación y selección de la macro localización....................................................57

4. Evaluación y selección de la micro localización..................................................58

1. Proximidad al Mercado..............................................................58

2. Proximidad De Mano De Obra Calificada.......................................59

3. Disponibilidad de energía eléctrica.................................................59

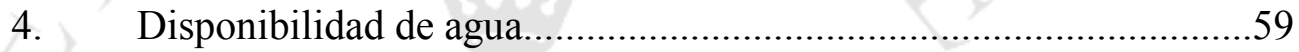

5. Costo de terreno e instalación de planta............................................61

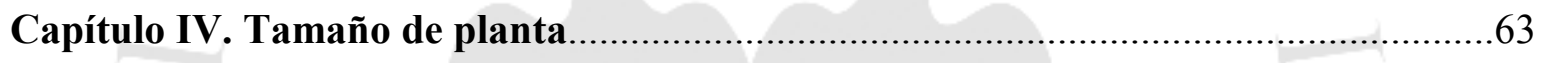

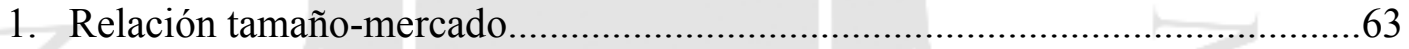

2. Relación tamaño-recursos productivos.............................................................63

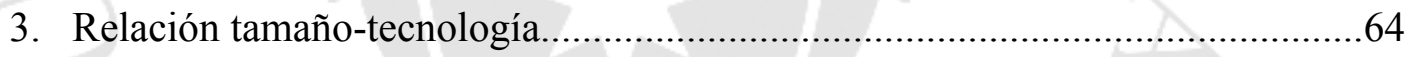

4. Relación tamaño-punto de equilibrio...............................................................65

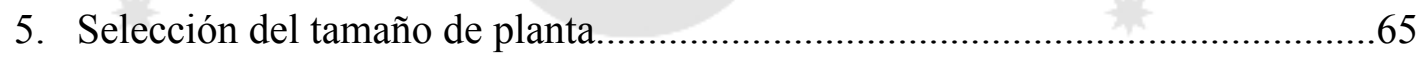

Capítulo V. Ingeniería del proyecto ......................................................................66

1. Definición del producto basada en sus características de fabricación..............66

1. Especificaciones técnicas del producto.............................................66

2. Tecnologías existentes y procesos de producción...............................................69

1. Naturaleza de la tecnología requerida.............................................71

a. Descripción de la tecnología existente......................................71

b. Selección de la tecnología......................................................71 
2. Proceso de producción.

a. Descripción del proceso............................................... 71

b. Diagrama de proceso: DOP...........................................74

c. Balance de materia: Diagrama de bloques........................75

3. Características de las instalaciones y equipo...............................................76

1. Selección de la maquinaria y equipo............................................76

2. Especificaciones de la maquinaria............................................76

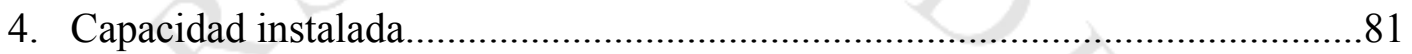

1. Cálculo de la capacidad instalada...............................................81

2. Cálculo detallado del número de máquinas requeridas..................81

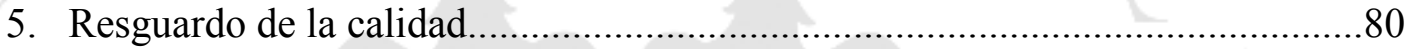

1. Calidad de la materia prima, de los insumos, del proceso y del

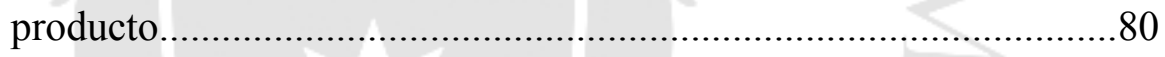

2. Medidas de resguardo de la calidad en la producción......................80

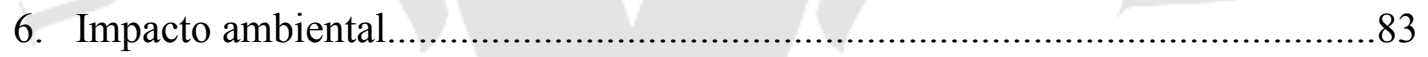

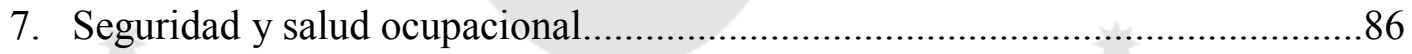

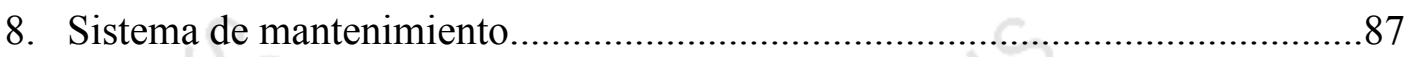

9. Programa de producción para la vida útil del proyecto...................................88

10. Requerimiento de insumos, personal y servicios..................................... 88

1. Materia prima, insumos y otros materiales..................................89

2. Determinación del número de operarios y trabajadores indirectos...89

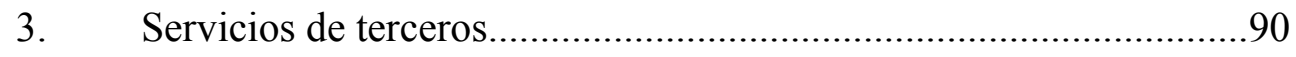

11. Características físicas del proyecto....................................................91 


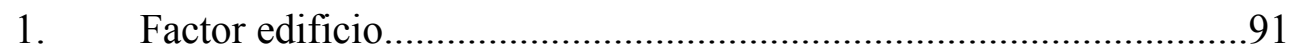

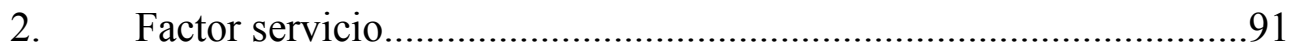

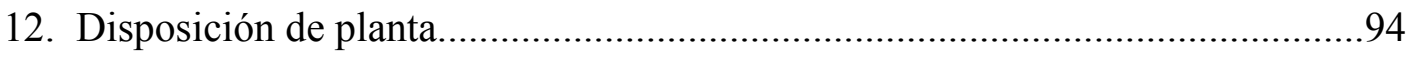

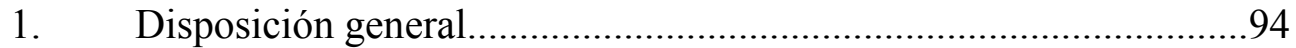

2. Disposición de detalle....................................................................100

13. Cronograma de implementación del proyecto.....................................................103

Capítulo VI. Aspectos económicos y financieros.........................................................104

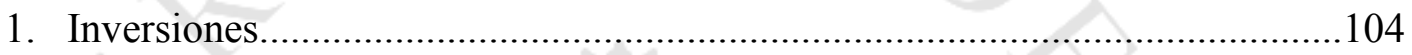

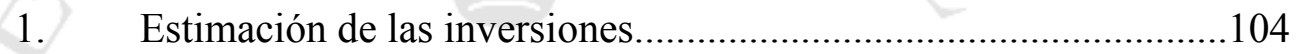

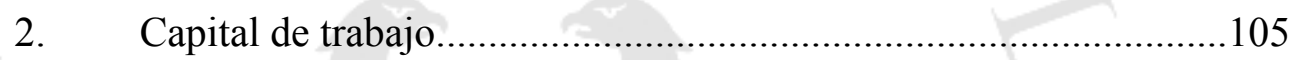

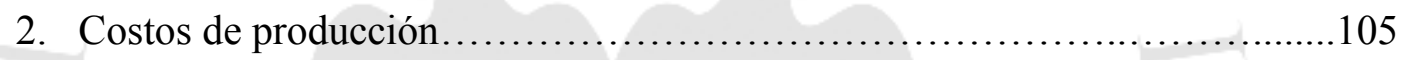

1. Costos de materias primas, insumos y otros materiales................105

2. Costo de los servicios (energía eléctrica, agua, combustible, etc.).106

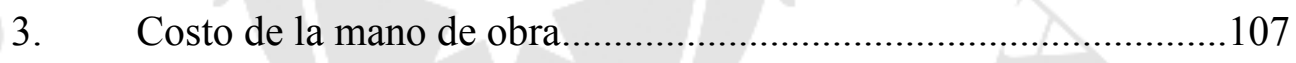

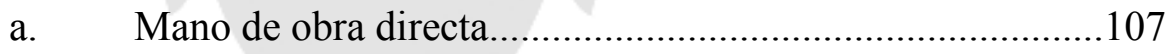

b. $\quad$ Mano de obra indirecta........................................................107

3. Presupuesto de ingresos y egresos.............................................................108

1. Presupuesto de ingreso por ventas..................................................108

2. Presupuesto operativo de costos de materias primas (mano de obra directa, depreciación, costos indirectos de fabricación, costo de

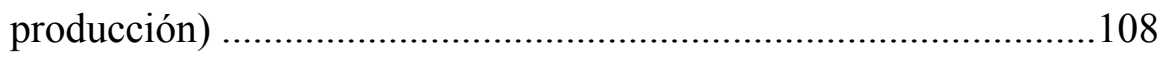

3. Presupuesto operativo de gastos administrativos (ventas, marketing, distribución, atención a clientes y gastos generales) ……................109 


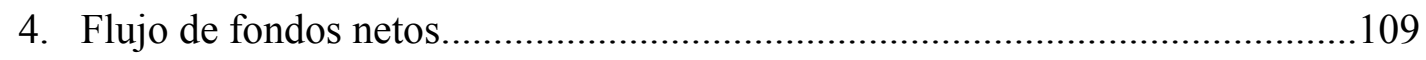

1. Flujo de fondos económicos..................................................111

2. Flujo de fondos financieros...............................111

Capítulo VII. Evaluación económica y financiera del proyecto $\ldots \ldots \ldots \ldots \ldots \ldots \ldots \ldots 112$

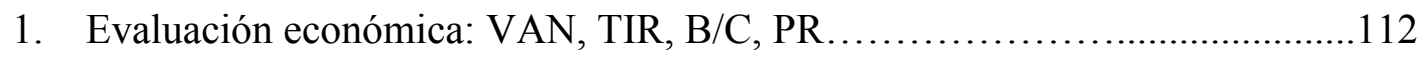

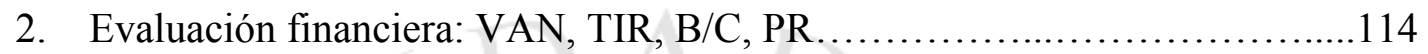

3. Análisis de los resultados económicos y financieros del proyecto............114

4. Análisis de Sensibilidad ............................................. 115

Conclusiones.............................................................. 117

Recomendaciones..................................................... 117

Fuentes Bibliográficas y Electrónicas......................................... 119

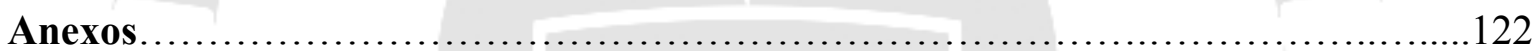




\section{INDICE DE FIGURAS}

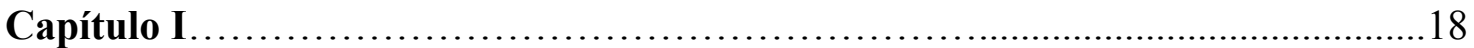

Figura 1.1. Tabla de ventas en toneladas categoría aceites vegetales..........................19

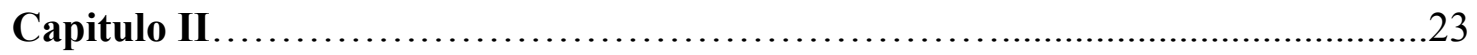

Tabla 2.1. Comparación de ácidos grasos en aceites....................................25

Figura 2.2. Lima Metropolitana..............................................27

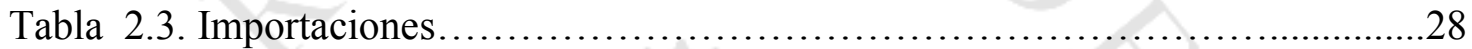

Tabla 2.4. Exportaciones....................................................28

Tabla 2.5. Producción..........................................................28

Tabla 2.6. Demanda Interna Aparente...............................................29

Figura 2.7. Diagrama de fluctuación de la demanda.............................29

Figura 2.8. Marcas más consumidas de Aceite de Oliva.............................30

Figura 2.9. Lugares de compra más frecuente...................................31

Tabla 2.10. Consumo en mn de soles en aceites comestibles en el Perú.....................32

Tabla 2.11. Obtención y proyección del Índice....................................32

Tabla 2.12. Proyección de la demanda Lima.........................................32

Figura 2.13. Grafico linear de la demanda......................................33

Figura 2.14. Gráfico de barras de la demanda...................................33

Tabla 2.15. Cuadro de participación del mercado en categoría aceites y grasas........34

Figura 2.16. Gráfico de participación del mercado en categoría aceites y grasas..........35

Figura 2.17. Fuerzas de Porter............................................... 35

Figura 2.18. Competencia en Supermercados Wong...............................38 
Tabla 2.19. Variables para la segmentación.

Figura 2.20. Población nacional por grupo de edad $\%$...............................39

Figura 2.21. Actitud hacia una vida sana.......................................40

Figura 2.22. ¿Quién realiza las compras del hogar? (jóvenes adultos) ..................40

Figura 2.23. Distribución de Nivel socio económico por zonas............................43

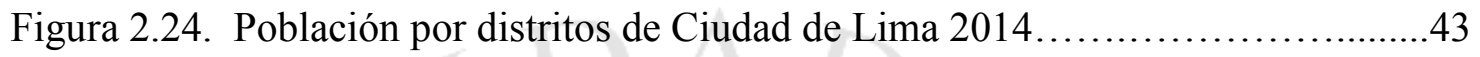

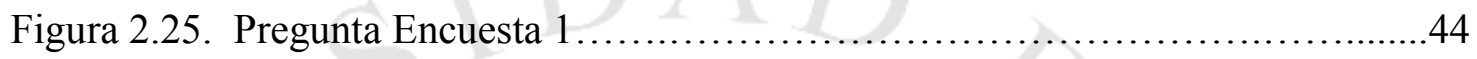

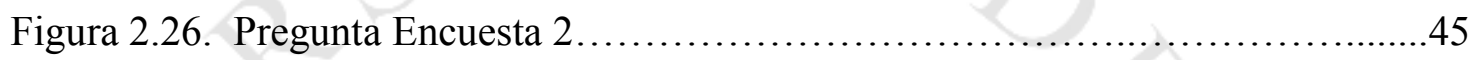

Tabla 2.27. Demanda del proyecto...........................................46

Tabla 2.28. Precios actuales de diferentes aceites para el consumo masivo.............49

Tabla 2.29. Composición Aceite de Sacha Inchi........................................49

Tabla 2.30. Producción sacha Inchi vs. Demanda del proyecto.......................51

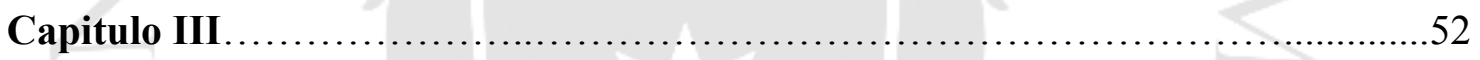

Figura 3.1. Mapa de Producción de Sacha Inchi...................................52

Tabla 3.2. Potencia instalada en los departamentos de Lima, Ucayali y San Martin....54

Tabla. 3.3. Tensión eléctrica y precio en Lima.................................55

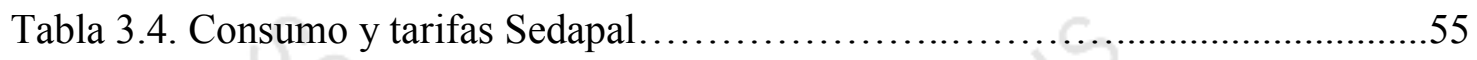

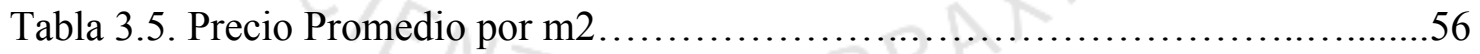

Tabla 3.6. Matriz de enfrentamiento........................................57

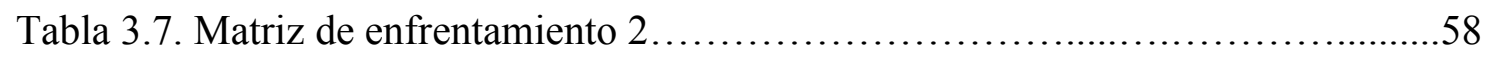

Tabla 3.8. Tensión eléctrica y precio en Lima.................................59

Tabla 3.9. Precio de $m 3$ de Agua en Ate.........................................60

Tabla 3.10. Precio de m3 de Agua en Lima.........................................60 
Tabla 3.11. Precio de m3 de Agua en Ventanilla....................................60

Tabla 3.12. Precio de terrenos en Lima..........................................61

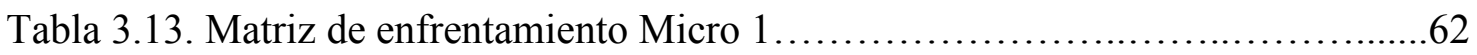

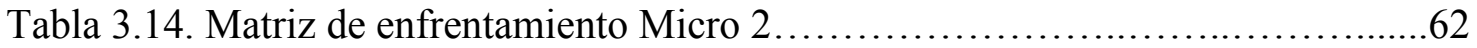

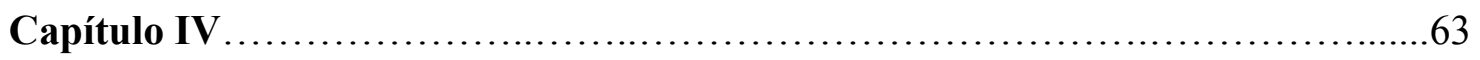

Tabla 4.1. Demanda del proyecto. ...........................................63

Tabla 4.2. Demanda del proyecto vs producción. ..................................64

Tabla 4.3. Tamaño de planta..................................................65

Capítulo V.............................................................66

Figura 5.1. Botella de S.inchi Oil.............................................66

Tabla 5.2. Propiedades fisicoquímicas del aceite de las semillas del sacha Inchi.......67

Tabla 5.3. Composición de ácidos grasos del aceite crudo de las semillas del sacha.....

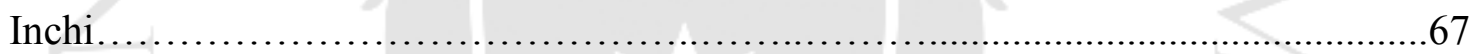

Tabla 5.4. Cuantificación de tocoferoles del aceite crudo de tres ecotipos de las semillas

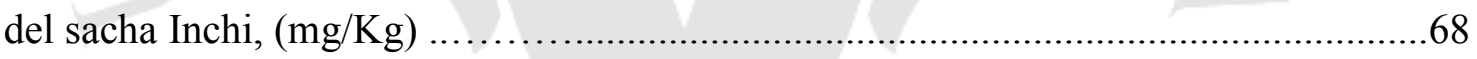

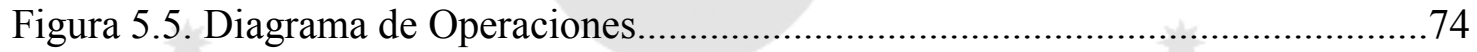

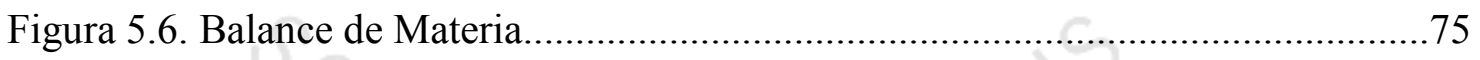

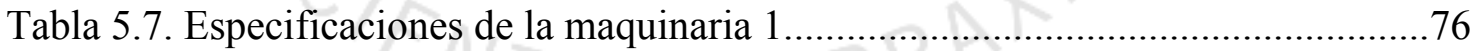

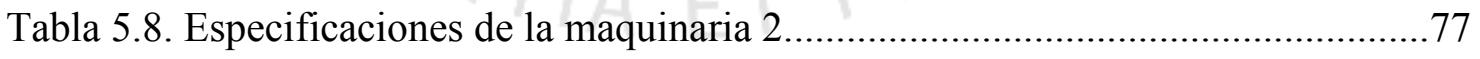

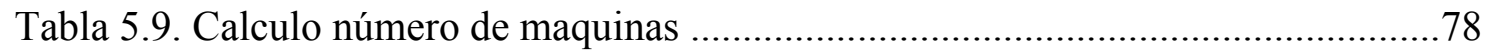

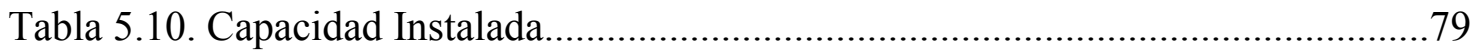

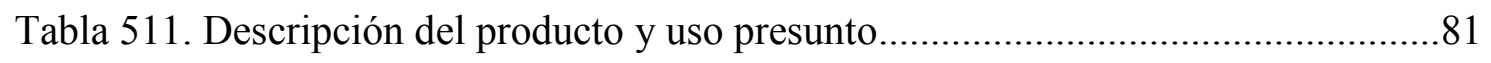

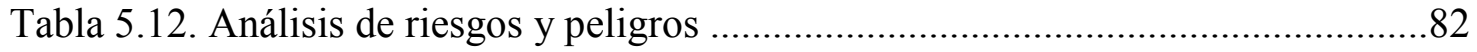




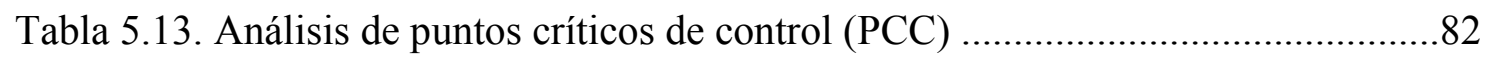

Tabla 5.14. Aspectos e Impactos ambientales.........................................................84

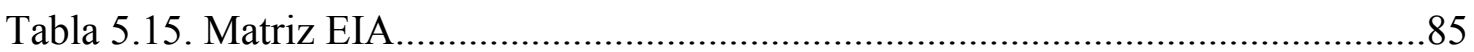

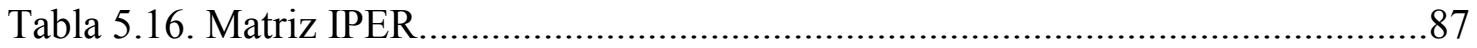

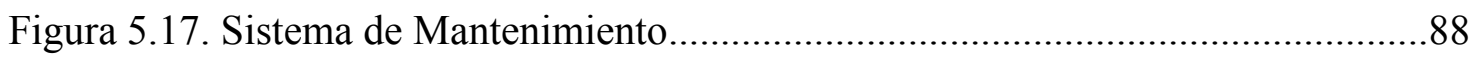

Tabla 5.18. Proyección de la producción para la vida útil del proyecto........................89

Tabla 5.19. Requerimiento de insumos para la producción........................................89

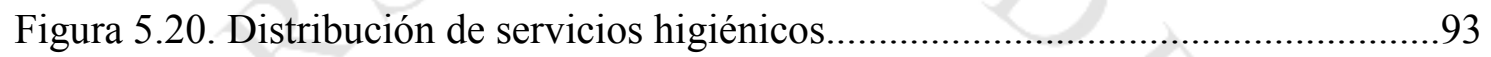

Figura 5.21. Distribución de cafetería..........................................................93

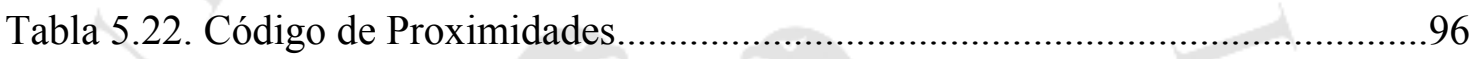

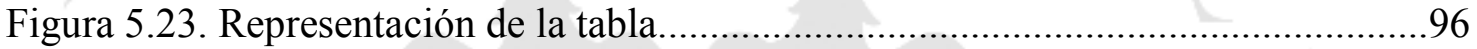

Figura 5.24. Tabla relacional......................................................................... 97

Tabla 5.25. Simbología diagrama relacional...................................................98

Figura 5.26. Diagrama relacional de actividades.................................................99

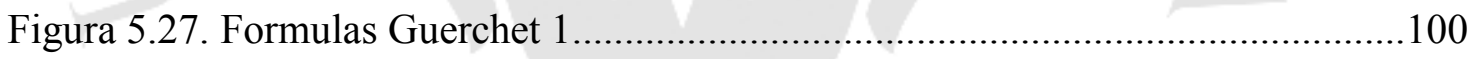

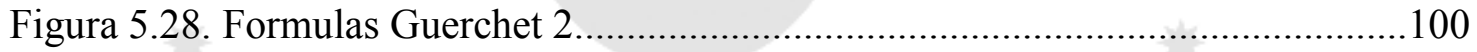

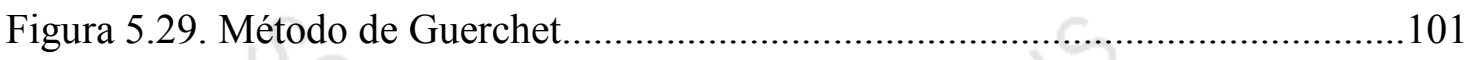

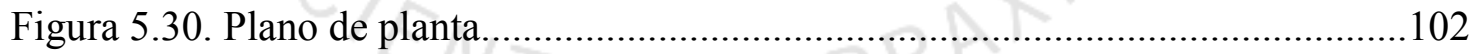

Figura 5.31. Cronograma de implementación.................................................... 103

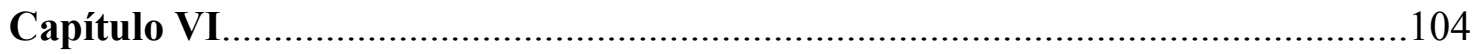

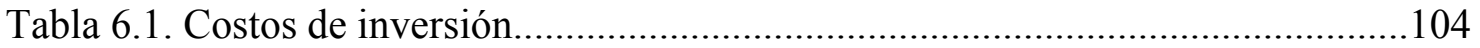

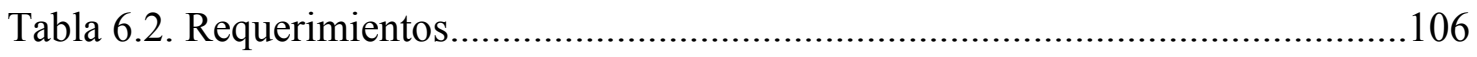

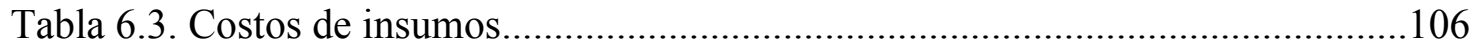


Tabla 6.4. Costos de servicios. 107

Tabla 6.5. Costo de Mano de obra directa. .107

Tabla 6.6. Costo de Mano de obra Indirecta. .108

Tabla 6.7. Presupuesto de Ingresos. 108

Tabla 6.8. Presupuesto de depreciación fabril.........................................................108

Tabla 6.9. Presupuesto de depreciación no fabril..................................................109

Tabla 6.10. Presupuesto de costos de producción.....................................................109

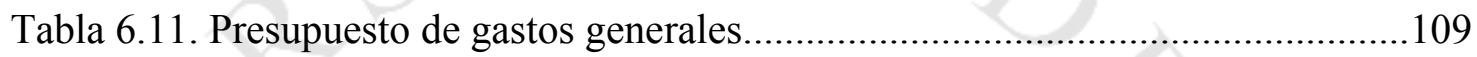

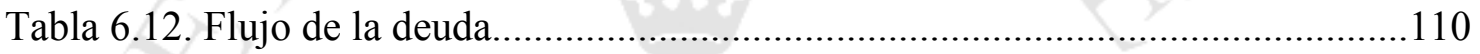

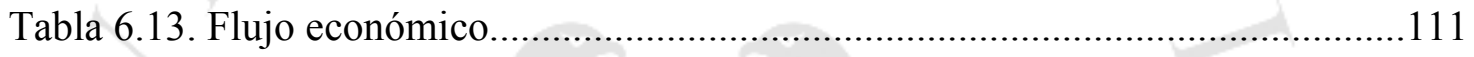

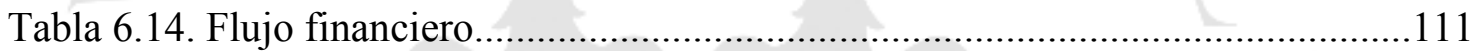

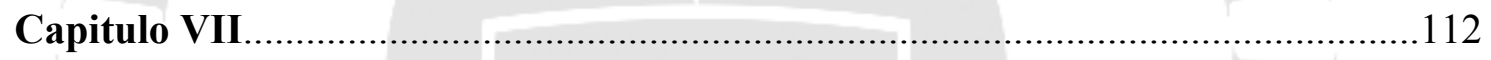

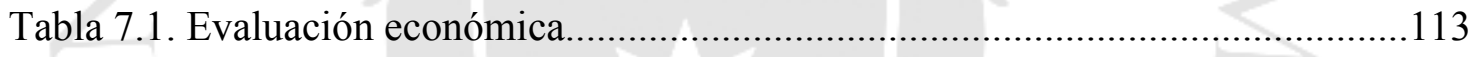

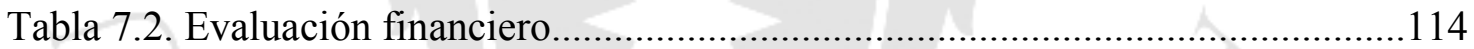

Tabla 7.3. Flujo económico (análisis sensibilidad) ...............................................116

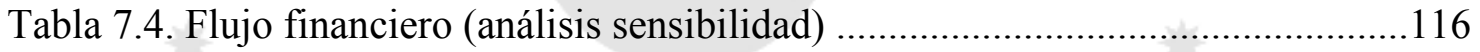

Tabla 7.5. Evaluación económica (análisis sensibilidad) .....................................116

Tabla 7.6. Evaluación financiero (análisis sensibilidad) ......................................116

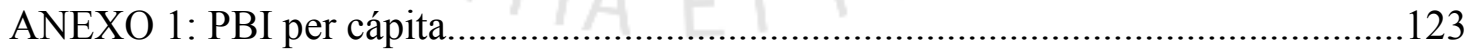

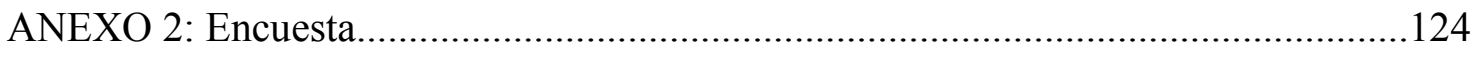

ANEXO 3: Población peruana y nivel de educación...............................................125

ANEXO 4: Términos nutritivos relacionados al aceite de Sacha Inchi...............127 


\section{RESUMEN EJECUTIVO}

Este proyecto presenta el estudio preliminar para la implementación de una planta de producción de aceite de Sacha Inchi (Plukenetia Volubilis), a partir de las semillas de esta misma. Para determinar si el proyecto es viable, se realizó un arduo estudio de mercado, con el cuál determinamos la demanda del proyecto utilizando como referencia su principal y más utilizado producto sustituto, el aceite de oliva. Para extraer la información, se utilizó una gran cantidad de bases de datos, entre ellas Euromonitor, Ipsos Apoyo, entre otras. Así mismo se realizó un estudio para determinar el tamaño y la localización de planta en el Perú, utilizando herramientas aprendidas en el transcurso de la carrera de Ingeniería Industrial, como Guerchet, ranking de factores, diagramaciones, etc. Los cuales fueron de mucha ayuda para determinar el lugar de localización y su tamaño adecuado, optimizando los espacios necesarios, la cercanía de la maquinaria y a su vez, optimizar los costos de producción.

Finalmente en este proyecto, se puede demostrar gracias a las herramientas financieras y económicas utilizadas, como tablas de presupuestos, costos, estados financieros de resultados y ratios como TIR, VAN y B/C., que el proyecto es viable y que se debe implementar de acuerdo a los estudios realizados ya que generaría una rentabilidad positiva. 


\section{EXECUTIVE SUMMARY}

This project presents the preliminary study for a production plant of Sacha Inchi Oil (Plukenetia Volubilis). To determine if the project is viable, we made an arduous market study. We used these results in addition to the reference of its substitute product the Olive Oil to determine the demand. To obtain the information, it was used a lot of databases, among them Euromonitor, Ipsos Apoyo, among others.

In addition, a study to determine the size and location of the plant in Peru was made, using tools learned in the course of Industrial Engineering, as Guerchet, "Ranking de factores", layouts and others. These methods, which were very helpful to determine the place of location and adequate size of the plant, also help us optimize the space needed, the proximity of machinery and optimize production costs.

Finally with this project we can demonstrated by the financial and economic tools we used such as Budgets tables, Costs, Financial Statements of Income percentages and IRR, NPV and B / C, the project is viable and should be implemented according to the studies because this would generate a positive return. 


\section{CAPÍTULO I. ASPECTOS GENERALES}

\subsection{Objetivo general}

El objetivo general de la investigación es establecer la viabilidad técnica, económica, financiera y de mercado para la instalación de una planta productora de aceite de Sacha Inchi (Plukenetia Volubilis), determinando los costos del proyecto.

\subsection{Objetivos específicos}

Los objetivos específicos son:

- Realizar un estudio de mercado del consumo de aceites de distintos tipos y de Sacha Inchi para establecer si el proyecto es viable.

- Evaluar e identificar las empresas que actualmente comercializan el producto, los cuales serían posibles competidores.

- Evaluar la viabilidad técnica y operativa del proyecto.

- Evaluar los costos asociados a la instalación del proyecto.

- Realizar y evaluar la viabilidad económica y financiera del proyecto.

\subsection{Justificación de la investigación}

\subsubsection{Social}

Producir y ofrecer a los distintos clientes en el sector un producto nuevo y atractivo que satisfaga sus necesidades de alimentarse sanamente y obtener la mayor cantidad de nutrientes. El aceite de Sacha Inchi contiene gran cantidad de Omega 3 y otras características que dan gran valor al producto (Anexo 5), lo que brinda una gran ventaja de ingresar al mercado que está creciendo en consumo de productos "saludables". 


\subsubsection{Técnica}

En lo relacionado a la maquinaria, podemos encontrarlas dentro del litoral Peruano lo que facilita la implementación de la planta. Necesitaríamos una máquina de prensado, descascarado, filtrado, embotellado, etiquetado y las fajas transportadoras. Como la producción de aceite no es un tema nuevo en nuestro país, podemos encontrar fácilmente proveedores de los equipos.

\subsubsection{Económica}

Nuestro proyecto generará un producto de gran calidad que a su vez sea económico, esto lo lograremos gracias a un eficiente sistema de producción que nos ayudará a alcanzar los objetivos esperados. Contaremos con un sistema de gestión que beneficiará a todas las partes relacionadas al proyecto.

En la siguiente tabla podemos observar como las ventas (TON) de aceites de Alicorp, empresa líder en la categoría, se viene incrementando con el paso de los años. A pesar de que Alicorp no posea productos de Sacha Inchi, nos demuestra como el mercado está creciendo y se está invirtiendo más dinero en él.

\section{Figura 1.1}

Tabla de ventas en toneladas de aceites de la empresa Alicorp

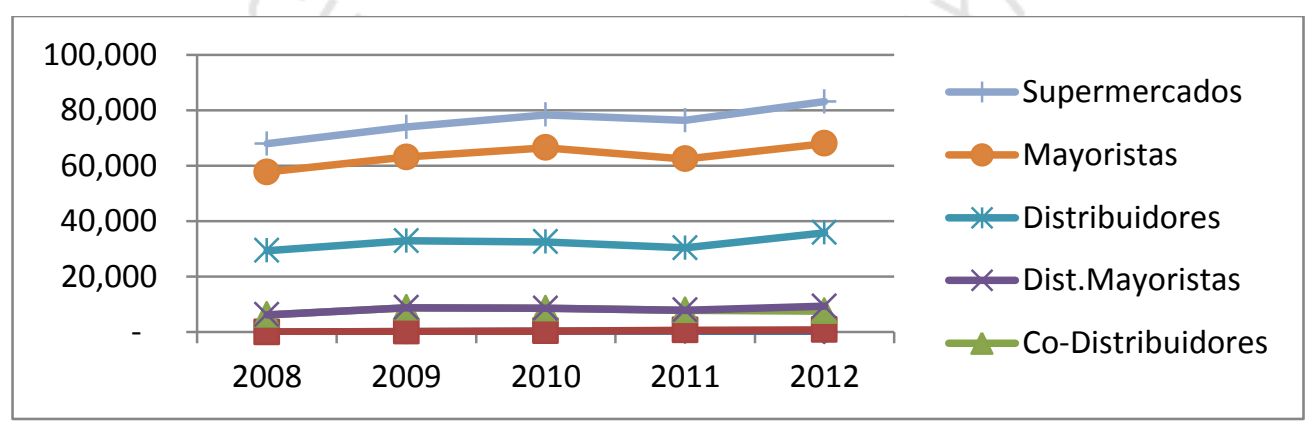

Fuente: Alicorp 


\subsection{Hipótesis de trabajo}

\subsubsection{Hipótesis del trabajo}

La instalación de una planta productora de aceite de Sacha Inchi (Plukenetia Volubilis) es viable, ya que existe un mercado que aceptaría el producto por la demanda creciente de productos de esta categoría y además, el proyecto es viable tecnológica y económicamente.

\subsubsection{Variable dependiente}

$\mathrm{Y}=$ Viabilidad técnica para la implementación de un planta productora de Aceite de Sacha Inchi (Plukenetia Volubilis)

\subsubsection{Variable Independiente}

$\mathrm{X} 1=$ Demanda en el mercado

$\mathrm{X} 2$ = Tecnología existente

X3 = Rentabilidad Económica

$$
\mathrm{Y}=\mathrm{F}(\mathrm{X} 1, \mathrm{X} 2, \mathrm{X} 3)
$$

Marco referencial y conceptual de la investigación

Marco referencial

Dentro de las investigaciones realizadas en la facultad y disponibles en la biblioteca no se ha encontrado una investigación de un producto similar pero si otros productos a base del Sacha Inchi. 
- Estudio preliminar para la instalación de una planta productora de chocolate con sacha Inchi.

- Escudero Asin, Andrea - 2010

Semejanzas

En ambos trabajos utilizamos la misma materia prima y ambos extraemos los componentes funcionales del Sacha Inchi.

Diferencias

La diferencia es principalmente el producto final, ya que se propone una planta productora de chocolate con sacha Inchi y nosotros proponemos la extracción del aceite de sacha Inchi.

- Estudio preliminar para la implementación de una planta productora de crema anti envejecimiento a base de sacha Inchi.

○ Conroy Ferreccio, Alessandra - 2008

Semejanzas

Las semejanzas son que utilizamos la misma materia prima y ambos extraemos las bondades del Sacha Inchi.

\section{Diferencias}

La diferencia es principalmente el producto final. En el trabajo se propone una planta productora de crema anti envejecimiento, mientras que nosotros proponemos la extracción de aceite para fines alimenticios.

- Estudio preliminar para la instalación de una empresa productora de aceite de semilla de la vid.

- Chang Cornejo, Christian Benjamín - 2008 


\section{Semejanzas}

Las semejanzas son que ambos queremos producir aceite, un producto semejante y sustituto.

\section{Diferencias}

Las diferencias entre este proyecto y el que proponemos, son la materia prima que en nuestro caso sería el sacha Inchi.

- Estudio preliminar para la implementación de una planta productora de aceite de sancha Inchi extra virgen

○ Herrera Lladró, Jorge Luis y Vásquez Sologuren, Alonso Andrés - 2013

Semejanzas

La semejanza es que estamos desarrollando una planta de aceite de Sacha Inchi

Diferencias

Las diferencias entre este proyecto y el que proponemos, es que el producto de este trabajo tiene un nivel superior de calidad. 


\section{CAPÍTULO II: ESTUDIO DE MERCADO}

Aspectos generales del estudio de mercado

\subsection{Definición comercial del producto}

El aceite de sacha Inchi (Plukenetia Volubilis), como su nombre lo indica, es un aceite producido a partir de la semilla de sacha Inchi. Este producto es $100 \%$ natural y no requiere ninguna materia adicional en su proceso. El producto estará ubicado dentro de la categoría de productos beneficiosos para la salud.

El producto vendrá en presentaciones de $250 \mathrm{ml}$. En botellas de vidrio de $30 \mathrm{~cm}$ de alto y $8 \mathrm{~cm}$ de ancho aproximadamente. Se utilizará etiquetas sofisticadas y coloridas que posicionen al producto en el segmento de mercado que deseamos.

Además de promover nuestro producto en los supermercados y por medio de los encartes mensuales de estos, se creará una página web en donde se colocará los beneficios del aceite y recetas que ayudaran a consumir mejor el producto. Además tendremos una sección donde recibiremos comentarios o algún inconveniente que el cliente puede encontrar y que mejoraremos con el paso del tiempo.

\subsubsection{Producto Básico}

Aceite de Sacha Inchi el cual satisface la necesidad de alimentación.

\subsubsection{Producto Real}

El producto posee grandes valores nutricionales, altos contenidos de Omega 3,6 y 9, vitamina A y E y digestibilidad alta por ello posee un gran valor en el mercado. Además, previene distintas enfermedades, ayuda a las personas a sentirse saludables y 
llevar una vida sana. Además, tendrá un alto nivel de calidad que lo distinga de la competencia además de presentar un precio cómodo para su consumo. El empaque (botella de vidrio de $30 \mathrm{~cm}$ de alto y $8 \mathrm{~cm}$ de ancho) y su empaque (colorido, sofisticado y llamativo) lo posicionaran como un producto de gran valor.

\subsubsection{Producto Aumentado}

El producto aumentado seria el servicio post-venta que se ofrecerá a los clientes. Además de colocar en nuestra página web los atributos del producto, también colocaremos recetas y tips de cómo utilizarlo de mejor manera. La garantía ofrecida también será parte del producto aumentado, ya que si el producto posee algún defecto, el cliente podrá realizar un cambio y se le otorgará una recompensa.

\section{Principales características del producto}

\section{Usos y propiedades}

El aceite de sacha Inchi no es un aceite utilizado para freír, ya que pierde sus propiedades beneficiosas. Su consumo es similar al del aceite de oliva, de ajonjolí, entre otros, principalmente como complemento de muchos tipos de ensaladas. Es recomendable utilizarlo a temperatura ambiente para que este no pierda sus propiedades. A comparación de otros tipos de aceites para el consumo, el aceite de sacha Inchi posee gran concentración de ácido Linoleico y Linolénico (Omega 6 y Omega 3), lo cual genera las propiedades beneficios en el producto.

En el siguiente cuadro podemos observar las características del aceite en comparación a otros tipos de aceite. 
Tabla 2.1.

Comparación de ácidos grasos en aceites

\begin{tabular}{|c|c|c|c|c|c|}
\hline \multirow[t]{2}{*}{ Tipo de Aceite } & \multicolumn{5}{|c|}{ Ácidos Grasos (\%) } \\
\hline & Palmítico & Esteárico & Oleico & Linoleico & Linolénico \\
\hline Oliva & $11.8( \pm 0.7)$ & $2.8( \pm 0.06)$ & $74.3( \pm 2.1)$ & $8.4( \pm 1.0)$ & $0.6( \pm 0.02)$ \\
\hline Canola & $5.2( \pm 0.09)$ & $2.3( \pm 0.03)$ & $64.1( \pm 0.3)$ & $20.2( \pm 0.3)$ & $6.6( \pm 0.2)$ \\
\hline $\begin{array}{l}\text { Semilla de } \\
\text { algodón }\end{array}$ & $22.4( \pm 0.9)$ & $2.8( \pm 0.05)$ & $18.4( \pm 0.5)$ & $52.8( \pm 0.7)$ & $0.5( \pm 0.03)$ \\
\hline Maíz & $11.2( \pm 0.5)$ & $2( \pm 0.09)$ & $28.5( \pm 0.5)$ & $56( \pm 0.2)$ & $0.9( \pm 0.1)$ \\
\hline $\begin{array}{l}\text { Girasol alto en } \\
\text { Oleico }\end{array}$ & $5.1( \pm 0.05)$ & $2.7( \pm 0.05)$ & $\begin{array}{l}78.6 \\
( \pm 0.03)\end{array}$ & $\begin{array}{l}11.6 \\
( \pm 0.06)\end{array}$ & $\begin{array}{l}0.1 \\
( \pm 0.001)\end{array}$ \\
\hline Girasol & $4.7( \pm 0.05)$ & $3.8( \pm 0.05)$ & $\begin{array}{l}60.2 \\
( \pm 0.03)\end{array}$ & $29( \pm 0.05)$ & $\begin{array}{l}0.37 \\
( \pm 0.0007)\end{array}$ \\
\hline Linaza & & $4.4( \pm 0.05)$ & $20( \pm 0.8)$ & $\begin{array}{c}15.5( \pm 0.5) \\
C^{2}\end{array}$ & $\begin{array}{l}53.4 \\
( \pm 0.007)\end{array}$ \\
\hline $\begin{array}{l}\text { Sacha Inchi } \\
\text { Semilla }\end{array}$ & $4.67( \pm 0.3)$ & $3.5( \pm 0.1)$ & $10.7( \pm 0.6)$ & $33.5( \pm 1.0)$ & $44( \pm 1.3)$ \\
\hline $\begin{array}{l}\text { Sacha Inchi } \\
\text { Comercial }\end{array}$ & $4.8( \pm 0.3)$ & $3.4( \pm 0.1)$ & $10.1( \pm 0.5)$ & $37.7( \pm 1.6)$ & $42.4( \pm 1.3)$ \\
\hline
\end{tabular}

Elaboración propia

Fuente: Food Chemistry - www.sciencedirect.com 
En relación a las enfermedades que previene, la semilla de sacha Inchi en forma de aceite ayuda a disminuir los niveles de colesterol y presión sanguínea del cuerpo. Esto podemos corroborarlo en muchas investigaciones de nutricionistas. (Fuente electrónica desarrollada por la Nutricionista Licenciada Sara Abu-Sabbah) También se tiene información que ayuda a mejorar ciertas enfermedades como la diabetes y artritis. Inclusive en algunas enfermedades psicológicas y cáncer (cáncer de mama). Esto está siendo estudiado por científicos Alemanes los cuales escribieron el libro "Nut Oil and its therapeutic and nutritional uses" encontrado en la web de Science Direct.

\section{Bienes sustitutos y complementarios}

\section{Bienes sustitutos}

Los bienes sustitutos son aquellos que cubren la misma necesidad pero se diferencian por la materia prima, composición, etc. En esta categoría podemos encontrar los distintos aceites domésticos vegetales y light. Además, podemos encontrar como sustitutos el aceite de oliva y soja. Cabe resaltar que el aceite de Sacha Inchi no va a competir con los aceites sustitutos. Nuestro producto será una opción saludable en el mercado de aceites.

\section{Bienes complementarios}

Los bienes complementarios son aquellos que se ven relacionados con otros en su consumo y su demanda o precio pueden verse afectados. El aceite es un bien de primera necesidad que posee muchos bienes complementarios. Por ejemplo el arroz, distintos tipos de carnes, verduras, etc. 


\section{Determinación del área geográfica que abarcará el estudio}

El área geográfica donde enfocaremos el estudio será la ciudad de Lima Metropolitana, esto se debe a que queremos enfocar la venta de este producto en los supermercados de la capital, los cuales poseen locales en la mayoría de distritos de nuestra ciudad.

Figura 2.2.

Lima Metropolitana

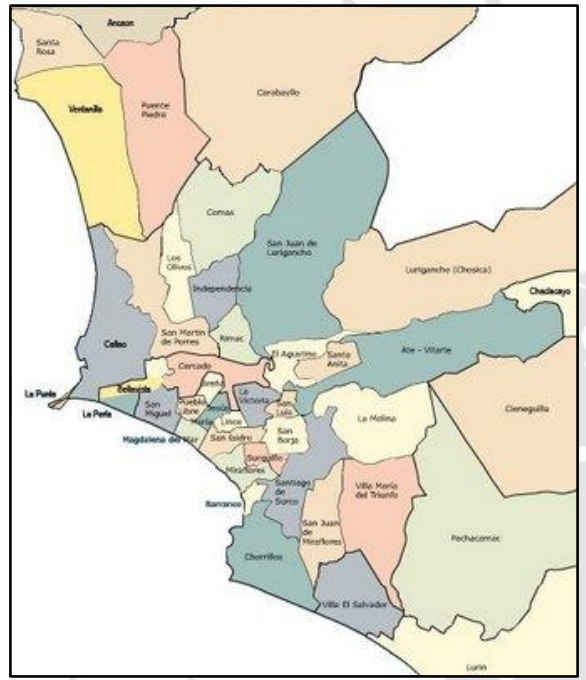

Fuente: Para Viajar - Mapas

\section{Análisis de la demanda}

Para el análisis de la demanda hemos utilizado información de importaciones, exportaciones y producción del aceite de Oliva. Este aceite es muy similar al aceite de sacha Inchi en usos y comercialización.

Como dato adicional utilizaremos la densidad del aceite de sacha Inchi (densidad=peso/volumen): $0.918 \mathrm{~kg} / \mathrm{lt}$ (1089.32 lt/ton) 


\section{Demanda histórica}

\section{a. Importación}

Tabla 2.2

Importaciones

\begin{tabular}{|r|r|r|r|r|}
\hline Importaciones & \multicolumn{1}{|c|}{ kilogramos } & \multicolumn{1}{c|}{ toneladas } & \multicolumn{1}{c|}{ litros } & \multicolumn{1}{c|}{ botellas 250ml. } \\
\hline $\mathbf{2 0 0 7}$ & $82,459.00$ & 82.46 & $89,824.24$ & 359,297 \\
\hline $\mathbf{2 0 0 8}$ & $144,500.00$ & 144.50 & $157,406.74$ & 629,627 \\
\hline $\mathbf{2 0 0 9}$ & $199,019.00$ & 199.02 & $216,795.38$ & 867,182 \\
\hline $\mathbf{2 0 1 0}$ & $209,739.00$ & 209.74 & $228,472.89$ & 913,892 \\
\hline $\mathbf{2 0 1 1}$ & $224,440.00$ & 224.44 & $244,486.98$ & 977,948 \\
\hline $\mathbf{2 0 1 2}$ & $254,895.00$ & 254.90 & $277,662.22$ & $1,110,649$ \\
\hline
\end{tabular}

Elaboración propia

Fuente: Data Trade

\section{b. Exportaciones}

Tabla 2.3

Exportaciones

\begin{tabular}{|c|}
\hline Exportaciones \\
\hline 2007 \\
\hline 2008 \\
\hline 2009 \\
\hline 2010 \\
\hline 2011 \\
\hline 2012 \\
\hline
\end{tabular}

\begin{tabular}{|l|}
\hline kilogram \\
\hline \\
\hline \\
\hline \\
\hline \\
\hline
\end{tabular}

Elaboración propia

Fuente: Data Trade

\section{c. Producción}

Tabla 2.4

Producción

\begin{tabular}{|r|r|r|r|r|}
\hline Produccion & kilogramos & toneladas & \multicolumn{1}{c|}{ litros } & \multicolumn{1}{c|}{ botellas 250ml. } \\
\hline $\mathbf{2 0 0 7}$ & $400,000.00$ & 400.00 & $435,728.00$ & $1,742,912$ \\
\hline $\mathbf{2 0 0 8}$ & $500,000.00$ & 500.00 & $544,660.00$ & $2,178,640$ \\
\hline $\mathbf{2 0 0 9}$ & $475,000.00$ & 475.00 & $517,427.00$ & $2,069,708$ \\
\hline $\mathbf{2 0 1 0}$ & $425,000.00$ & 425.00 & $462,961.00$ & $1,851,844$ \\
\hline $\mathbf{2 0 1 1}$ & $450,000.00$ & 450.00 & $490,194.00$ & $1,960,776$ \\
\hline $\mathbf{2 0 1 2}$ & $460,000.00$ & 460.00 & $501,087.20$ & $2,004,349$ \\
\hline
\end{tabular}

Elaboración propia

Fuente: Euromonitor (Producción) 


\section{d. Demanda interna aparente (DIA)}

La Demanda Aparente la estamos calculando en botellas de $250 \mathrm{ml}$. Y tomando una densidad del aceite de 1089.32 lt/ton.

Tabla 2.6.

Demanda Interna Aparente en botellas de $250 \mathrm{ml}$.

\begin{tabular}{|c|r|r|r|r|}
\hline Botellas & \multicolumn{1}{|c|}{ Produccion } & Importaciones & \multicolumn{1}{c|}{ Exportaciones } & \multicolumn{1}{c|}{ Demanda Aparente } \\
\hline $\mathbf{2 0 0 7}$ & $1,742,912$ & 359,297 & 175,415 & $1,926,794$ \\
\hline $\mathbf{2 0 0 8}$ & $2,178,640$ & 629,627 & 496,612 & $2,311,655$ \\
\hline $\mathbf{2 0 0 9}$ & $2,069,708$ & 867,182 & 918,467 & $2,018,423$ \\
\hline $\mathbf{2 0 1 0}$ & $1,851,844$ & 913,892 & $1,009,752$ & $1,755,984$ \\
\hline $\mathbf{2 0 1 1}$ & $1,960,776$ & 977,948 & 471,972 & $2,466,752$ \\
\hline $\mathbf{2 0 1 2}$ & $2,004,349$ & $1,110,649$ & 556,699 & $2,558,299$ \\
\hline
\end{tabular}

Elaboración propia

Al ser el 2008 un año anómalo en el registro de demanda aparente hemos optado por no tomar en cuenta ese año. Esta anomalía se debe a la gran caída de la economía en potencias como Estados Unidos y Europa. Es por ello la caída en las exportaciones y la variación de los resultados.

Figura 2.7.

Diagrama de fluctuación de la demanda

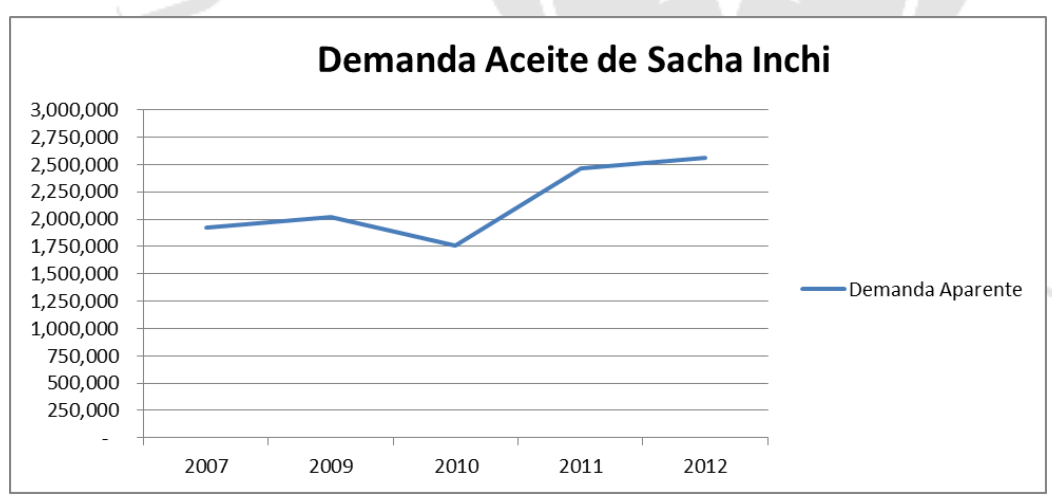

Elaboración propia

En el cuadro podemos observar una caída en la demanda de aceite en los entre el 2009 y 2010. Esto se debe al efecto que produjo la crisis económica mundial en el consumo de 
Estados Unidos y Europa en relación a los bienes que no son de consumo primario. Esto podemos corroborarlo con el diario "El Confidencial" de España (bibliografía).

\section{Demanda potencial}

\section{a. Patrones de consumo}

Para poder evaluar correctamente los patrones de consumo de aceites en Lima, hemos buscado información en distintas bases de datos que justifiquen el propósito de esta investigación.

Para poder utilizar datos más exactos, tomaremos información de aceite de Oliva. Esto se debe a que nuestro producto es nuevo y este aceite es el más similar a lo que nosotros queremos comercializar.

Figura 2.8.

Marcas más consumidas de Aceite de Oliva 2012

\begin{tabular}{|c|c|c|c|c|c|c|}
\hline \multirow{2}{*}{$\begin{array}{l}\text { Marca más consumida en } \\
\text { los últimos tres meses }\end{array}$} & \multirow{2}{*}{$\begin{array}{l}\text { TOTAL } \\
(\%)\end{array}$} & \multicolumn{5}{|c|}{ Nivel Socioeconómico (\%) } \\
\hline & & A & B & c & D & $\mathrm{E}$ \\
\hline El Olivar & 35 & 53 & 49 & 35 & 15 & - \\
\hline Olivos del Sur & 4 & 4 & 11 & 0 & 0 & - \\
\hline Montefiori & 3 & 0 & 4 & 0 & 8 & - \\
\hline Carbonell & 3 & 7 & 0 & 8 & 0 & - \\
\hline La Española & 0 & 2 & 0 & 0 & 0 & - \\
\hline Otras & 5 & 10 & 5 & 7 & 0 & - \\
\hline A granel & 2 & 0 & 0 & 0 & 7 & - \\
\hline No precisa & 48 & 24 & 31 & 50 & 70 & - \\
\hline BASE REAL (Abs.) & 116 & 51 & 37 & $12^{*}$ & $12^{*}$ & $4^{*}$ \\
\hline
\end{tabular}

Fuente: Ipsos Apoyo

Aquí podemos apreciar cuales serían nuestros principales competidores según el nivel socioeconómico al que se apunta. El aceite El Olivar seria nuestra competencia más fuerte. 
Figura 2.9.

Lugares de compra más frecuente 2012

\begin{tabular}{|c|c|c|c|c|c|c|}
\hline \multirow{2}{*}{$\begin{array}{l}\text { Lugar de compra más } \\
\text { frecuente }\end{array}$} & \multirow{2}{*}{$\begin{array}{l}\text { TOTAL } \\
(\%)\end{array}$} & \multicolumn{5}{|c|}{ Nivel Socioeconómico (\%) } \\
\hline & & A & B & C & D & $\mathrm{E}$ \\
\hline Supermercado / autoservicio & 56 & 96 & 82 & 43 & 26 & - \\
\hline Mercado / puestos & 20 & 0 & 11 & 43 & 24 & - \\
\hline Bodega & 12 & 2 & 3 & 0 & 39 & - \\
\hline Otros & 11 & 2 & 4 & 7 & 11 & - \\
\hline No precisa & 1 & 0 & 0 & 7 & 0 & - \\
\hline BASE REAL (Abs.) & 116 & 51 & 37 & $12^{*}$ & $12^{*}$ & $4^{*}$ \\
\hline
\end{tabular}

Fuente: Ipsos Apoyo

Los niveles socioeconómicos A y B, en su mayoría, realizan la compra de aceites de oliva en supermercados. Esto nos favorece ya que nuestra investigación usa este canal de distribución.

Con respecto a la parte económica de los patrones de consumo, podemos analizar la buena situación económica que se presenta en nuestro país en los últimos años. La calidad de vida de las personas y su nivel socioeconómico ha ido incrementando con el tiempo. En los siguientes cuadros podemos analizar la disminución de la pobreza en el país y el incremento de los ingresos de las personas.

\section{b. Determinación de la demanda potencial}

Luego de apreciar el patrón del consumo peruano de aceites comestibles en general que va en aumento, obtuvimos un índice que nos indica el incremento de demanda que posee el Perú. 
Tabla 2.10.

Consumo en mn de soles en aceites comestibles en el Perú.

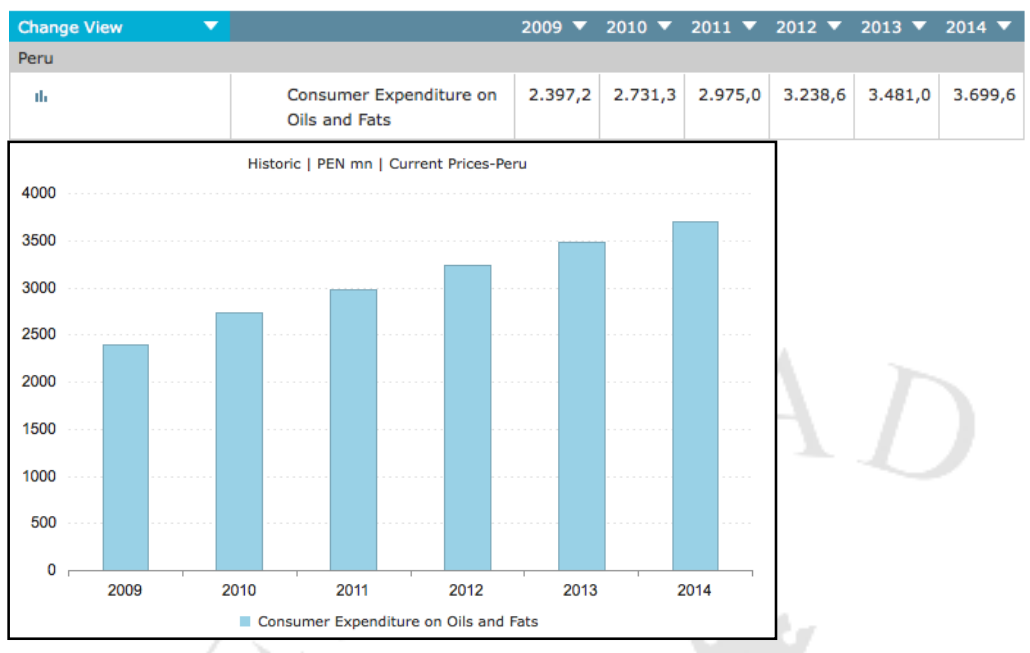

Fuente: Euromonitor (Peru)

\section{Proyección de la demanda y metodología del análisis}

Para poder proyectar nuestra demanda utilizamos el método de regresión lineal. Los datos trabajados son referentes a la ciudad de Lima.

Tabla 2.12.

Proyección de la demanda Lima

\begin{tabular}{|l|r|}
\hline & \multicolumn{1}{c|}{$\begin{array}{c}\text { Botellas de 250ml. } \\
\text { Demanda Aparente }\end{array}$} \\
\hline $\mathbf{2 0 0 7}$ & $1,926,793.57$ \\
\hline $\mathbf{2 0 0 9}$ & $2,018,422.81$ \\
\hline $\mathbf{2 0 1 0}$ & $1,755,983.84$ \\
\hline $\mathbf{2 0 1 1}$ & $2,466,752.07$ \\
\hline $\mathbf{2 0 1 2}$ & $2,558,298.52$ \\
\hline $\mathbf{2 0 1 3}$ & $2,382,236.40$ \\
\hline $\mathbf{2 0 1 4}$ & $2,472,969.28$ \\
\hline $\mathbf{2 0 1 5}$ & $2,563,702.17$ \\
\hline $\mathbf{2 0 1 6}$ & $2,654,435.06$ \\
\hline $\mathbf{2 0 1 7}$ & $2,745,167.94$ \\
\hline $\mathbf{2 0 1 8}$ & $2,835,900.83$ \\
\hline $\mathbf{2 0 1 9}$ & $2,926,633.72$ \\
\hline $\mathbf{2 0 2 0}$ & $3,017,366.60$ \\
\hline $\mathbf{2 0 2 1}$ & $3,108,099.49$ \\
\hline $\mathbf{2 0 2 2}$ & $3,198,832.38$ \\
\hline $\mathbf{2 0 2 3}$ & $3,289,565.26$ \\
\hline $\mathbf{2 0 2 4}$ & $3,380,298.15$ \\
\hline 2025 & $3,471,031.03$ \\
\hline
\end{tabular}

Elaboración propia 
Figura 2.13.

Grafico linear de la demanda

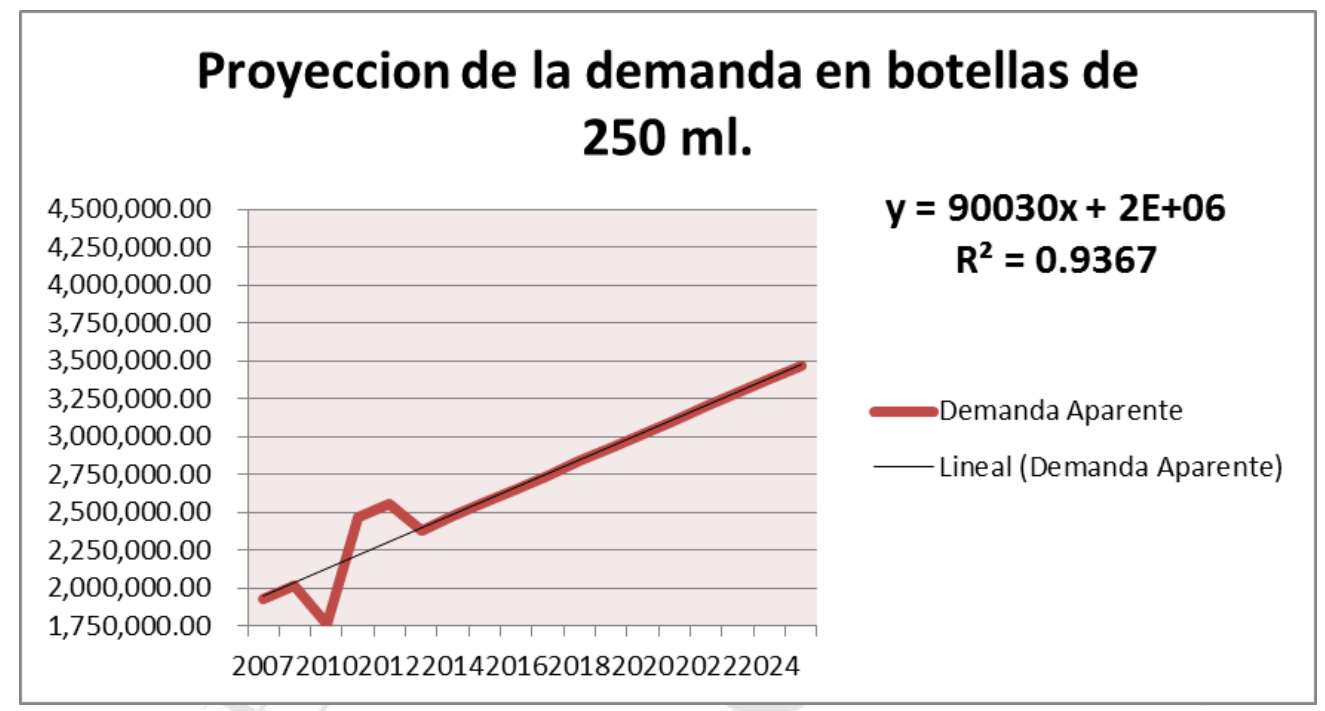

Elaboración propia

Figura 2.14.

Gráfico de barras de la demanda

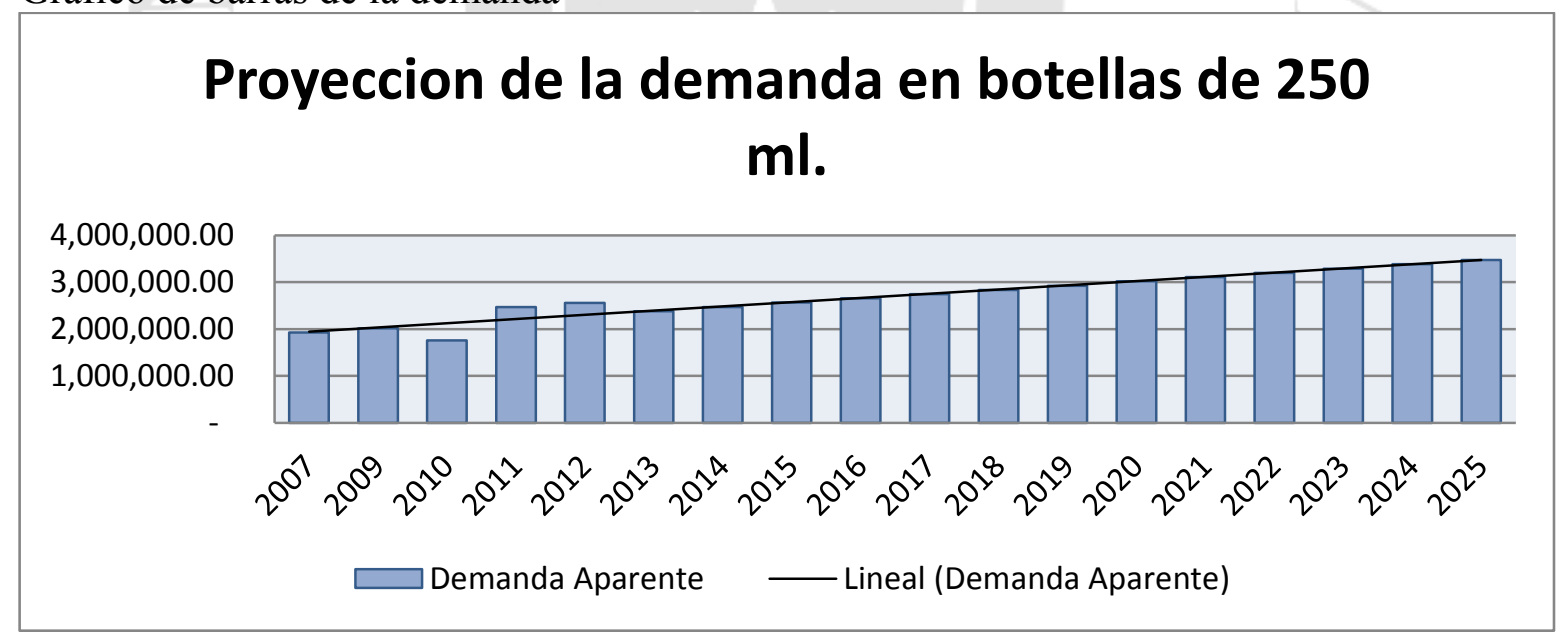

Elaboración propia 


\section{Análisis de la oferta}

\section{Empresas productoras, importadoras y comercializadoras}

Como el mercado de aceite de sacha Inchi es pequeño, se analizará el mercado de aceites en general, el cual vendría a ser nuestra competencia directa. Los distintos aceites vegetales, de oliva, de girasol, etc. Vendrían a ser los productos que podrían reemplazar al nuestro. En el siguiente cuadro podemos observar la participación de las principales empresas de la categoría Aceites y Grasas. Además, podemos observar un gráfico que lo explica mejor.

Tabla 2.15.

Cuadro de participación del mercado en categoría aceites y grasas

\begin{tabular}{|c|c|c|c|c|c|c|}
\hline mn PEN & 2009 & 2010 & 2011 & 2012 & 2013 & 2014 \\
\hline Alicorp & S/.1,249.6 & S/. $1,420.1$ & S/.1,561.9 & S/. 1,655.6 & S/. 1,785.1 & S/. $1,895.0$ \\
\hline Aemsa & $\$ / .114 .8$ & $\$ / .130 .8$ & $\$ / .148 .8$ & $\$ / .245 .8$ & $\$ / .273 .6$ & $\$ / .281 .5$ \\
\hline ADM Sao Peru Sa & S/.179.5 & S/.245.8 & S/.267.8 & S/.235.1 & S/.249.2 & S/. 269.7 \\
\hline GSW SA & S/. 145.5 & S/.172.1 & S/.177.3 & S/.177.1 & S/. 189.0 & S/. 202.3 \\
\hline $\begin{array}{l}\text { Corporacion Trascontinental del } \\
\text { Peru SAC }\end{array}$ & S/.125.6 & $5 / .115 .0$ & S/.140.7 & S/.144.7 & S/. 170.9 & S/. 181.3 \\
\hline Laive SA & $5 / .82 .5$ & S/.92.0 & S/.100.3 & S/. 104.6 & S/.116.3 & S/. 122.4 \\
\hline Unilever Andina Peru SA & $\$ / .64 .5$ & \$/. 90.1 & \$/.98.2 & $\mathrm{S} / .148 .3$ & $\$ / .97 .8$ & \$/. 104.7 \\
\hline Gloria SA & S/.38.8 & S/.46.2 & S/.50.3 & S/.51.8 & S/.58.1 & S/. 61.8 \\
\hline Productos Encurtidos SA & $\$ / .21 .3$ & S/.27.6 & S/. 30.0 & S/. 33.4 & S/.40.0 & S/. 45.1 \\
\hline Hipermercados Metro SA & S/. 15.3 & $\mathrm{~s} / .30 .6$ & S/. 33.3 & $\mathrm{~S} / .33 .0$ & $\mathrm{~s} / .39 .3$ & $S / .44 .4$ \\
\hline Molinos del Peru & S/.46.3 & S/.47.2 & $\mathrm{S} / .51 .5$ & $\mathrm{~S} / .40 .2$ & $\mathrm{~S} / .47 .7$ & $\mathrm{~S} / .43 .3$ \\
\hline Industrial del Espino & $\$ / .16 .5$ & \$/.25.7 & \$/.28.0 & S/. 27.2 & $\$ / .32 .4$ & S/. 36.3 \\
\hline Intradevco Industrial SA & S/.53.9 & S/.35.5 & S/.11.0 & S/.13.3 & S/.15.3 & S/. 14.8 \\
\hline GW Yichang y Cia Sa & S/.1.2 & S/.1.4 & S/. 1.5 & S/.1.9 & S/.10.1 & S/.11.5 \\
\hline Agroindustrias Amazonicas SAC & $5 / .1 .9$ & $5 / .2 .5$ & $5 / .2 .7$ & $5 / .3 .2$ & $\mathrm{~S} / .3 .8$ & $5 / .4 .1$ \\
\hline Olivos del Peru & $5 / .5 .0$ & S/.6.6 & S/.7.1 & S/.8.4 & S/.2.1 & $\mathrm{S} / .2 .6$ \\
\hline Otros & \$/.234.7 & S/.242.0 & S/. 264.8 & S/. 314.4 & \$/. 350.2 & \$/. 378.4 \\
\hline TOTAL & S/.2,397.0 & $S / .2,731.0$ & S/. 2,975.0 & $S / .3,238.0$ & $S / .3,481.0$ & S/. 3,699.0 \\
\hline
\end{tabular}

Fuente: Euromonitor

Elaboración propia 
Figura 2.16.

Gráfico de participación del mercado en categoría aceites y grasas

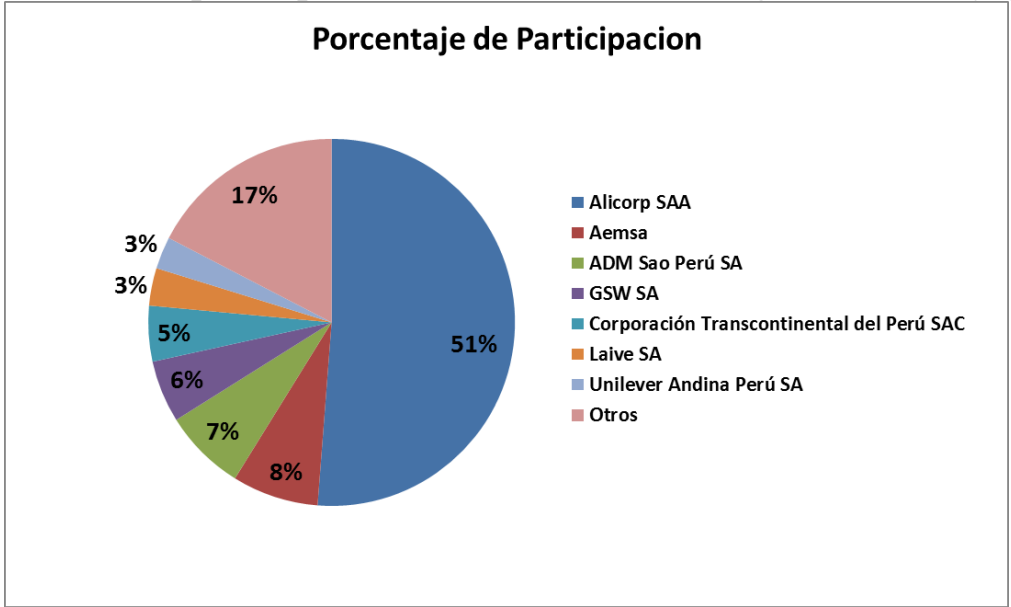

Fuente: Euromonitor

Elaboración propia

\section{Análisis de los competidores}

Para poder realizar un mejor análisis de los competidores, utilizaremos las fuerzas de Porter.

Figura 2.17.

Fuerzas de Porter

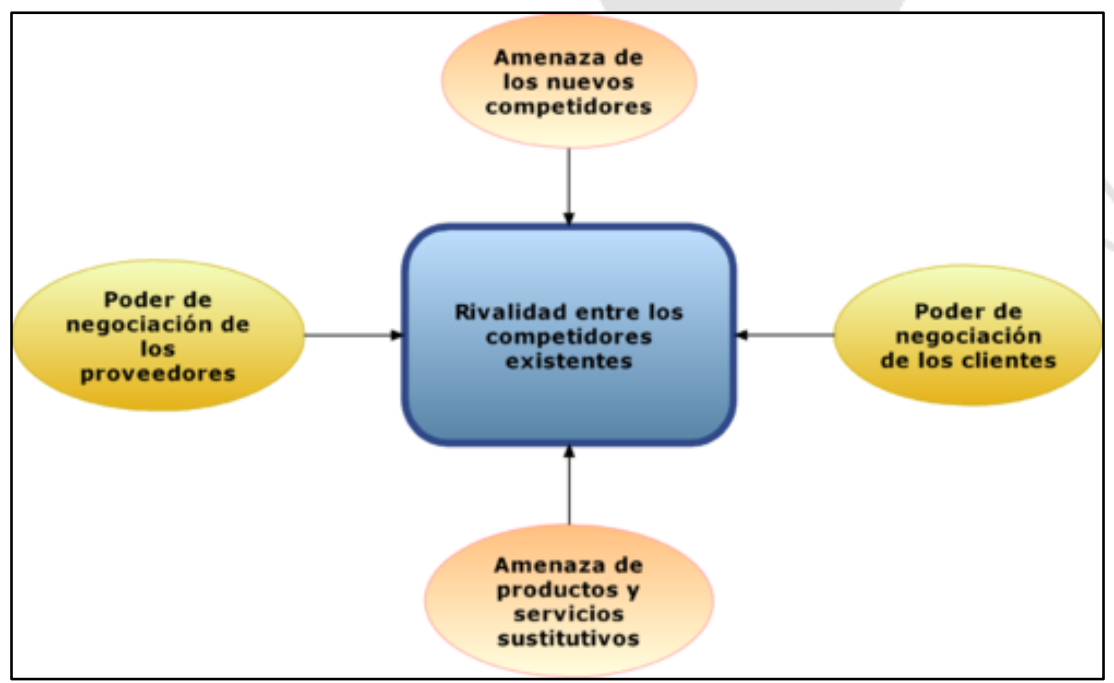

Fuente: Marketing \& Business Blog 


\section{a. Poder de negociación de los proveedores}

Los proveedores que nos brindan nuestro principal insumo, granos de sacha Inchi, poseen un poder alto de negociación ya que de ellos dependemos para nuestra producción. Un punto a favor, es que existen muchas empresas en la Amazonía que cosechan este producto y no poseen precios muy altos.

\section{b. Amenaza de nuevos competidores}

A través de los años hemos visto un incremento en las ventas de productos naturales y orgánicos, así como la concientización de la gente para tomar una vida sana. Se están creando nuevas pequeñas empresas que están comercializando productos similares al nuestro pero no ingresan con mucha fuerza al mercado. Por ello, agregamos a este punto un poder de negociaciones medio.

\section{c. Poder de negociación de los clientes}

Los clientes tienen un poder de negociación alto ya que todo depende de que ellos compren nuestros productos. El proyecto se enfocará en que el producto sea atractivo hacia ellos presentando las características saludables y buenas que posee el aceite de sacha Inchi.

\section{d. Amenaza de productos sustitutos}

La amenaza de productos sustitutos es alta ya que existe una gran variedad de aceites en el mercado. Desde los más comerciales como los vegetales y de oliva hasta los específicos como el de girasol. Debemos de enfocarnos en mostrar las diferencias con estos y los beneficios que los demás no poseen. 


\section{e. Rivalidad entre los competidores existentes}

La rivalidad es alta ya que existen muchas pequeñas empresas que comercializan productos similares a los nuestros. El principal competidor es Agroindustrias Amazónicas SAC, el cual ya está posicionado en el mercado.

\section{f. Principal competidor}

En los últimos años la competencia de productos saludables y beneficiosos para la salud se ha incrementado. Las personas están más preocupadas por su salud y el cuidado de ella. Por ello cada vez aparecen más empresas que producen y comercializan este tipo de productos.

Entre las empresas competidoras tenemos:

- Agroindustrias Amazónicas

- Roda Selva SAC

- Amazon Health Products SAC

- Andinoindustrias SAC

- EL Olivar

- Nutriomega

Dentro del mercado de supermercados podemos categorizar como el principal competidor a Agroindustrias Amazónicas SAC, empresa considerada como pionera en el rubro de la sacha Inchi. La empresa ha llegado a ser reconocida a nivel internacional por su proyecto "Omega" en el cual promueve y desarrolla la investigación, cultivo, industria, comercio y producción de distintos productos basados en la sacha Inchi. 
Esta empresa destina sus productos a la exportación y a venta en Supermercados. En Wong ingresó como un producto Premium a un costo de S/. 30.60.

En la cadena también comercializan un aceite de Sacha Inchi de la empresa Nutriomega, el cual se venda a S/. 23.70, y Aceite de Sacha Inchi de la empresa El Olivar, el cual se vende a S/. 26.90. Nuestro producto se diferencia de los anteriores en el servicio de post venta que brindaremos a través de internet. Por ello nuestro producto estará en un precio intermedio entre el Aceite Premium (Agroindustrias amazónicas) y los demás competidores como Nutriomega y el Olivar.

El precio al supermercado será de S/.18.50. Agregando la ganancia promedio del supermercado y el IGV nuestro producto costaría para el consumidor final S/. 27.30.

Figura 2.18.

Competencia Aceites en Supermercados Wong

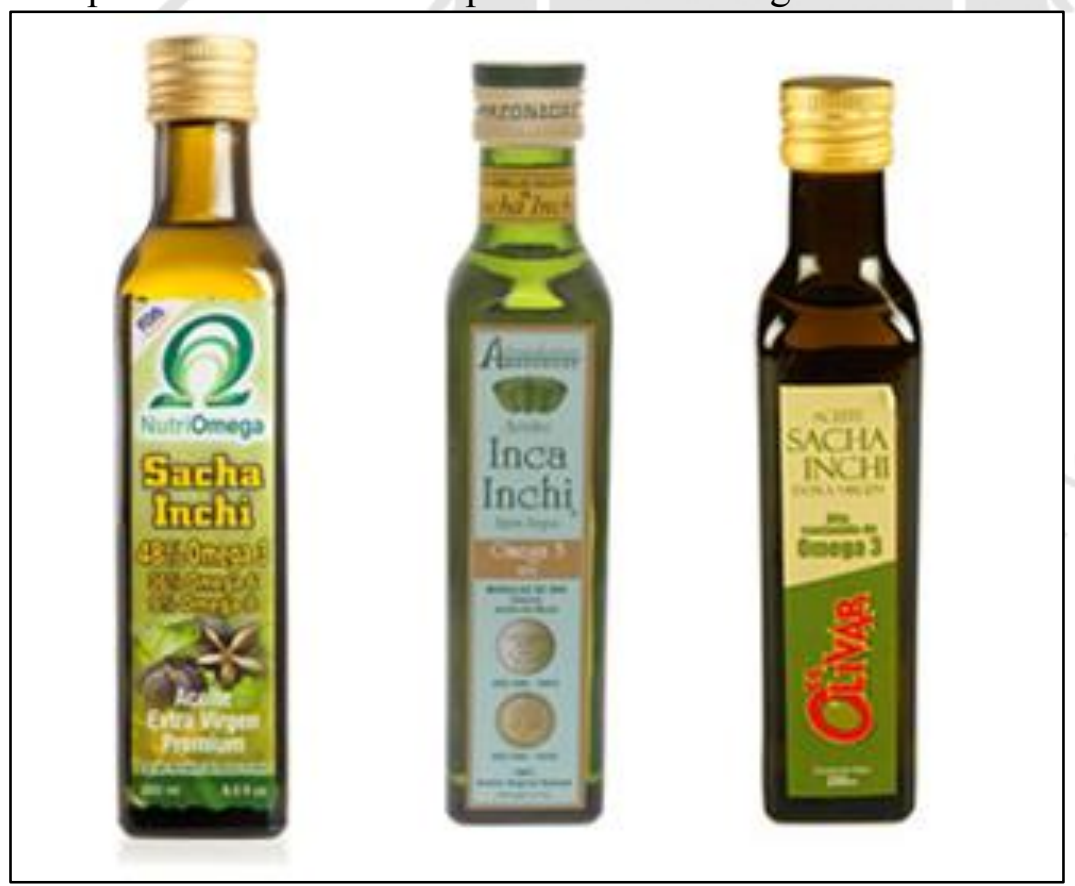

Fuente: Supermercados Wong 


\section{Demanda para el proyecto}

\section{Segmentación del mercado}

Para poder realizar una correcta segmentación de mercado debemos analizar todas las variables que pueden influenciar la compra de nuestro producto. En el siguiente cuadro podemos apreciar las variables a tomar en cuenta, así como algunos resultados obtenidos a través de la investigación de las distintas bases de datos.

Tabla 2.19.

Variables para la segmentación

\begin{tabular}{|c|c|}
\hline Variable & Detalle \\
\hline Geografica & Mercado Nacional, Region, Departamento, Ciudad \\
\hline Demográfica & Edad, Sexo, Estado Civil \\
\hline Psicografica & Nivel socioeconomico \\
\hline Conductual & Beneficios buscados, ocasión de compra \\
\hline
\end{tabular}

Elaboración propia

El siguiente cuadro podemos apreciar a nivel de edades que la segunda población más grande es la de adultos y adultos jóvenes (25 a 39 años). No hemos tomado en cuenta a la población de 0 a 17 años, ya que ellos no poseen los ingresos necesarios para poder realizar las compras en supermercados y por ende de este producto.

Figura 2.20.

Población nacional por grupo de edad \%

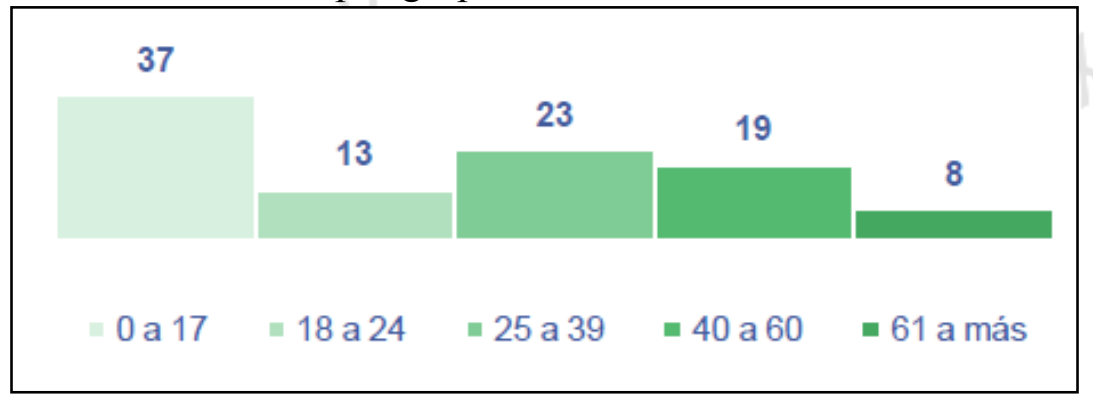

Fuente: Ipsos Apoyo

Podemos apreciar en el siguiente cuadro que la actitud hacia una vida sana viene mayormente en personas jóvenes y adultas. 
Figura 2.21.

Actitud hacia una vida sana

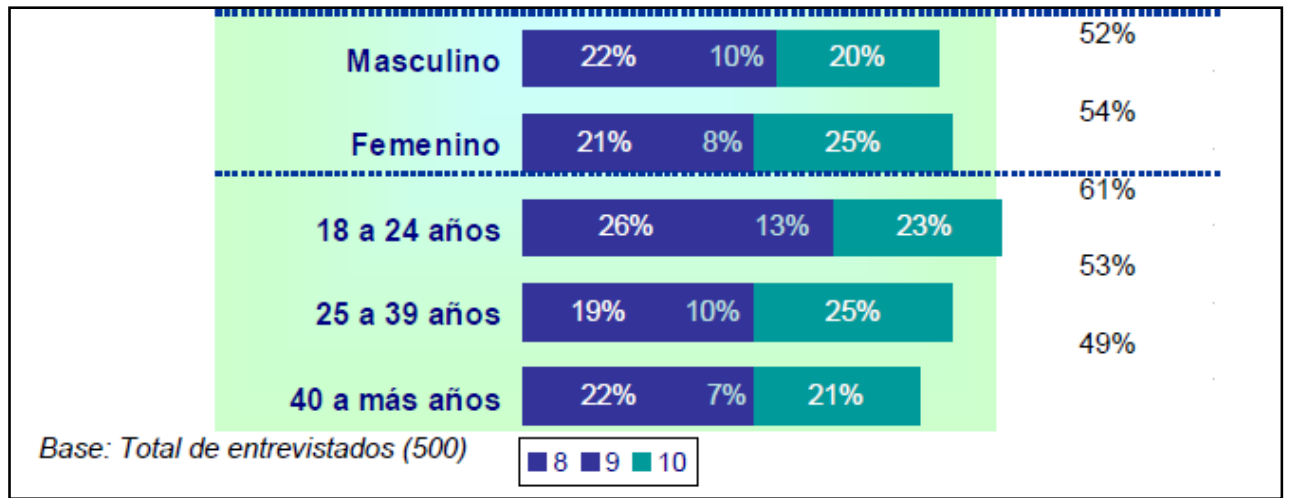

Fuente: Ipsos Apoyo

También elegiremos como ratio la población que realiza las compras por sí mismos, los cuales son un porcentaje de $47 \%$ de la población.

Figura 2.22.

¿Quién realiza las compras del hogar?

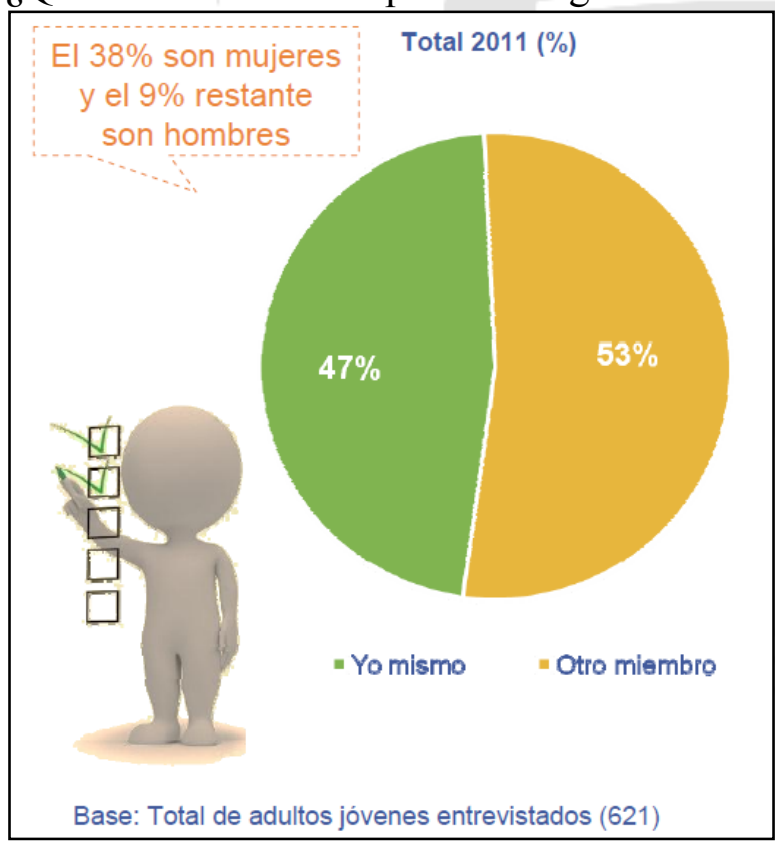

Fuente: Ipsos Apoyo 


\section{Selección del mercado meta}

Luego de analizar la información obtenida de Ipsos Apoyo llegamos a la conclusión que nuestro producto será dirigido a la población de la ciudad de Lima Metropolitana. Nos enfocaremos en los distritos A y B donde se concentran los supermercados como Wong, Vivanda, Metro y Plaza Vea. Además, se enfocará en un público adulto joven, ya que es la generación con más cuidado personal y en su salud. Además nos enfocaremos en las personas que realizan las compras del hogar.

Los siguientes puntos resumen nuestra segmentación escogida:

- Geográfico: Lima Metropolitana distritos socio-económicos A y B

- Demográfico: Población adulto joven

- Socioeconómico: Población de nivel socioeconómico A y $\mathrm{B}$ que realizan compras en supermercados.

- Conductual: Población que busca una vida saludable y cuidado personal.

\section{Determinación de la demanda para el proyecto}

Para poder hallar la demanda del proyecto se relacionarán dos ratios hallados, primero el ratio de la información obtenida de las bases de datos y luego relacionarlo con el ratio obtenido de las encuestas.

Ratio base de datos: $0.23 * 0.53 * 0.47=0.057=5.7 \%$

0.23: Población adulta joven de 25 a 39 años según Ipsos Apoyo

0.53: Población adulta joven de 25 a 39 años enfocada en una vida sana según Ipsos Apoyo

0.47: Población de adultos jóvenes que realiza compras del hogar por si misma según Ipsos apoyo 


\section{$\underline{\text { Encuesta }}$}

Para poder realizar la encuesta primero calculamos el número de personas a quienes debemos entrevistar.

Utilizamos la fórmula:

$\mathrm{n}=\mathrm{N}^{*} \mathrm{~S}^{\wedge} 2 /\left[(\mathrm{N}-1)^{*} \mathrm{~B}^{\wedge} 2 / \mathrm{z}^{\wedge} 2+\mathrm{S}^{\wedge} 2\right]$

- Fuente: "Elementos de Muestreo" por Richard I. Scheaffer \& William Mendenhall. 2006.

$\mathbf{n}=$ Tamaño de muestra necesario

$\mathbf{N}=$ Tamaño de la población = numero obtenido en la parte inferior

$\mathbf{S}=$ Varianza de la variable en la población $=\mathbf{0 . 0 5}$

$\mathbf{B}=$ Tamaño máximo del error que se quiere cometer $=\mathbf{0 . 0 5}$

$\mathbf{z}=$ Cuantil de la distribución normal estándar que corresponde al nivel de confianza que se quiere alcanzar. Al querer obtener un intervalo de confianza del $95 \%$ utilizamos la variable $=\mathbf{1 . 9 6}$

\section{Dato tamaño de población:}

Para hallar el tamaño de la población primero analizamos en que distritos se encuentra la mayor población A-B. En este caso elegimos los distritos de Miraflores, San Isidro, La Molina, San Borja y Surco, según información de la Asociación Peruana de Empresas de Investigación de Mercados (Apeim). 
Figura 2.23.

Distribución de Nivel socio económico por zonas

\begin{tabular}{|c|c|c|c|c|c|c|}
\hline \multicolumn{7}{|l|}{$\begin{array}{l}\text { Apeim DISTRIBUCIÓN DE NIVELES } \\
\text { PERSONAS - (\%) HORIZONTALES }\end{array}$} \\
\hline \multirow{2}{*}{ Zona } & \multirow[b]{2}{*}{ TOTAL } & \multicolumn{5}{|c|}{ Niveles Socioeconómicos } \\
\hline & & NSE "A" & NSE "B" & NSE "C" & NSE "D" & NSE "E" \\
\hline Total & 100 & 4.8 & 18.3 & 40.8 & 29.1 & 7.0 \\
\hline Zona 1 (Puente Piedra, Comas, Carabayllo) & 100 & 0.7 & 9.7 & 47.0 & 32.8 & 9.7 \\
\hline Zona 2 (Independencia, Los Olivos, San Martin de Porras) & 100 & 2.9 & 24.6 & 46.3 & 22.0 & 4.2 \\
\hline Zona 3 (San Juan de Lurigancho) & 100 & 1.0 & 16.0 & 39.6 & 37.2 & 6.2 \\
\hline Zona 4 (Cercado, Rímac, Breña, La Victoria) & 100 & 1.7 & 16.1 & 47.4 & 29.7 & 5.1 \\
\hline $\begin{array}{l}\text { Zona } 5 \text { (Ate, Chaclacayo, Lurigancho, Santa Anita, San Luis, El } \\
\text { Agustino) }\end{array}$ & 100 & 2.3 & 14.0 & 40.8 & 36.4 & 6.5 \\
\hline Zona 6 (Jesús María, Lince, Pueblo Libre, Magdalena, San Miguel) & 100 & 15.5 & 49.2 & 23.1 & 10.9 & 1.4 \\
\hline Zona 7 (Miraflores, San Isidro, San Borja, Surco, La Molina) & 100 & 35.1 & 35.0 & 21.8 & 6.6 & 1.5 \\
\hline Zona 8 (Surquillo, Barranco, Chorrillos, San Juan de Miraflores) & 100 & 2.6 & 16.9 & 37.8 & 33.7 & 9.0 \\
\hline Zona 9 (Villa El Salvador, Villa Maria del Triunfo, Lurin, Pachacamác) & 100 & 0.0 & 6.2 & 43.5 & 39.9 & 10.4 \\
\hline $\begin{array}{l}\text { Zona } 10 \text { (Callao, Bellavista, La Perla, La Punta, Carmen de la Legua, } \\
\text { Ventanilla) }\end{array}$ & 100 & 1.3 & 15.8 & 41.7 & 28.6 & 12.5 \\
\hline Otros & 100 & 3.8 & 9.0 & 76.9 & 9.0 & 1.3 \\
\hline
\end{tabular}

Fuente: APEIM

Luego analizamos la población de cada uno de los distritos obtenida del INEI.

Figura 2.24.

Población por distritos de Ciudad de Lima 2014

\begin{tabular}{|c|c|c|c|}
\hline \multicolumn{4}{|c|}{$\begin{array}{l}\text { DISTRITOS DE LA PROVINCIA DE LIMA Y LA PROVINCIA } \\
\text { CONSTITUCIONAL DEL CALLAO, } 2014\end{array}$} \\
\hline Distrito & $\begin{array}{l}\text { Población } \\
2014\end{array}$ & Distrito & $\begin{array}{c}\text { Población } \\
2014\end{array}$ \\
\hline 1 Lima & 276857 & 27 Punta Negra & 7568 \\
\hline 2 Ancón & 38482 & 28 Rimac & 167286 \\
\hline 3 Ate & 611082 & 29 San Bartolo & 7463 \\
\hline 4 Barranco & 30641 & 30 San Borja & 111808 \\
\hline 5 Brễa & 77116 & 31 San Isidro & 55006 \\
\hline 6 Carabayllo & 290311 & $\begin{array}{l}32 \text { San Juan De } \\
\text { Lurigancho }\end{array}$ & 1069566 \\
\hline 7 Chaclacayo & 43355 & $\begin{array}{l}33 \text { San Juan De } \\
\text { Miraflores }\end{array}$ & 400630 \\
\hline 8 Chorrillos & 322066 & 34 San Luis & 57530 \\
\hline 9 Cieneguilla & 43975 & 35 San Martin de Porres & 686702 \\
\hline 10 Comas & 522760 & 36 San Miguel & 135366 \\
\hline 11 El Agustino & 190961 & 37 Santa Anita & 223447 \\
\hline 12 Independencia & 216764 & 38 Santa María del Mar & 1467 \\
\hline 13 Jesús Maria & 71514 & 39 Santa Rosa & 17563 \\
\hline 14 La Molina & 166912 & 40 Santago de Surco & 338509 \\
\hline 15 La Victoria & 175372 & 41 Surquillo & 91686 \\
\hline 16 Lince & 51144 & 42 Villa El Salvador & 454114 \\
\hline 17 Los Olivos & 365921 & 43 Villa Maria del Triunio & 441239 \\
\hline 18 Lurigancho & 212987 & 44 Callao & 410640 \\
\hline 19 Lurin & 82319 & 45 Bellavista & 72665 \\
\hline 20 Magdalena Del Mar & 54566 & $\begin{array}{l}46 \text { Carmen de } \\
\text { La Legua Reynoso }\end{array}$ & 41431 \\
\hline 21 Pueblo Libre & 76437 & 47 La Perla & 59518 \\
\hline 22 Miraflores & 82805 & 48 La Punta & 3521 \\
\hline 23 Pachacamac & 120015 & 49 Mi Perú $1 /$ & 56371 \\
\hline 24 Pucusana & 16120 & 50 Ventanila & 355830 \\
\hline 25 Puente Piedra & 336928 & & \\
\hline 26 Punta Hermosa & 7381 & & \\
\hline
\end{tabular}

Fuente: INEI 
Según la información, el 71.3\% de la población AB se encuentra en los distritos mencionados. Por ello utilizamos $\mathbf{N}=\mathbf{5 3 8 , 3 4 3 . 5 2}$ para obtener nuestros datos Entonces:

$\mathrm{n}=(538343.52)^{*}(0.5)^{\wedge} 2 /\left\{(538342,52)^{*}\left[(0.05)^{\wedge} 2 /(1.96)^{\wedge} 2\right]\right\}+(0.5)^{\wedge} 2$

$n=38.39=40$ personas encuestadas

Realizamos una encuesta por la web en la cual 70 personas participaron. Según las encuestas realizadas, se obtuvo la siguiente información en las preguntas clave:

Figura 2.25.

Pregunta Encuesta 1

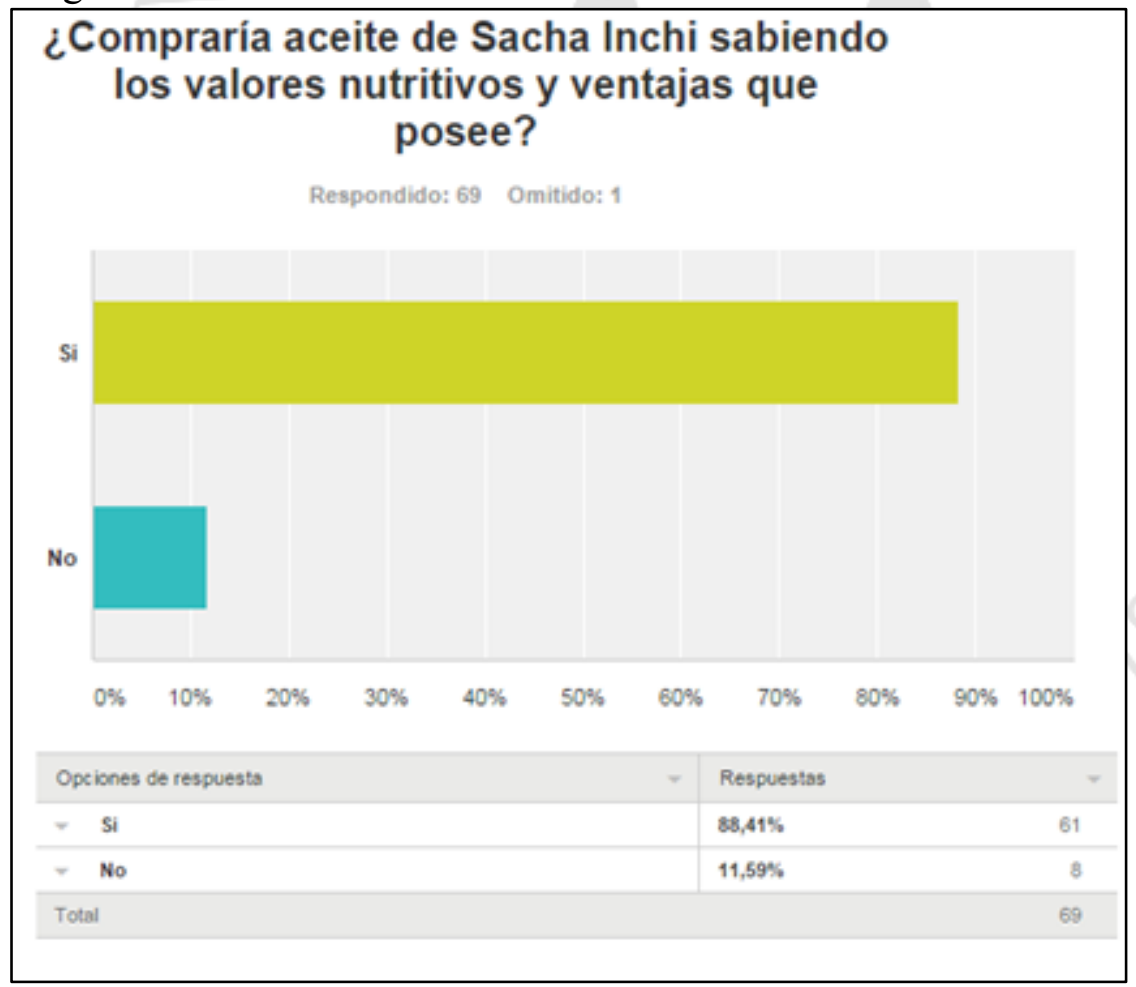

Elaboración propia 
Figura 2.26.

Pregunta Encuesta 2

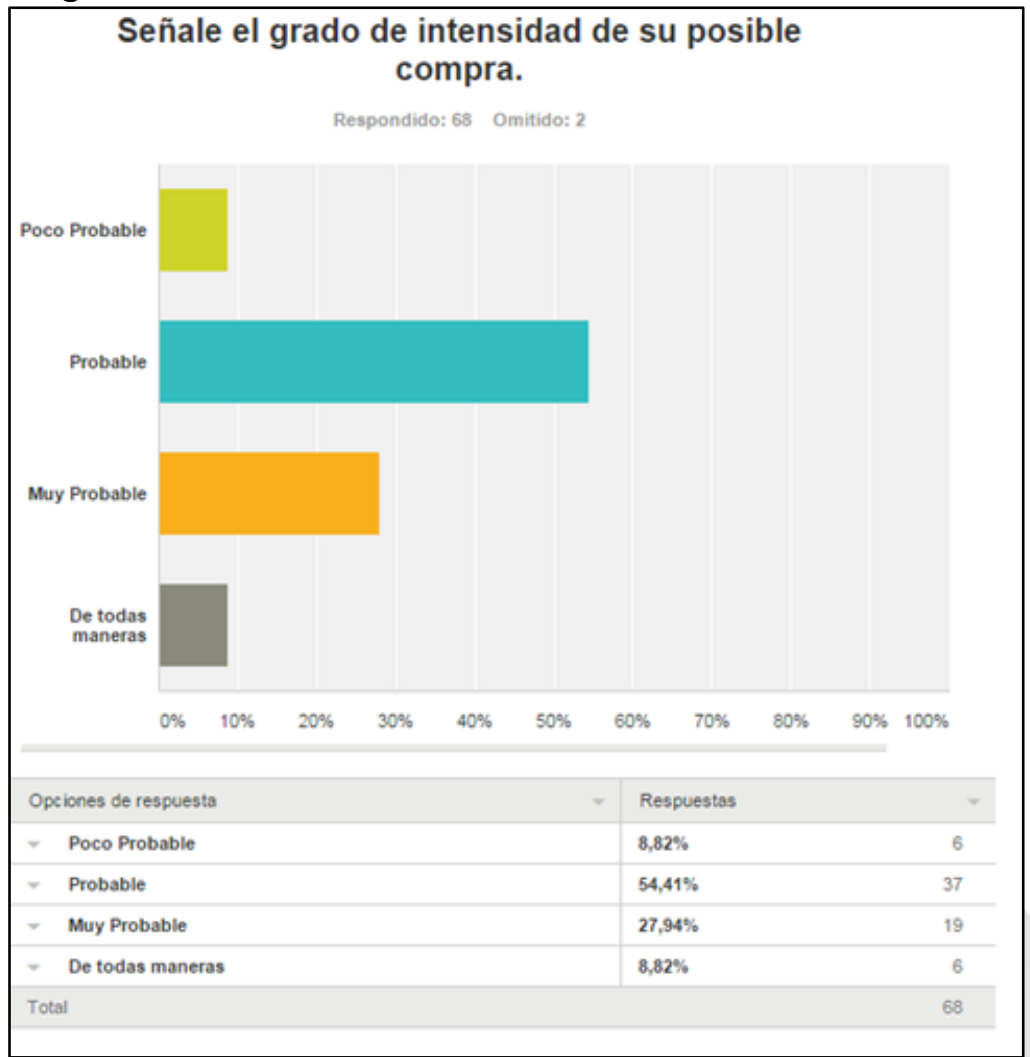

Elaboración propia

Los resultados de la encuesta indican que de las 70 personas entrevistadas un $88.41 \%$ consumiría aceite de sacha Inchi y un $54.41 \%$ posee una intensidad de compra probable.

Se toma el ratio de la intención de compra para los cálculos de la demanda segmentada:

\section{Ratio encuesta: $0.8841 * 0.5441=48.10 \%$}

Multiplicando ambos corregimos la intención de compra y llegamos al siguiente porcentaje de segmentación del mercado.

$0.4810 * 0.057=0.027417=2.74 \%$

(El valor 0.057 fue hallado según las variables de segmentación demográfica comienzos del capítulo 2.4.3) 
Tabla 2.27.

Demanda del proyecto

\begin{tabular}{|c|c|c|}
\hline & & $2.740 \%$ \\
\hline & Botellas de $250 \mathrm{ml}$. & Botellas de $250 \mathrm{ml}$. \\
\hline & Demanda Aparente & Demanda del proyecto \\
\hline 2015 & $2,563,702.17$ & $70,245.44$ \\
\hline 2016 & $2,654,435.06$ & $72,731.52$ \\
\hline 2017 & $2,745,167.94$ & $75,217.60$ \\
\hline 2018 & $2,835,900.83$ & $77,703.68$ \\
\hline 2019 & $2,926,633.72$ & $80,189.76$ \\
\hline 2020 & $3,017,366.60$ & $82,675.84$ \\
\hline 2021 & $3,108,099.49$ & $85,161.93$ \\
\hline 2022 & $3,198,832.38$ & $87,648.01$ \\
\hline 2023 & $3,289,565.26$ & $90,134.09$ \\
\hline 2024 & $3,380,298.15$ & $92,620.17$ \\
\hline 2025 & $3,471,031.03$ & $95,106.25$ \\
\hline
\end{tabular}

Elaboración propia

\section{Comercialización}

\section{Políticas de comercialización y distribución}

\section{a. Producto}

Como ya se ha mencionado anteriormente, nuestro producto vendrá en botellas oscuras de $250 \mathrm{ml}$ con una tapa metálica. Además se utilizará una etiqueta llamativa/elegante que muestre los valores nutricionales del producto, así como las características legales que se requieren. La etiqueta también será biodegradable para contribuir con el medio ambiente.

El producto se llamará "S.inchi Oil". 


\section{b. Plaza}

El producto será comercializado en los distintos supermercados de nuestro país, enfocándonos en las cadenas de Supermercados Peruanos, Cencosud y Tottus. Además, ingresaremos a los autoservicios (grifos) pero no será nuestro canal principal.

\section{c. Precio}

Para poder posicionarse en el mercado y además generar ingresos, se mantendrá un precio similar al de la competencia. El precio al supermercado será de S/.18.50. Agregando la ganancia promedio del supermercado y el IGV nuestro producto costaría para el consumidor final S/. 27.30.

\section{Publicidad y promoción}

\section{a. Publicidad}

Con ayuda de una agencia de publicidad, crearemos una campaña de ingreso al mercado, donde se enfocará el valor nutricional del producto y la calidad que este posee. Se diseñaran artes para los volantes y además para los uniformes del personal de degustación.

\section{b. Promoción}

Para promocionar el producto utilizaremos medios que nos relacionen directamente con los clientes. Se utilizará volantes para que las personas conozcan el producto y sus beneficios. Crearemos una página web en donde los clientes podrán investigar y también un Fanpage en Facebook para que nuestro producto se vuelva popular. 
También realizaremos degustaciones de producto en donde se podrá sentir el verdadero sabor del aceite. Por ejemplo, algunas verduras sazonadas con el aceite de Sacha Inchi y granos.

No se utilizarán medios de comunicación masiva ya que primero debemos posicionar nuestro producto.

\section{Análisis de precios}

\section{a. Tendencia histórica de los precios}

La tendencia de los precios en la categoría de productos naturales y de "vida sana" ha ido incrementando con el paso del tiempo. Esto se debe a los nuevos estilos de vida que las personas están tomando, llevándolos a cuidar mejor de su salud y a tomar conciencia de los beneficios que ciertos productos pueden darles.

\section{b. Precios actuales}

En la actualidad, los precios en el mercado varían mucho ya que podemos encontrar muchas presentaciones y tipos de aceites en los distintos canales. Dependiendo de las características del producto y que tan comercial es, el precio disminuye o se eleva. Para poder obtener el precio de nuestro producto, debemos analizar los precios de la competencia en los supermercados, ya que este es nuestro canal principal. Además, se debe de tomar en cuenta todos los gastos relacionados a la ubicación e ingreso de nuestro producto a la tienda. 
Tabla 2.28.

Precios actuales de diferentes aceites para el consumo masivo

\begin{tabular}{|c|c|c|c|}
\hline Producto & Canal & Presentacion & Costo \\
\hline Aceite de Sacha Inchi "Eco Wasi" mas gastos de envio & Internet & Botella de $250 \mathrm{ml}$. & S/. $\quad 20.00$ \\
\hline Aceite de Sacha Inchi extra virgen "Santa Natura" & Tienda Naturista & Botella de $250 \mathrm{ml}$. & 32.00 \\
\hline Aceite de Sacha Inchi "Inca Inchi" al por mayor & Internet & Botella de $250 \mathrm{ml}$. & 22.00 \\
\hline
\end{tabular}

Elaboración Propia

\subsection{Disponibilidad de insumos}

\section{Características principales de la materia prima}

La materia prima utilizada para la producción del aceite es el sacha Inchi. No es necesario utilizar otros insumos ya que la semilla de la planta es procesada y obtenemos el aceite directamente. En el siguiente cuadro podemos apreciar los componentes nutricionales del aceite obtenido.

Tabla 2.29.

Composición Aceite de Sacha Inchi \%peso

\section{COMPOSICIÓN DE ÁCIDOS GRASOS \%}

Palmítico C 16:0 $\quad 3.65$

Esteárico C 18:0 2.54

Oleico omega 9 C 18:1 w9 $\quad 8.28$

Linoleico omega 6 C 18:2 w6 36.80

Alfa Linolénico omega 3 C 18:3 w3 48.61

Total Saturados 6.19

Total Insaturados $\quad 93.81$

\section{ANTIOXIDANTES}

\begin{tabular}{|ll} 
Vitamina A & $681 \mathrm{mg}$ \\
\hline Vitamina E & $17 \mathrm{mg} / 100 \mathrm{gr}$
\end{tabular}

\section{CARACTERISTICAS DE CALIDAD}

\begin{tabular}{|ll|}
\hline Índice de acidez & 0.22 \\
\hline Índice de Peróxidos & 3.12 \\
\hline Aditivos Alimentarios & Ninguno \\
\hline
\end{tabular}

Elaboración propia

Fuente: http://www.incainchi.es/pdf/ficha.pdf 
Los elementos que ingresan al proceso como la botella, etiqueta y tapa metálica serán comprado a un tercero.

\section{Potencialidad del recurso en la zona de influencia del proyecto}

Nuestra planta será ubicada en el departamento de Lima. Esto se debe a la cercanía del público objetivo y además de la disminución en costos que representa. Si trasportamos el producto final, las botellas del aceite, desde la selva; Nuestros costos se incrementan. En cambio, si transportamos la materia prima desde la selva a Lima para luego procesarla, nuestros gastos se reducen.

Cuando nuestra planta ya se encuentre operativa ayudaremos a que la población de la zona se beneficie otorgando puestos de trabajo. Previamente a la labor, realizaremos capacitaciones para que el personal esté capacitado y sepa lo que está realizando. Además, tendremos mucho cuidado en respetar todas las normas ambientales y para que la población de los alrededores no se sienta amenazada por las labores de la empresa.

Para poder analizar numéricamente la potencialidad del recurso para nuestro proyecto utilizaremos la producción de la semilla de sacha Inchi vs. La demanda segmentada.

Al no encontrar la producción nacional de aceite de sacha Inchi, debido a que es un producto que recién está surgiendo en el mercado, hemos decidido utilizar la demanda segmentada obtenida.

Además, la producción de sacha Inchi en toneladas la hemos proyectado hasta el 2021, ya que la información que encontramos solo estaba disponible del 2007 al 2011. 
La información colocada en demanda segmentada ha sido transformada de botellas de sacha Inchi a toneladas de sacha Inchi para poder relacionar mejor la demanda vs. La producción.

*Hemos utilizado el siguiente dato como densidad del aceite de sacha Inchi (densidad=peso/volumen): $0.918 \mathrm{~kg} / \mathrm{lt}$ (1089.32 lt/ton)

Tabla 2.30.

Producción sacha Inchi vs. Demanda del proyecto

\begin{tabular}{|c|r|r|c|}
\hline Año & $\begin{array}{c}\text { Producción Sacha } \\
\text { Inchi TON }\end{array}$ & $\begin{array}{c}\text { Demanda del } \\
\text { proyecto TON }\end{array}$ & $\begin{array}{c}\text { Relacion insumo } \\
\text { producto }\end{array}$ \\
\hline $\mathbf{2 0 1 4}$ & $174,999.00$ & 16.12 & $0.009 \%$ \\
\hline $\mathbf{2 0 1 5}$ & $194,210.00$ & 16.69 & $0.009 \%$ \\
\hline $\mathbf{2 0 1 6}$ & $213,421.00$ & 17.26 & $0.008 \%$ \\
\hline $\mathbf{2 0 1 7}$ & $232,632.00$ & 17.83 & $0.008 \%$ \\
\hline $\mathbf{2 0 1 8}$ & $251,843.00$ & 18.40 & $0.007 \%$ \\
\hline $\mathbf{2 0 1 9}$ & $271,054.00$ & 18.97 & $0.007 \%$ \\
\hline $\mathbf{2 0 2 0}$ & $290,265.00$ & 19.54 & $0.007 \%$ \\
\hline $\mathbf{2 0 2 1}$ & $309,476.00$ & 20.12 & $0.006 \%$ \\
\hline
\end{tabular}

Elaboración propia

Fuente: Programa de desarrollo de la Amazonia Peruana Estudio preliminar para la instalación de una planta productora de chocolate con sacha Inchi - Escudero Asin, Andrea - 2010 


\section{CAPÍTULO III. LOCALIZACIÓN DE PLANTA}

\subsection{Análisis de los factores de localización}

El Sacha Inchi se cultiva en varios departamentos de la selva alta y baja del Perú como Loreto, San Martín, Huánuco, Pasco, Ucayali, Junín, Madre de Dios, Amazonas y Cuzco. La mayor parte de la producción se realiza en Ucayali y San Martín.

Figura 3.1.

Mapa de Producción de Sacha Inchi

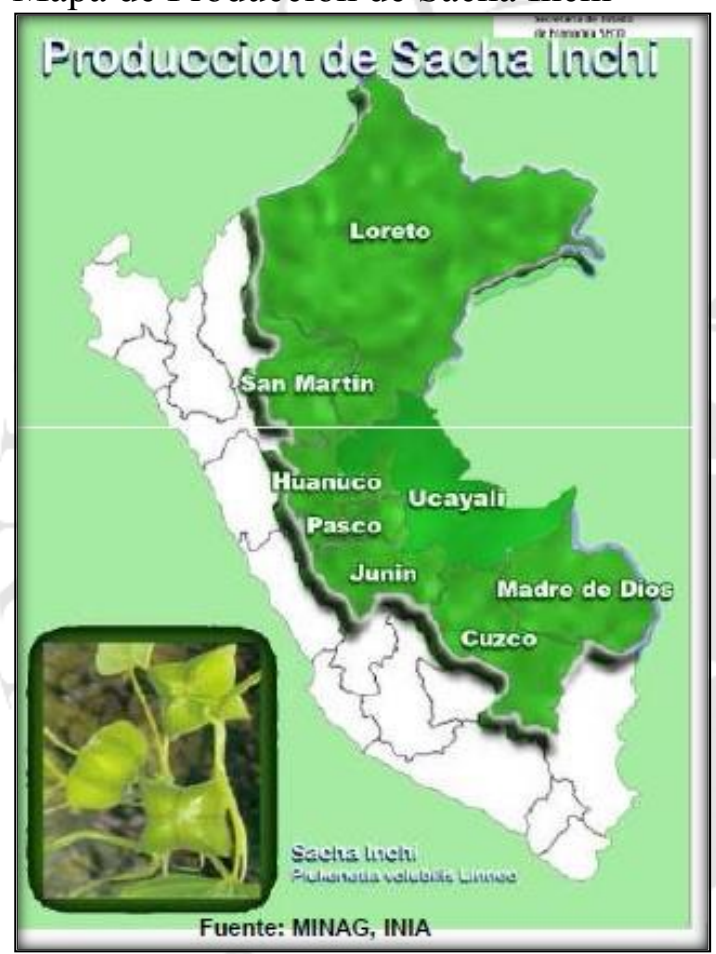

Fuente: PyGestión Exportaciones en Perú Blog

Las posibles ubicaciones que se elegirán para realizar el ranking de factores, así como los factores predominantes que se utilizan para determinar las puntuaciones están descritas a continuación. 


\subsubsection{Disponibilidad De Materia Prima}

Este factor es importante pues su disponibilidad condicionará la producción de los productos a elaborar, ya que el abastecimiento dependerá de cuan cerca o lejos se encuentre la materia prima.

De las alternativas, Lima no ofrece un suministro de materia prima directa, pues el Sacha Inchi crece solo en San Martín, Ucayali, Huánuco, Amazonas, Madre de Dios y Loreto, se podría trasladar de ahí la materia prima. En Ucayali la producción llegó a 938 toneladas en 2005, cultivándose en 625 hectáreas, mientras que en San Martín la producción llegó a 900 toneladas en 600 hectáreas.

Se espera que la producción nacional en el Perú incremente a 2,8 mil toneladas para el 2015 (investigación de mercado de PROMPEX).

Lo óptimo es ubicar la planta lo más cerca al campo de cultivo para ahorrar en flete o transporte, de ser muy alejado se incurrirían en gastos por flete al momento de trasportarlo al puerto de embarque. Lima es la más lejana de todas, sin embargo, Ucayali y San Martín cuentan con producción de materia prima. De los dos últimos solo Ucayali tiene embarque fluvial (para llevarlo a otros lugares).

\subsubsection{Proximidad al Mercado}

La planta va a producir direccionando los productos al mercado nacional, principalmente Lima. Por lo tanto, se necesita cercanía a los supermercados. San Martin se ubica a $1500 \mathrm{Km}$ de Lima y Ucayali se encuentra a $842 \mathrm{Km}$ de la capital. 


\subsubsection{Proximidad De Mano De Obra Calificada}

Debido a que estos productos tienen una serie de transformaciones y operaciones la mano de obra debe de estar capacitada para ello. En Lima se encuentra la mayor mano de obra calificada y con estudios universitarios enfocados en ello. En provincia si podemos encontrar mano de obra calificada pero en menor cantidad que la capital.

\subsubsection{Disponibilidad de energía eléctrica}

No solo es importante tener un buen abastecimiento de energía eléctrica, sino hay que tener en cuenta también los costos de esta, ya que no en todas las regiones del país la energía eléctrica a la tarifa industrial cuesta lo mismo, esto se debe a diversos factores como demanda, pocas fuentes de generación de energía cercana, etc.

Tabla 3.2.

Potencia instalada en los departamentos de Lima, Ucayali y San Martin

\begin{tabular}{|l|l|}
\hline Departamento & Potencia Instalada (MW) \\
\hline Lima & 2238 \\
\hline Ucayali & 242 \\
\hline San Martin & 47 \\
\hline
\end{tabular}

Elaboración propia

Fuente: Osinerg 
Tabla. 3.3.

Tensión eléctrica y precio en Lima

\begin{tabular}{|c|c|c|c|}
\hline \multirow{2}{*}{ Region } & \multirow{3}{*}{ Area } & Tension & PPM $^{*}$ \\
\cline { 3 - 4 } & & Kv & S/. Kw - mes \\
\hline \multirow{3}{*}{ Lima } & Ate & 220 & 17.03 \\
\cline { 2 - 4 } & Lima & 220 & 17.03 \\
\cline { 2 - 4 } & Ventanilla & 220 & 17.03 \\
\hline \multicolumn{4}{|l}{} \\
*PPM: Precio de la potencia a nivel de generacion \\
\hline
\end{tabular}

Elaboración propia

Fuente: Osinerg

\subsubsection{Disponibilidad de agua}

El agua en nuestra planta es indispensable. Se necesita para múltiples procesos para la elaboración del aceite, así también como para el uso diario de los empleados.

Lamentablemente otra vez viendo que las provincias no están tan desarrolladas la opción de obtener agua en Ucayali y San Martín sería directamente del río que no está purificada previamente y no se encuentra muy cerca, por otro lado en Lima existe un muy buen servicio de agua para plantas industriales que incluso sería menos costoso.

Tabla 3.4.

Consumo y tarifas Sedapal

\begin{tabular}{|c|c|c|c|}
\hline \multirow{2}{*}{ Region } & Rasgos de consumo & \multicolumn{2}{|c|}{ Tarifa (S/./ m3) } \\
\cline { 2 - 4 } & $\mathrm{m} 3 /$ mes & Agua Potable & Alcantarillado \\
\hline \multirow{2}{*}{ Lima } & 0 a 1000 & 3959 & 1730 \\
\cline { 2 - 4 } & 1000 a mas & 4246 & 1855 \\
\hline
\end{tabular}

Elaboración propia

Fuente: Sedapal 


\subsubsection{Costo de terreno e instalación de planta}

En relación con los costos del terreno e instalación de planta debemos tomar en cuenta que nuestro país se centraliza mucho en Lima, por ello los precios de los terrenos en la capital son abismalmente más caros que en cualquier otro departamento.

Sin embargo, en Ucayali o en San Martin sería más factible encontrar terrenos grandes a precios muy cómodos.

Costo de terreno aproximado en Ucayali y San Martin: 170 dólares $\mathrm{x}$ m2

Fuente: http://peru.inmobiliaria.com/

Tabla 3.5.

Precio Promedio por $\mathrm{m} 2$ dólares

\begin{tabular}{|c|c|}
\hline Distrito & Precio Promedio (m2) \\
\hline Ate & $800-1200$ \\
\hline Ventanilla & $800-1000$ \\
\hline Callao & $1000-1400$ \\
\hline
\end{tabular}

Elaboración propia

Fuente: Colliers International

\section{Posibles ubicaciones de acuerdo a factores predominantes}

Factores predominantes:
A. Disponibilidad de materia prima.
B. Proximidad del mercado.
C. Proximidad de mano de obra calificada.
D. Disponibilidad de energía eléctrica.
E. Disponibilidad de agua. 
F. Costo de Terreno e Instalación de planta

Ubicaciones:
A. Lima.
B. Ucayali
C. San Martín

Escala de calificación

0: Malo

2: Intermedio

4: Bueno

6: Muy Bueno

\subsection{Evaluación y selección de la macro localización}

Para analizar la posible ubicación de la planta, se utilizarán dos métodos en el que se analizan los factores más importantes para la elección. Se Utilizará el Ranking de Factores para seleccionar la ubicación Macro (por departamentos) y luego, enfocado en la selección micro (por distrito).

Tabla 3.6.

Matriz de enfrentamiento Macro 1

\begin{tabular}{|c|c|c|c|c|c|c|c|c|c|}
\hline Importancia & & $\mathrm{A}$ & $\mathrm{B}$ & $\mathrm{C}$ & $\mathrm{D}$ & $\mathrm{E}$ & $\mathrm{F}$ & Conteo & Ponderado \\
\hline 1 & $\mathrm{~A}$ & - & 1 & 1 & -1 & 1 & 1 & 5 & 0.23 \\
\hline 1 & $\mathrm{~B}$ & 1 & - & 1 & -1 & 1 & 1 & 5 & 0.23 \\
\hline 2 & $\mathrm{C}$ & 0 & 0 & - & 1 & 1 & 1 & 3 & 0.14 \\
\hline 2 & $\mathrm{D}$ & 0 & 0 & 1 & - & 1 & 1 & 3 & 0.14 \\
\hline 2 & $\mathrm{E}$ & 0 & 0 & 1 & 1 & - & 1 & 3 & 0.14 \\
\hline 2 & $\mathrm{~F}$ & 0 & 0 & 1 & 1 & 1 & - & 3 & 0.14 \\
\hline & & & & & & & & 22 & 1 \\
\hline
\end{tabular}

Elaboración propia 
Tabla 3.7.

Matriz de enfrentamiento Macro 2

\begin{tabular}{|c|c|c|c|c|c|c|c|}
\hline \multicolumn{2}{|c|}{} & \multicolumn{2}{c}{ Lima } & \multicolumn{2}{c}{ Ucayali } & \multicolumn{2}{c|}{ San Martin } \\
\hline A & W & Calificación & Punt. & Calificación & Punt. & Calificación & Punt. \\
\hline B & 0.23 & 0 & 0 & 4 & 0.92 & 2 & 0.46 \\
\hline C & 0.14 & 4 & 0.92 & 2 & 0.46 & 0 & 0 \\
\hline D & 0.14 & 4 & 0.56 & 2 & 0.28 & 0 & 0 \\
\hline E & 0.14 & 4 & 0.56 & 2 & 0.28 & 0 & 0 \\
\hline F & 0.14 & 0 & 0 & 2 & 0.28 & 2 & 0.28 \\
\cline { 7 - 9 }
\end{tabular}

Elaboración propia

\subsection{Evaluación y selección de la micro localización}

Para la Microlocalización vamos a utilizar también el método de Ranking de factores en el cual se comparan tres posibles distritos de la capital: Ate, Ventanilla y Lurín. Estos tres distritos han sido escogidos debido a su enfoque en las industrias.

Las variables a analizar serán las siguientes:

\subsubsection{Proximidad al Mercado}

La planta va a producir direccionando los productos al mercado nacional, principalmente Lima. Por lo tanto, nuestra planta debe de estar en un distrito central a la ciudad y con accesos adecuados. Es por ello que se elegirá los distritos de Ate, Cercado de Lima y Ventanilla, como opciones a analizar. 


\subsubsection{Proximidad De Mano De Obra Calificada}

La mano de obra calificada en la capital es abundante. Al apreciar el Anexo 3, podemos observar que en el distrito de Lima se encuentra la mayor cantidad de personas con grado universitario completo, luego Ate y por último Ventanilla.

\subsubsection{Disponibilidad de energía eléctrica}

La tensión eléctrica en los distritos de Lima es similar. Por ello agregaremos una misma puntuación a los tres.

Tabla 3.8.

Tensión eléctrica y precio en Lima

\begin{tabular}{|l|c|c|c|}
\hline \multirow{2}{*}{ Region } & \multirow{2}{*}{ Area } & Tension & PPM* \\
\cline { 3 - 4 } & & $\mathrm{Kv}$ & $\mathrm{S} / . \mathrm{Kw}-\mathrm{mes}$ \\
\hline \multirow{3}{*}{ Lima } & Ate & 220 & 17.03 \\
\cline { 2 - 4 } & Lima & 220 & 17.03 \\
\cline { 2 - 4 } & Ventanilla & 220 & 17.03 \\
\hline \multirow{4}{|l}{} \\
*PPM: Precio de la potencia a nivel de generacion \\
\hline
\end{tabular}

Elaboración propia

Fuente: Osinerg

\subsubsection{Disponibilidad de agua}

El agua en la ciudad de Lima está disponible en todos los distritos. La elección de la mejor opción se basa en el costo de esta. Ate es el distrito con el menor costo de agua, luego Ventanilla y por ultimo Lima. 
Tabla 3.9.

Precio de m3 de Agua en Ate

\begin{tabular}{lccc|}
\hline Tipo & Rango & Und. & $\begin{array}{c}\text { Costo } \\
(\mathbf{S} / .) / \mathrm{m}^{3}\end{array}$ \\
\hline Doméstico & $0-20$ & $\mathrm{~m}^{3}$ & 0,581 \\
& $21-\mathrm{más}$ & $\mathrm{m}^{3}$ & 0,929 \\
\hline Comercial & $0-30$ & $\mathrm{~m}^{3}$ & 0,791 \\
& $31-\mathrm{más}$ & $\mathrm{m}^{3}$ & 1,411 \\
\hline \multirow{2}{*}{ Industrial } & $0-100$ & $\mathrm{~m}^{3}$ & 1,057 \\
\hline \multirow{2}{*}{ Social } & $101-\mathrm{más}$ & $\mathrm{m}^{3}$ & 1,863 \\
\hline
\end{tabular}

Fuente: Sedapal

Tabla 3.10.

Precio de m3 de Agua en Lima

\begin{tabular}{|lccc|}
\hline Tipo & Rango & Und. & $\begin{array}{c}\text { Costo } \\
(\mathbf{S} / .) / \mathrm{m}^{3}\end{array}$ \\
\hline Social & $0-10$ & $\mathrm{~m}^{3}$ & 0,272 \\
\hline \multirow{2}{*}{ Doméstico } & $0-20$ & $\mathrm{~m}^{3}$ & 0,818 \\
& $21-\mathrm{más}$ & $\mathrm{m}^{3}$ & 1,635 \\
\hline \multirow{2}{*}{ Comercial } & $0-30$ & $\mathrm{~m}^{3}$ & 1,293 \\
& $31-\mathrm{más}$ & $\mathrm{m}^{3}$ & 2,584 \\
\hline \multirow{2}{*}{ Industrial } & $0-60$ & $\mathrm{~m}^{3}$ & 1,767 \\
& $61-\mathrm{más}$ & $\mathrm{m}^{3}$ & 3,533 \\
\hline \multirow{2}{*}{ Estatal } & $0-50$ & $\mathrm{~m}^{3}$ & 0,818 \\
& $51-\mathrm{más}$ & $\mathrm{m}^{3}$ & 1,635 \\
\hline
\end{tabular}

Fuente: Sedapal

Tabla 3.11.

Precio de $\mathrm{m} 3$ de Agua en Ventanilla

\begin{tabular}{|lclc|}
\hline Tipo & Rango & Und. & $\begin{array}{c}\text { Costo } \\
(\mathbf{S} / .) / \mathbf{m}^{3}\end{array}$ \\
\hline Social & 0 - más & $\mathrm{m}^{3}$ & 0,484 \\
\hline Doméstico & $0-$ más & $\mathrm{m}^{3}$ & 0,779 \\
\hline Comercial & $0-30$ & $\mathrm{~m}^{3}$ & 0,885 \\
\hline Industrial & $0-100$ & $\mathrm{~m}^{3}$ & 1,310 \\
\hline Estatal & $01-\mathrm{más}$ & $\mathrm{m}^{3}$ & 2,006 \\
\hline
\end{tabular}

Fuente: Sedapal 


\subsubsection{Costo de terreno e instalación de planta}

Para la elección del costo de terreno se obtuvo la información de la consultora inmobiliaria Colliers. Por ello, se ubicó Ventanilla como el distrito con mejor puntaje, seguido de Ate y luego Lima.

Se ha utilizado el costo por $\mathrm{m} 2$ de Callao envés de Lima, ya que este es distrito vecino al que se está realizando una comparación.

Tabla 3.12.

Precio de terrenos en Lima

\begin{tabular}{|c|c|}
\hline Distrito & Precio Promedio (m2) \\
\hline Ate & $800-1200$ \\
\hline Ventanilla & $800-1000$ \\
\hline Callao & $1000-1400$ \\
\hline
\end{tabular}

Fuente: Colliers International

Factores predominantes:
A. Proximidad del mercado.
B. Proximidad de mano de obra calificada.
C. Disponibilidad de energía eléctrica.
D. Disponibilidad de agua.
E. Costo de Terreno e Instalación de planta

Ubicaciones:
A. Ate
B. Lima
C. Ventanilla

Escala de calificación 
0: Malo

2: Intermedio

4: Bueno

6: Muy Bueno

Tabla 3.13.

Matriz de enfrentamiento Micro 1

\begin{tabular}{|c|c|c|c|c|c|c|c|c|}
\hline Importancia & & $\mathrm{A}$ & $\mathrm{B}$ & $\mathrm{C}$ & $\mathrm{D}$ & $\mathrm{E}$ & Conteo & Ponderado \\
\hline 1 & $\mathrm{~A}$ & 1 & - & 1 & 1 & 1 & 5 & 0.23 \\
\hline 2 & $\mathrm{~B}$ & 0 & 0 & - & 1 & 1 & 3 & 0.14 \\
\hline 2 & $\mathrm{C}$ & 0 & 0 & 1 & - & 1 & 3 & 0.14 \\
\hline 2 & $\mathrm{D}$ & 0 & 0 & 1 & 1 & - & 3 & 0.14 \\
\hline 2 & $\mathrm{E}$ & 0 & 0 & 1 & 1 & 1 & 3 & 0.14 \\
\hline
\end{tabular}

Elaboración propia

Tabla 3.14.

Matriz de enfrentamiento Micro 2

\begin{tabular}{|c|c|c|c|c|c|c|c|}
\hline \multirow{2}{*}{\multicolumn{2}{|c|}{$\mathbf{W}$}} & \multicolumn{2}{|l|}{ Ate } & \multicolumn{2}{|l|}{ Lima } & \multicolumn{2}{|c|}{ Ventanilla } \\
\hline & & Calificación & Punt. & Calificación & Punt. & Calificación & Punt \\
\hline A & 0.23 & 2 & 0.46 & 2 & 0.46 & & 0.26 \\
\hline B & 0.14 & 4 & 0.56 & 6 & 0.84 & 2 & 0.28 \\
\hline $\mathrm{C}$ & 0.14 & 2 & 0.28 & 2 & 0.28 & 2 & 0.28 \\
\hline $\mathrm{D}$ & 0.14 & 6 & 0.84 & 2 & 0.28 & 4 & 0.56 \\
\hline $\mathrm{E}$ & 0.14 & 4 & 0.56 & 2 & 0.28 & 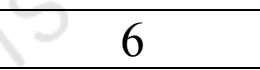 & 0.84 \\
\hline & & & 2.7 & & 2.14 & & 2.22 \\
\hline
\end{tabular}

Elaboración propia 


\section{CAPÍTULO IV. TAMAÑo DE PLANTA}

\section{Relación tamaño-mercado}

Para definir adecuadamente el tamaño de planta es importante que se tenga en cuenta los requerimientos de mercado, proyectando la demanda que se tendrá a lo largo del horizonte del proyecto. De esta forma se define cuanto es lo máximo que se podría producir de acuerdo a la demanda actual. Según los datos ya expuestos, se obtiene la siguiente proyección en botellas de $250 \mathrm{ml}$ :

Tabla 4.1.

Demanda del proyecto.

\begin{tabular}{|r|r|r|}
\hline & & \multicolumn{2}{|c|}{$\mathbf{2 . 7 4 0 \%}$} \\
\hline & $\begin{array}{c}\text { Botellas de 250ml. } \\
\text { Demanda Aparente }\end{array}$ & $\begin{array}{c}\text { Botellas de 250ml. } \\
\text { Demanda del proyecto }\end{array}$ \\
\hline $\mathbf{2 0 1 5}$ & $2,563,702.17$ & $70,245.44$ \\
\hline 2016 & $2,654,435.06$ & $72,731.52$ \\
\hline 2017 & $2,745,167.94$ & $75,217.60$ \\
\hline 2018 & $2,835,900.83$ & $77,703.68$ \\
\hline 2019 & $2,926,633.72$ & $80,189.76$ \\
\hline 2020 & $3,017,366.60$ & $82,675.84$ \\
\hline 2021 & $3,108,099.49$ & $85,161.93$ \\
\hline 2022 & $3,198,832.38$ & $87,648.01$ \\
\hline 2023 & $3,289,565.26$ & $90,134.09$ \\
\hline 2024 & $3,380,298.15$ & $92,620.17$ \\
\hline 2025 & $3,471,031.03$ & \\
\hline
\end{tabular}

Elaboración propia

\section{Relación tamaño-recursos productivos}

La materia prima requerida para la producción de este producto, es únicamente la semilla de Sacha Inchi. 
La disponibilidad de este recurso se encuentra limitada por la producción de las zonas amazónicas que producen este recurso. Sin embargo, evaluando la demanda proyectada, con la producción nacional histórica y proyectada de Sacha Inchi, la cual está creciendo a pasos agigantados, este ratio no es muy relevante, debido a que la producción de esta semilla es bastante más grande de la que necesitamos para la producción, por lo cual no se la considerará como un factor limitante.

Tabla 4.2.

Demanda del proyecto vs producción.

\begin{tabular}{|c|r|r|c|}
\hline Año & $\begin{array}{c}\text { Producción Sacha } \\
\text { Inchi TON }\end{array}$ & $\begin{array}{c}\text { Demanda del } \\
\text { proyecto TON }\end{array}$ & $\begin{array}{c}\text { Relacion insumo } \\
\text { producto }\end{array}$ \\
\hline $\mathbf{2 0 1 4}$ & $174,999.00$ & 16.12 & $0.009 \%$ \\
\hline $\mathbf{2 0 1 5}$ & $194,210.00$ & 16.69 & $0.009 \%$ \\
\hline $\mathbf{2 0 1 6}$ & $213,421.00$ & 17.26 & $0.008 \%$ \\
\hline $\mathbf{2 0 1 7}$ & $232,632.00$ & 17.83 & $0.008 \%$ \\
\hline $\mathbf{2 0 1 8}$ & $251,843.00$ & 18.40 & $0.007 \%$ \\
\hline $\mathbf{2 0 1 9}$ & $271,054.00$ & 18.97 & $0.007 \%$ \\
\hline $\mathbf{2 0 2 0}$ & $290,265.00$ & 19.54 & $0.007 \%$ \\
\hline $\mathbf{2 0 2 1}$ & $309,476.00$ & 20.12 & $0.006 \%$ \\
\hline
\end{tabular}

Elaboración propia

\section{Relación tamaño-tecnología}

Actualmente se cuenta con la tecnología y maquinaría necesaria para poder llevar a cabo el proyecto y la producción del aceite.

La tecnología seleccionada fue la de extracción de aceite por prensado frío, utilizando etapas de filtrado y tamizado para homogenizar la mezcla. Esta tecnología no requiere de maquinaria especializa o complicada de conseguir. Por ello, se concluye que el factor tecnología no es un limitante para este proyecto. 


\section{Relación tamaño-punto de equilibrio}

Para poder calcular el punto de equilibrio utilizamos la demanda y costos estimados para el año 2015.

$$
\mathbf{P e}=\mathrm{CF} /(\mathbf{P V u}-\mathbf{C v u})
$$

Dónde:

Pe $=$ Punto de equilibrio

$\mathrm{CF}=$ Costo fijo anual

$\mathrm{PVu}=$ Precio de venta unitario

$\mathrm{CVu}=$ Costo de venta unitario

$$
P e=384258 /(18.50-5)=28,463.5 \text { botellas anuales. }
$$

\section{Selección del tamaño de planta}

Luego de analizar las distintas relaciones en este capítulo, se concluyó que el tamaño de planta es de 41,319.59 botellas por año. Cantidad que resulta favorable ya que es mayor al punto de equilibrio.

Tabla 4.3.

\begin{tabular}{|c|c|}
\hline \multicolumn{2}{|l|}{ Relación } \\
\hline Tamano-mercado & 72,731 bot/anio \\
\hline Tamaño-tecnologia & No es limitant \\
\hline Tamaho-recursos productivos & 213,421 Ton/año \\
\hline Tamano-Punto de equillbro & 28,463 Soles/año \\
\hline
\end{tabular}

Tamaño de planta

Elaboración propia 


\section{CAPÍTULO V. INGENIERÍA DEL PROYECTO}

\section{Definición del producto basada en sus características de fabricación}

Para la presentación de nuestro producto utilizaremos una botella de vidrio oscura para que el aceite pueda preservar sus propiedades y no presente oxidación. Esto se debe a que la luz solar puede dañar el producto. Utilizaremos envases de $250 \mathrm{ml}$. Y se utilizará una tapa metálica en la botella.

Se utilizará una etiqueta simple y sofisticada para darle un concepto de producto Premium al aceite.

Figura 5.1.

Botella de S.inchi Oil

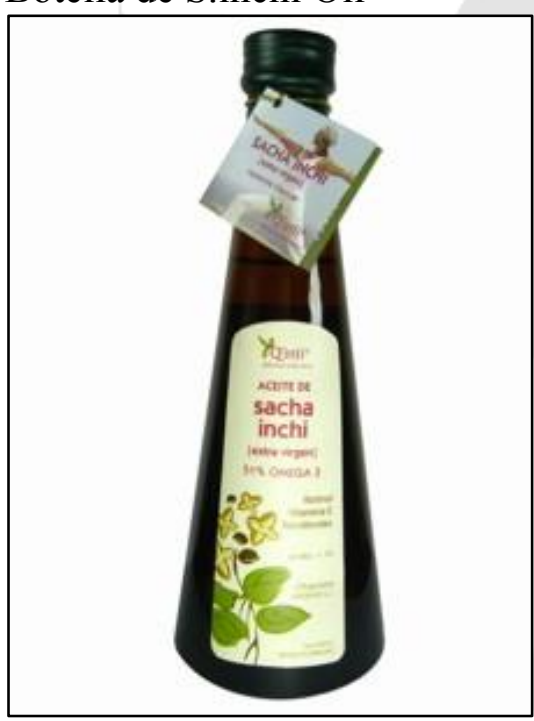

Imagen referencial

Fuente: www.ajonjoli-peru.com

\section{Especificaciones técnicas del producto}

El aceite de sacha Inchi es un producto que con los años está ganando importancia a nivel mundial. Es el producto con mayor cantidad de Omega en el mundo y ha sido catalogado como alimento beneficioso a nivel mundial. Para que nuestro producto pueda tener los 
estándares de calidad necesarios debemos tomar en cuenta las siguientes especificaciones técnicas:

Tabla 5.2.

Propiedades fisicoquímicas del aceite de las semillas del sacha Inchi

\begin{tabular}{|c|c|}
\hline Requisito & Valor \\
\hline $\begin{array}{c}\text { Densidad a } 20^{\circ} \mathrm{C} \text { (determinación de } \\
\text { masa volumica a } 20^{\circ} \mathrm{C} \text { ) }\end{array}$ & 0.93 \\
\hline Índice de Yodo & 199.61 \\
\hline Índice de saponificación & 192.04 \\
\hline Índice de refracción a $20^{\circ} \mathrm{C}$ & 14815.00 \\
\hline Materia insaponificable $\%$ & 0.51 \\
\hline $\begin{array}{c}\text { Acidez libre expresada como acido } \\
\text { oleico \% }\end{array}$ & 1.10 \\
\hline $\begin{array}{c}\text { Índice de peróxido, miliequivalentes } \\
\text { de oxigeno / kg de aceite }\end{array}$ & 1.48 \\
\hline Humedad y materias volátiles \% & 0.05 \\
\hline
\end{tabular}

Fuente: Norma Tenica Peruana 151.4002014

- El índice de Iodo nos indica si el aceite tiene propiedades secantes. En este caso si tiene este tipo de propiedades por la alta instauración del aceite.

- El índice de saponificación indica la cantidad de miligramos de hidróxido de sodio que se necesitan para saponificar un aceite.

- El índice de refracción se utiliza para saber el nivel de pureza del elemento.

Tabla 5.3.

Composición de ácidos grasos del aceite crudo de las semillas del sacha Inchi

\begin{tabular}{|c|c|}
\hline Acido Graso & Valor \% \\
\hline Acido Palmítico (C16:0) & 4.6 \\
\hline Acido Esteárico (C18:0) & 1.7 \\
\hline Acido Oleico (C18:1n9c) & 8.7 \\
\hline Acido Linoleico (C18:2n6c) & 26.4 \\
\hline Acido Linolénico (C18:3n3) & 57.2 \\
\hline Acido Araquidico (C20:0) & 0.1 \\
\hline Acido Erucico (C22:1) & $<0.1$ \\
\hline Total Ácidos grasos saturados & 6.5 \\
\hline Total Ácidos grasos monoinsaturados & 9.0 \\
\hline Total Ácidos grasos poliinsaturados & 83.6 \\
\hline Total Ácidos no identificados & 0.9 \\
\hline Total Ácidos grasos & 99.1 \\
\hline Ácidos grasos trans & 2.0 \\
\hline
\end{tabular}

Fuente: Norma Tenica Peruana 151.4002014 
También se ha analizado el contenido de Tocoferoles de tres tipos de ecotipos (EC) del aceite de la semilla de sacha Inchi. Los tocoferoles son compuestos orgánicos que actúan como vitamina $\mathrm{E}$.

Tabla 5.4. Cuantificación de tocoferoles del aceite crudo de tres ecotipos (EC) de las semillas del sacha Inchi, $(\mathrm{mg} / \mathrm{Kg})$

\begin{tabular}{|c|c|c|c|}
\hline $\begin{array}{c}\text { TOCOFEROLES } \\
(\mathbf{m g} / \mathbf{K g})\end{array}$ & EC1 & EC2 & EC3 \\
\hline$\alpha$ & 0 & 0 & 0 \\
$\beta$ & 0 & 0 & 0 \\
$\gamma$ & 2755 & 3878 & 2936 \\
$\delta$ & 1803 & 2650 & 2040 \\
Total & 4559 & 6528 & 4976 \\
\hline
\end{tabular}

Fuente: Nancy Chasquibol, M.Carmen Pérez-Camino, Wenceslao Moreda, M. Angeles Garín, Juan C. Yácono. Caracterización química y autenticación del aceite de tres ecotipos de las semillas del Sacha Inchi (Plunkenetia volubilis L.), cultivados en la región del Departamento de San Martín, Facultad de Ingeniería Industrial, Instituto de Investigación Científica (IDIC), Universidad de Lima, 2012

\section{Tecnologías existentes y procesos de producción}

Las tecnologías que existen para la extracción de aceite de cualquier tipo de insumo son muchas pero el estudio se enfoca en las que van a mas relacionadas con nuestro proyecto. Luego, se elegirá una y explicaremos la razón de su elección.

Debemos especificar que antes de realizar el método de extracción debemos de triturar las semillas para poder obtener un prensado más eficiente.

Entre los tipos de extracción de aceite tenemos:

- Prensado: Este método se emplea mediante instrumentos o maquinaria que aplica presión a la semilla o frutas para exprimir el aceite que contiene. Este método puede 
ser realizado en frio o calor. Esta característica depende de las características nutritivas que queramos para el producto final. Se puede realizar un prensado hidráulico o por medio de un expeller. Las desventajas de utilizar un expeller son que la temperatura en el interior del equipo es alta, alterando las características del aceite. Además el aceite extraído contiene muchas impurezas lo cual dificulta el filtrado. En cambio, la prensa hidráulica no posee mayores dificultades. El único defecto es la continuidad del proceso ya que la prensa debe ser utilizada con mayor cuidado.

- Prensado caliente: La pasta es calentada antes de ser prensada. Esto hace que sea más manejable y se obtenga más cantidad de aceite. La desventaja se encuentra en que al calentar la pasta y prensarla se pierden muchas vitaminas y nutrientes importantes.

- Prensado frio: La pasta se trabaja a temperatura ambiente, obteniendo menos cantidad de aceite pero conservando todas las vitaminas y nutrientes necesarios nutricionalmente.

- Extracción por fluidos supercríticos con CO2: Se trata la pasta con $\mathrm{CO} 2$ en un estado de presión y temperatura por encima del punto crítico para que los aceites adheridos sean expulsados. El punto crítico es el estado hibrido del CO2, el cual se encuentra entre el estado líquido y gaseoso. El líquido actúa como un disolvente potente y el gas como un separador de las partículas y el aceite.

- Extracción por inyección de vapor: Consiste en inyectar vapor de agua en la mezcla para separar las sustancias volátiles de las no volátiles. La mezcla pasa por una fase inmiscible en donde el vapor de agua, el aceite y los materiales volátiles se 
separan. El material volátil se encuentra debajo del punto de ebullición de agua. Luego se separa el aceite por medio de una destilación.

- Extracción por destilación al vacío: Es un proceso de destilación en donde se genera un vacío dentro de la mezcla para poder destilar la sustancia por debajo de su punto de ebullición normal.

Luego de analizar las tecnologías existentes para la extracción de aceite, hemos concluido que utilizaremos el prensado frio utilizando una maquina prensadora hidráulica. Esto se debe a que queremos conservar la mayor cantidad de vitaminas, antioxidantes y nutrientes de la sacha Inchi.

\section{Naturaleza de la tecnología requerida}

La tecnología a utilizar debe de conservar todos los factores nutricionales del producto ya que nosotros queremos enfocarnos en vender un producto nutritivo y natural. Podemos observar que existen métodos que no se enfocan en la conservación del producto sino más en la eficiencia de la extracción. Por ello se ha tomado la decisión de utilizar el prensado frio, para así conservar todos los valores nutricionales del sacha Inchi.

\section{a. Descripción de la tecnología existente}

La tecnología que se usa actualmente para procesar la semilla de sacha Inchi, es similar a la usada para cualquier otro tipo de aceite ya que el proceso se enfoca en la parte de extracción. En este caso, el proyecto se centrará en la extracción del aceite por prensado frío y luego añadiendo maquinaria que le dará la calidad necesaria para la venta. Agregaremos máquinas para el filtrado, control, entre otros que explicaremos más adelante. 


\section{b. Selección de la tecnología}

La maquinaria que elegimos para nuestro proceso está detallada a continuación:

- Descascaradora

- Mesa de Trabajo

- Filtro - Prensa

- Embotelladora
- Etiquetadora

- Montacargas

- Faja transportadora

\section{Proceso de producción}

- Descripción del proceso

- Recepcionar y pesar

Las semillas de Sacha Inchi son cosechadas en la selva central del país para luego ser transportadas a la planta de producción por un tercero. Al llegar a la planta personal se encarga de pesar la masa de semillas que ingresa al proceso. Debemos saber la cantidad de kg. Que ingresan al proceso para no exceder la capacidad de la máquina.

\section{- Descascarar, seleccionar, triturar y tamizar}

Primero, los granos de sacha Inchi pasan por la Descascaradora, en esta máquina se retira la cáscara de los granos con alto cuidado y luego la misma maquina separa las cascaras de la semilla que utilizaremos en el proceso. Las semillas que salen del descascarado pasan por una selección manual, en donde personal calificado se encarga de seleccionar los granos que no están en un estado óptimo para pasar a la producción y los retira del proceso. 


\section{- Prensar y Filtrar}

Primero, la semilla triturada ingresa a la máquina y son transportados al prensado por medio de fajas especiales. Este proceso es realizado a temperatura ambiente para no perder las características nutricionales de la semilla.

El aceite obtenido del presado es filtrado para obtener un aceite sin residuos y listo para el envasado.

\section{- Control por inspección}

Antes de que el aceite sea envasado, este pasa por una inspección en donde los operarios observan el aceite en reposo e identifican algún residuo que pueda haber pasado el filtrado. Además se analizan tres propiedades químicas importantes: índice de peróxido, índice de acidez y la densidad.

- Determinación del índice de peróxido: El Índice de peróxidos mide el estado de oxidación inicial de un aceite, este se expresa en miliequivalentes de oxígeno activo por kilo de grasa. Los peróxidos o compuestos de oxidación inicial se originan de las siguientes maneras: si la semilla se maltrata, si el aceite no se protege de la luz y el calor o no se guarda en envases adecuados. Esto puede dar como consecuencia un mayor índice de peróxidos que afectará la capacidad antioxidante de un aceite. El método oficial para la medición consiste en disolver el aceite en ácido acético y cloroformo y este se trata con solución de yoduro potásico. El yodo liberado se valora con solución valorada de tiosulfato sódico hasta el viraje del almidón. Y con este procedimiento obtenemos un resultado bastante acertado. El valor debe ser menor a 1 en el valor de peróxido. 
- Determinación del índice de acidez: Este índice nos sirve para determinar si el aceite está rancio, ya que los aceites cuando están en contacto con el aire, humedad y cierta temperatura sufren cambios. Para determinarlo se realiza una valoración Acido -base utilizando de 5 a $10 \mathrm{~g}$ de grasa $+50 \mathrm{ml}$ de (alcohol - éter 1:1) neutralizada con fenolftaleína $+\mathrm{ml}$ de solución alcohólica de fenolftaleína 1\%.

- Medición de la densidad: Para medir la densidad se utilizará como instrumento un oleómetro, que nos permite obtener la densidad directa de la densidad relativa.

Fuente: Q.F. Marilú Roxana Soto Vásquez - Docente Universidad Nacional de Trujillo

- Envasar y etiquetar

El producto es envasado y etiquetado por medio de una maquina especial. Los envases y tapas son comprados a un tercero y estos ya han sido inspeccionados antes de entrar en el proceso. La etiqueta ya cuenta con toda la información que se indican en las normas establecidas.

\section{- Control de calidad}

Por último, el aceite ya envasado y etiquetado es inspeccionado para ver que no presente ningún defecto y pueda ser llevado a la venta o almacenado. 


\section{b. Diagrama de proceso: DOP}

Figura 5.5.

Diagrama de Operaciones

\section{Diagrama de Operaciones del proceso de elaboración de aceite de Sacha Inchi envasado en frascos de $250 \mathrm{ml}$.}

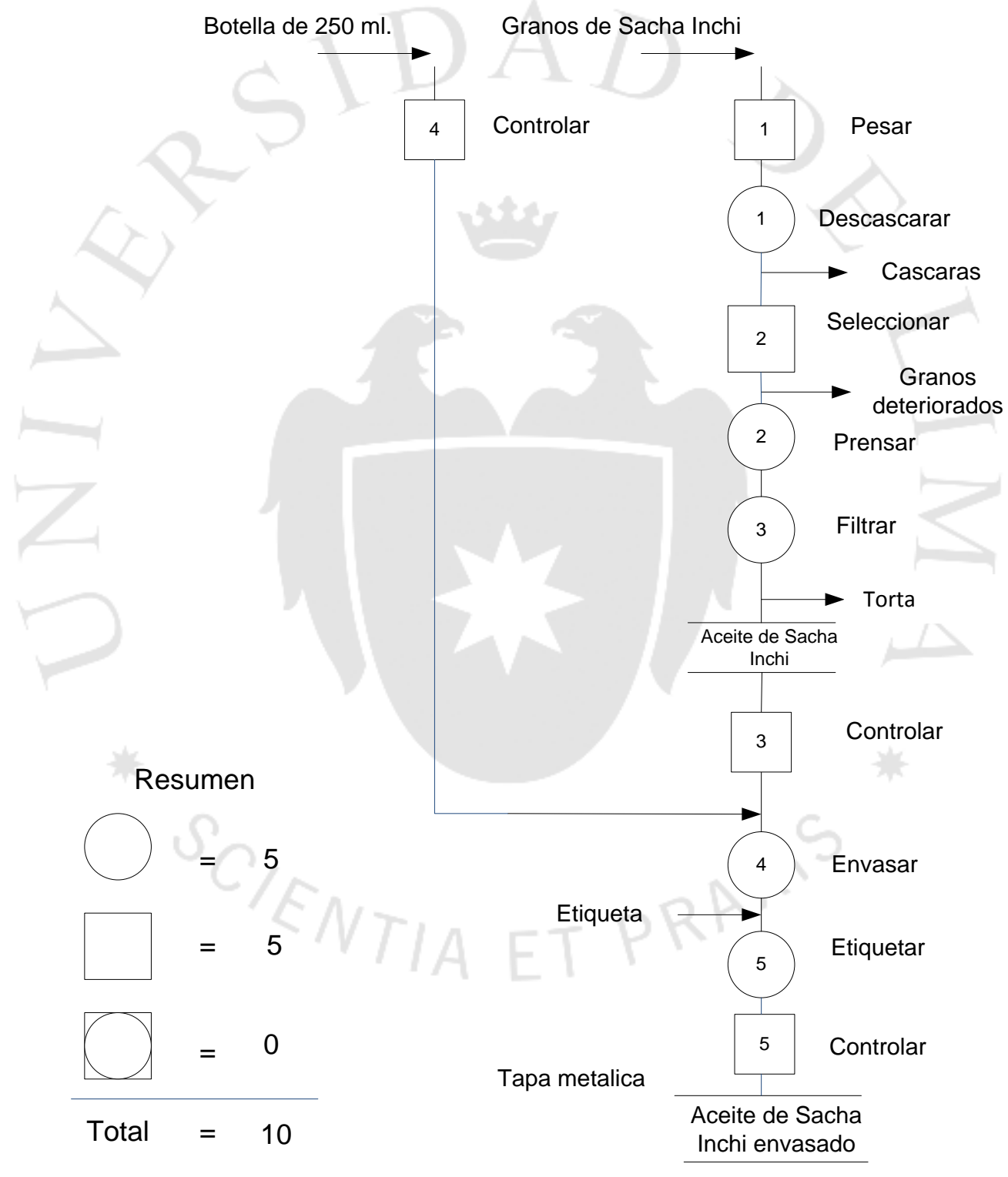

Elaboración Propia 


\section{c. Balance de materia: Diagrama de bloques}

Como dato adicional se utilizará la densidad (densidad=peso/volumen) del aceite: $1089.32 \mathrm{lt} / \mathrm{ton}$

Figura 5.6.

Balance de Materia

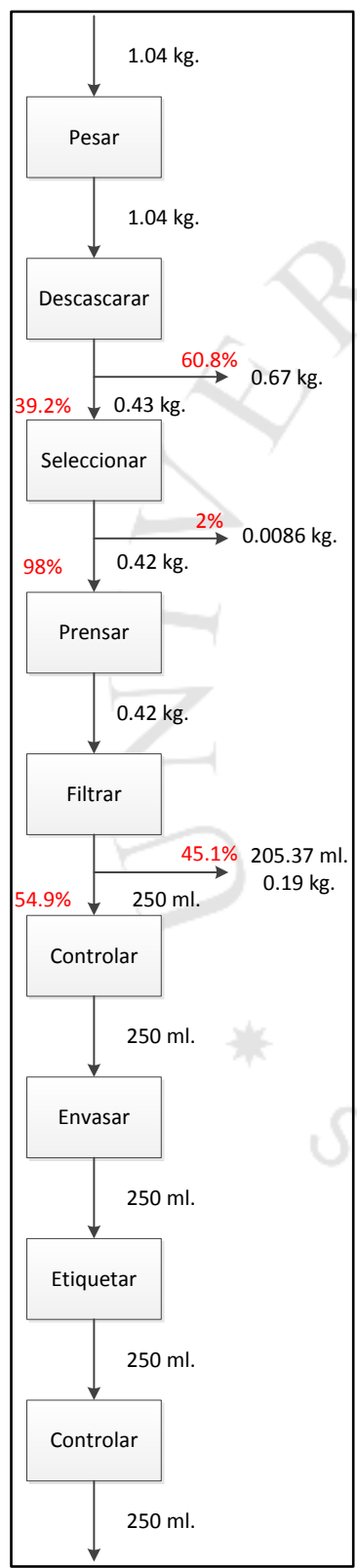

Elaboración propia 


\section{Características de las instalaciones y equipo}

\section{Selección de la maquinaria y equipo}

Para poder seleccionar la maquinaria del proyecto tomamos en cuenta las variables de capacidad de maquinaria y costos de compra de la maquinaria, relacionando estos dos puntos con la producción anual proyectada.

Como se mencionó anteriormente, se utilizará la siguiente maquinaria:

- Descascaradora

- Mesa de Trabajo

- Filtro - Prensa

- Embotelladora

- Etiquetadora

Además, se utilizará un montacargas, una faja transportadora y una mesa de trabajo, la cual se utilizará para las inspecciones que realizan los operarios,

\section{Especificaciones de la maquinaria}

\section{Tabla 5.7}

Especificaciones de la maquinaria 1

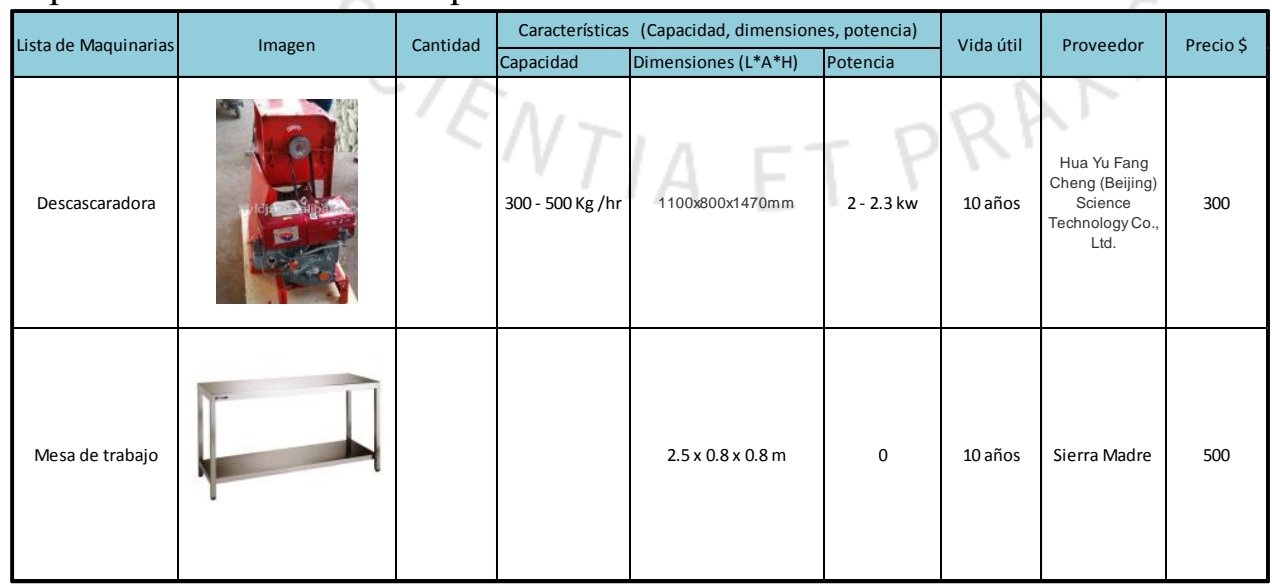

Fuente: Alibaba Global Trade

Elaboración propia 
Tabla 5.8.

Especificaciones de la maquinaria 2

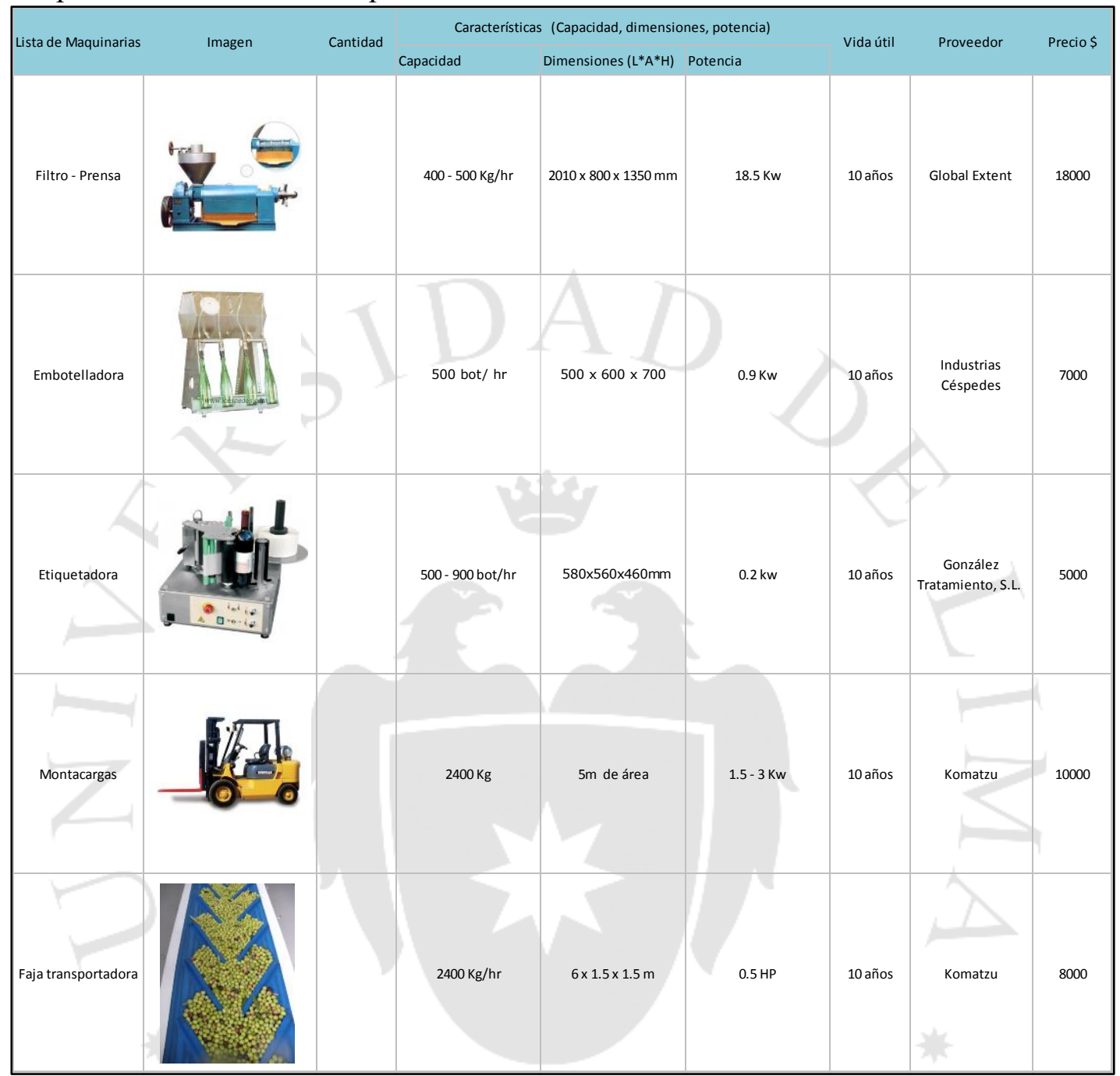

Fuente: Alibaba Global Trade Elaboración propia 


\section{Capacidad instalada}

\section{Cálculo detallado del número de máquinas requeridas}

Tabla 5.9.

Calculo número de máquinas

\begin{tabular}{|c|c|c|c|c|c|c|c|}
\hline Operaciones & $\begin{array}{l}\text { Cantidad } \\
\text { entrante según } \\
\text { balance de } \\
\text { materia }\end{array}$ & $\begin{array}{l}\text { Und. de } \\
\text { medida }\end{array}$ & $\begin{array}{l}\text { Procesam./ } \\
\text { hora de } \\
\text { máquina u } \\
\text { operario }\end{array}$ & $\begin{array}{c}\text { Nro. de } \\
\text { máquinas } \\
o \\
\text { personas }\end{array}$ & $\begin{array}{l}\text { Días / } \\
\text { sem. }\end{array}$ & $\begin{array}{c}\text { horas } \\
\text { reales / } \\
\text { turno }\end{array}$ & $\begin{array}{l}\text { Turnos } \\
\text { / día }\end{array}$ \\
\hline Descascarado & $83,286.77$ & $\mathrm{Kg}$ & 400 & 1 & 3 & 7.25 & 1 \\
\hline Selección & $32,648.41$ & $\mathrm{Kg}$ & 350 & 1 & 3 & 7.25 & 1 \\
\hline Prensado & $31,995.44$ & $\mathrm{Kg}$ & 450 & 1 & 3 & 7.25 & 1 \\
\hline Filtrado & $31,995.44$ & $\mathrm{Kg}$ & 450 & 1 & 3 & 7.25 & 1 \\
\hline Envasado & $4,391.37$ & Litros & 500 & 1 & 3 & 7.25 & 1 \\
\hline Etiquetado & $17,565.50$ & Botellas & 500 & 1 & 3 & 7.25 & 1 \\
\hline+2 & QS & Und. & 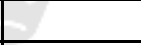 & & & 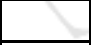 & \\
\hline $\begin{array}{c}\text { Producto } \\
\text { Terminado }\end{array}$ & $17,565.50$ & Botellas & & & & & \\
\hline
\end{tabular}

Elaboración propia

\section{Cálculo de la capacidad instalada}

Para el cálculo de la capacidad instalada, se determina un proceso continuo de producción, en el que las operaciones siempre son las mismas y siempre se produce el mismo producto. Tenemos poca flexibilidad para cambiar de producto, así como poca flexibilidad para cambiar la materia prima.

Así mismo es un proceso automatizado y requiere de una mínima intervención de línea, por lo que requerimos una cantidad de operarios mínima.

Se determinó que el cuello de botella se encuentra en el proceso de selección de granos, esto se debe a que el proceso se realiza de manera manual El operario debe realizar cuidadosamente la selección de granos ya que no debe dejar pasar granos defectuosos al proceso de producción. Así obtendremos un aceite de calidad superior.

Se realizó el cálculo de la capacidad instalada en unidades por semana. 
Tabla 5.10.

Capacidad Instalada

\begin{tabular}{|c|c|c|c|c|c|c|c|c|c|c|c|c|c|c|}
\hline & QE & & $\mathbf{P}$ & $\mathbf{M}$ & $D / S$ & $\mathrm{HR} / \mathrm{T}$ & $\mathbf{T}$ & $\mathbf{U}$ & E & CPOi & QS/QEi & $\begin{array}{l}\text { CPOi X } \\
\text { QS/QEi }\end{array}$ & & \\
\hline Operaciones & $\begin{array}{c}\text { Cantidad } \\
\text { entrante según } \\
\text { balance de } \\
\text { materia }\end{array}$ & $\begin{array}{l}\text { Und. de } \\
\text { medida }\end{array}$ & $\begin{array}{l}\text { Procesam./ } \\
\text { hora de } \\
\text { máquina u } \\
\text { operario }\end{array}$ & $\begin{array}{c}\text { Nro. de } \\
\text { máquinas } \\
\text { o } \\
\text { personas }\end{array}$ & $\begin{array}{l}\text { Días / } \\
\text { sem. }\end{array}$ & $\begin{array}{c}\text { horas } \\
\text { reales / } \\
\text { turno }\end{array}$ & $\begin{array}{c}\text { Turnos } \\
\text { / día }\end{array}$ & $\begin{array}{c}\text { Fact. de } \\
\text { utilización }\end{array}$ & $\begin{array}{l}\text { Fact. de } \\
\text { eficienc. }\end{array}$ & $\begin{array}{l}\text { Capac. de } \\
\text { producc. } \\
\text { de cada } \\
\text { operación } \\
\text { semanal }\end{array}$ & $\begin{array}{c}\text { Factor de } \\
\text { conversión }\end{array}$ & $\begin{array}{c}\text { Capac. de } \\
\text { producc. en } \\
\text { unds de P.T. de } \\
\text { cada operación } \\
\text { semanal }\end{array}$ & $\begin{array}{l}\text { Capac. de } \\
\text { producc. en } \\
\text { unds de P.T. } \\
\text { de cada } \\
\text { operación } \\
\text { anual } \\
\end{array}$ & $\begin{array}{c}\text { Utilización } \\
\%\end{array}$ \\
\hline Descascarado & $83,286.77$ & $\mathrm{Kg}$ & 400 & 1 & 3 & 7.25 & 1 & $90 \%$ & $80 \%$ & 6,264 & 0.21 & $29,700.74$ & $1,544,438.45$ & $5.39 \%$ \\
\hline Selección & $32,648.41$ & $\mathrm{Kg}$ & 350 & 1 & 3 & 7.25 & 1 & $90 \%$ & $80 \%$ & 5,481 & 0.54 & $10,187.35$ & $529,742.39$ & $6.16 \%$ \\
\hline Prensado & $31,995.44$ & $\mathrm{Kg}$ & 450 & 1 & 3 & 7.25 & 1 & $90 \%$ & $80 \%$ & 7,047 & 0.55 & $12,836.07$ & $667,475.41$ & $4.79 \%$ \\
\hline Filtrado & $31,995.44$ & $\mathrm{Kg}$ & 450 & 1 & 3 & 7.25 & 1 & $90 \%$ & $80 \%$ & 7,047 & 0.55 & $12,836.07$ & $667,475.41$ & $4.79 \%$ \\
\hline Envasado & $4,391.37$ & Litros & 500 & 1 & 3 & 7.25 & 1 & $90 \%$ & $80 \%$ & 7,830 & 4.00 & $1,957.50$ & $101,790.00$ & $4.31 \%$ \\
\hline \multirow[t]{2}{*}{ Etiquetado } & $17,565.50$ & Botellas & 500 & 12 & 3 & 7.25 & 1 & $90 \%$ & $80 \%$ & 7,830 & 1.00 & 7,830 & $407,160.00$ & $4.31 \%$ \\
\hline & QS & Und. & & & & & & & & & + & & & \\
\hline $\begin{array}{c}\text { Producto } \\
\text { Terminado } \\
\end{array}$ & $17,565.50$ & Botellas & & & & & & & & & $\square$ & & & \\
\hline
\end{tabular}

Elaboración propia

La capacidad de la planta se hallaría con el cuello de botella y el cálculo sería el siguiente:

$\left(350 \mathrm{Kg} / \mathrm{hr} * 1\right.$ hombre* $\left.5 \mathrm{dias} / \mathrm{sem}^{*} 7.25 \mathrm{hr} / \mathrm{t} * 1 \mathrm{t} / \mathrm{dia} * 0.9 * 0.8\right) / 1.107=4,951.22$ unidades $/$ sem 


\section{Resguardo de la calidad}

\section{Calidad de la materia prima, de los insumos, del proceso y del}

producto

Con respecto a la calidad de la materia prima e insumos, se trabajará con proveedores especializados en proveer sacha Inchi, botellas de vidrio, tapas y etiquetas. Ellos deberán tener todos los registros sanitarios y papeles en regla. Se firmará un acuerdo de trabajo en donde deberán entregarnos los insumos con los estándares necesarios para el proceso.

Luego en el proceso de producción, tenemos en la selección de los granos de sacha Inchi y, más adelante, en el control del aceite antes y después del envasado. Los operarios estarán capacitados para realizar su trabajo eficientemente. Ellos además deberán seguir un proceso correcto de limpieza antes de ingresar a las instalaciones de la planta y deberán llevar accesorios de higiene como mascarilla, redes de pelo y guantes.

Con respecto a la maquinaria, esta pasará por mantenimientos y revisiones que aseguraran que el producto está obteniéndose en la calidad esperada

\section{Medidas de resguardo de la calidad en la producción}

Para poder controlar la calidad en la producción se llevará a cabo un análisis de peligros y puntos críticos de control (HACCP), el cual garantiza la seguridad alimentaria del proceso. Primero presentamos una tabla en la cual observamos la descripción del producto, Luego un análisis de riesgos y peligros para la inocuidad. Al definir cuáles son los PPC realizamos un cuadro para analizar las acciones correctivas. 
Tabla 5.11.

Descripción del producto y uso presunto

\begin{tabular}{|c|c|c|c|c|c|c|}
\hline \multicolumn{7}{|c|}{ Descripción del producto y uso presunto } \\
\hline \multicolumn{7}{|c|}{ Aceite de Sacha Inchi } \\
\hline Nombre & \multicolumn{6}{|c|}{ Aceite } \\
\hline Descripción & \multicolumn{6}{|c|}{ Aceite } \\
\hline Composición & \multicolumn{6}{|c|}{ Aceite de Sacha Inchi obtenido directamente de la semilla de sacha Inchi } \\
\hline $\begin{array}{l}\text { Características } \\
\text { Sensoriales }\end{array}$ & \multicolumn{6}{|c|}{ Color amarillo, transparente, sin ningún residuo } \\
\hline \multirow{4}{*}{$\begin{array}{l}\text { Características } \\
\text { Físico, Químicas y } \\
\text { Microbiológicas }\end{array}$} & Palmítico C 16:0 & $3.65 \%$ & $\begin{array}{l}\text { a-Linolénico } \\
\text { w3 C18:3 }\end{array}$ & $48.61 \%$ & Vitamina $\mathrm{E}$ & $\begin{array}{c}17 \\
\mathrm{mg} / 100 \mathrm{~g}\end{array}$ \\
\hline & Esteárico C 18:0 & $2.54 \%$ & Total Saturados & $6.19 \%$ & $\begin{array}{l}\text { Índice de acidez (mg KOH/g } \\
\text { grasa) }\end{array}$ & 0.22 \\
\hline & Oleico 8:1 & $8.28 \%$ & Total Insaturados & $93.81 \%$ & $\begin{array}{l}\text { Índice de Peróxidos (meq. } \\
\text { Oxigeno / kg aceite) }\end{array}$ & 1.48 \\
\hline & Linoleico 18:2 $\omega 6$ & $36.80 \%$ & Vitamina A & $681 \mathrm{mg}$ & Aditivos Alimentarios & Ninguno \\
\hline Forma de uso & \multicolumn{6}{|c|}{ En Alimentos y productos nutraceuticos (capsulas) } \\
\hline $\begin{array}{c}\text { Empaque, } \\
\text { etiquetado y } \\
\text { presentaciones }\end{array}$ & \multicolumn{6}{|c|}{ Botella de vidrio ambar de $250 \mathrm{~mL}$. Tapa metálica. Etiqueta biodegradable. } \\
\hline Vida útil esperada & \multicolumn{6}{|c|}{$\begin{array}{l}\text { Un año en condiciones optimas de almacenamiento (lugar fresco y seco, por debajo de los } 30^{\circ} \mathrm{C} \text {, lejos de la } \\
\text { luz solar y con el envase sellado) }\end{array}$} \\
\hline $\begin{array}{l}\text { Condiciones de } \\
\text { manejo y } \\
\text { conservación }\end{array}$ & \multicolumn{6}{|c|}{ Conservar a temperatura menor a $30^{\circ} \mathrm{C}$ y en un lugar seco. No exponer al sol. } \\
\hline
\end{tabular}

Elaboración propia

Fuente: Norma Técnica Peruana 151.4002014

*Nutraceutico: Alimentos que poseen beneficios para la salud humana

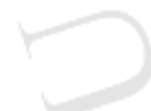

En las dos próximas tablas se observan los riesgos y peligros que pueden presentarse en el proceso. Luego de realizar el análisis, tabla 5.10., concluimos que existen riesgos en el filtrado y envasado del aceite. Esto se debe a que en estas etapas pueden filtrarse materiales orgánicos que pueden dañar el producto final.

En la tabla 5.11. Analizamos los dos procesos críticos y sus variables, llegando a la conclusión que con verificaciones diarias de los componentes de la máquina y del producto podemos controlar de mejor manera el producto terminado. 
Tabla 5.12.

Análisis de riesgos y peligros para la inocuidad

\begin{tabular}{|c|c|c|c|c|c|}
\hline $\begin{array}{c}-1 \\
\text { ETAPA DE } \\
\text { PROCESO }\end{array}$ & PELIGROSO & $\begin{array}{c}-3 \\
\text { ¿EL. PELIGRO ES } \\
\text { SIGNIFICATIVO? }\end{array}$ & $\begin{array}{c}-4 \\
\text { JUSTIFIQUE SU DECISIÓN DE (3) }\end{array}$ & $\begin{array}{l}-5 \\
\text { ¿QUÉ MEDIDAS PREVENTIVAS PUEDER } \\
\text { SER APLICADAS? }\end{array}$ & $\begin{array}{l}-6 \\
\text { ¿ES ESTA } \\
\text { ETAPA UN } \\
\text { PCC? } \\
\text { (SI/NO) }\end{array}$ \\
\hline \multicolumn{6}{|l|}{ Pesado } \\
\hline \multicolumn{6}{|l|}{ Descascarado } \\
\hline Selección & $\begin{array}{c}\text { Fisico: Semilla defectuosa: } \\
\text { secas, verdes o con } \\
\text { hongos }\end{array}$ & $\mathrm{Si}$ & $\begin{array}{l}\text { La semilla deteriorada puede acelerar el } \\
\text { proceso de oxidación del producto final }\end{array}$ & $\begin{array}{l}\text { Control de la semilla la cual debe estar en } \\
\text { optimas condiciones }\end{array}$ & $\mathrm{Si}$ \\
\hline \multicolumn{6}{|l|}{ Prensado } \\
\hline Filtrado & $\begin{array}{l}\text { Fisico: Dejar filtrar parte de } \\
\text { la torta en el aceite }\end{array}$ & $\mathrm{Si}$ & $\begin{array}{c}\begin{array}{l}\text { 日 aceite embotellado puede presentar solidos } \\
\text { suspendidos como parte de la torta y generar } \\
\text { producto defectuoso }\end{array} \\
\end{array}$ & $\begin{array}{l}\text { Revisar que las placas de los filtros no } \\
\text { tengan solidos suspendidos }\end{array}$ & $\mathrm{Si}$ \\
\hline Control & $\begin{array}{c}\text { Físico: Solidos } \\
\text { suspendidos } \\
\text { Químico: Control del índice } \\
\text { de acidez y del índice de } \\
\text { peróxido }\end{array}$ & $\mathrm{Si}$ & $\begin{array}{l}\text { 日 aceite embotellado puede presentar parte } \\
\text { de la torta generando producto defectuoso. } \\
\text { 日 control químico puede indicar que el aceite } \\
\text { esta oxidado }\end{array}$ & $\begin{array}{l}\text { Control de manera visual los solidos } \\
\text { suspendidos. } \\
\text { Controlar químicamente los índices }\end{array}$ & $\mathrm{Si}$ \\
\hline Envasado & \begin{tabular}{|c|} 
Físico: Botella puede \\
ingresar con algún residuo
\end{tabular} & $\mathrm{Si}$ & $\begin{array}{l}\text { Botella puede ingresar al proceso con algún } \\
\text { residuo }\end{array}$ & $\begin{array}{c}\text { Trabajar con un proveedor con estándares } \\
\text { de calidad altos y revisión por parte de } \\
\text { nuestro personal antes del proceso }\end{array}$ & $\mathrm{Si}$ \\
\hline \multicolumn{6}{|l|}{ Etiquetado } \\
\hline Control & \begin{tabular}{|c} 
Físico: Solidos \\
suspendidos y defectos en \\
etiquetador Químico: \\
Control del índice de acidez \\
y del índice de peróxido
\end{tabular} & $\mathrm{Si}$ & $\begin{array}{l}\text { 日 aceite embotellado puede presentar solidos } \\
\text { suspendidos. La botella puede estar mal } \\
\text { etiquetada. } \\
\text { 日 control químico puede indicar que el aceite } \\
\text { esta oxidado }\end{array}$ & $\begin{array}{l}\text { Control de manera visual los solidos } \\
\text { suspendidos y defectos en empaque. } \\
\text { Controlar químicamente los índices }\end{array}$ & $\mathrm{Si}$ \\
\hline
\end{tabular}

\section{Elaboración propia}

Tabla 5.13.

Análisis de puntos críticos de control (PCC)

\begin{tabular}{|c|c|c|c|c|c|c|c|c|c|}
\hline \multirow{2}{*}{$\begin{array}{c}\text { PUNTOS } \\
\text { CRÍTICOS } \\
\text { DE } \\
\text { CONTROL } \\
-1\end{array}$} & \multirow{2}{*}{$\begin{array}{l}\text { PELIGROS } \\
\text { SIGNIFICATIVOS } \\
\text { (2) }\end{array}$} & \multirow{2}{*}{$\begin{array}{c}\text { LÍMITES } \\
\text { CRÍTICOS } \\
\text { PARA CADA } \\
\text { MEDIDA } \\
\text { PREVENTIVA } \\
\text { (3) }\end{array}$} & \multicolumn{4}{|c|}{ MONITOREO } & \multirow{2}{*}{$\begin{array}{c}\text { ACCIONES } \\
\text { CORRECTORAS (8) }\end{array}$} & \multirow{2}{*}{ REGISTROS (9) } & \multirow{2}{*}{ VERIFICACIÓN (10) } \\
\hline & & & $\begin{array}{l}\text { Qué } \\
-4\end{array}$ & $\begin{array}{l}\text { Cómo } \\
-5\end{array}$ & $\begin{array}{c}\text { Frecuencia } \\
-6\end{array}$ & $\begin{array}{l}\text { Quién } \\
-7\end{array}$ & & & \\
\hline Selección & $\begin{array}{c}\text { Dejar pasar } \\
\text { semillas } \\
\text { defectuosas u } \\
\text { oxidadas }\end{array}$ & & $\begin{array}{c}\text { Parámetros } \\
\text { físicos }\end{array}$ & Vision & $\begin{array}{l}\text { Antes de } \\
\text { ingresar al } \\
\text { proceso }\end{array}$ & $\begin{array}{l}\text { Operario } \\
\text { calificado }\end{array}$ & $\begin{array}{c}\text { Realizar } \\
\text { revisiones } \\
\text { contstantes para } \\
\text { encontrar } \\
\text { semillas } \\
\text { defectuosa } \\
\end{array}$ & & $\begin{array}{l}\text { Verificacion de } \\
\text { semillas }\end{array}$ \\
\hline Filtrado & $\begin{array}{l}\text { Dejar pasar torta } \\
\text { al aceite por } \\
\text { envasar y que } \\
\text { este contenga } \\
\text { residuos solidos }\end{array}$ & & $\begin{array}{c}\text { Parámetros } \\
\text { físicos }\end{array}$ & Vision & $\begin{array}{l}\text { Al final del } \\
\text { filtrado }\end{array}$ & $\begin{array}{l}\text { Operario } \\
\text { calificado }\end{array}$ & \begin{tabular}{|c|} 
Realizar \\
revisiones \\
contstantes para \\
determinar si filtro \\
no esta \\
funcionando al \\
$100 \%$ \\
\end{tabular} & & $\begin{array}{c}\text { Verificacion diaria } \\
\text { del filtro }\end{array}$ \\
\hline Envasado & $\begin{array}{l}\text { Dejar ingresar al } \\
\text { proceso botellas } \\
\text { sucias }\end{array}$ & $\infty$ & $\begin{array}{l}\text { Parámetros } \\
\text { físicos }\end{array}$ & Vision & $\begin{array}{c}\text { Al final del } \\
\text { proceso }\end{array}$ & $\begin{array}{l}\text { Operario } \\
\text { calificado }\end{array}$ & $\begin{array}{c}\text { Revisar las } \\
\text { botellas antes de } \\
\text { ingresar al } \\
\text { proceso del } \\
\text { aceite } \\
\end{array}$ & & $\begin{array}{c}\text { Verificacion visual } \\
\text { de algun material } \\
\text { extraño al } \\
\text { proceso }\end{array}$ \\
\hline Controles & \begin{tabular}{|c|} 
Dejar el proceso \\
de control con \\
propiedades \\
quimicas no aptas
\end{tabular} & & $\begin{array}{c}\text { Parámetros } \\
\text { quimicos }\end{array}$ & $\begin{array}{l}\text { Analisis } \\
\text { quimico }\end{array}$ & $\begin{array}{l}\text { Al final del } \\
\text { proceso }\end{array}$ & $\begin{array}{l}\text { Operario } \\
\text { calificado }\end{array}$ & $\begin{array}{l}\text { Analizar el indice } \\
\text { de peroxidos y el } \\
\text { indico de acidez }\end{array}$ & & $\begin{array}{l}\text { Verificacion que } \\
\text { los valores son } \\
\text { los correctos }\end{array}$ \\
\hline
\end{tabular}

Elaboración propia 


\section{Impacto ambiental}

Antes de realizar la instalación de la planta, siempre se debe realizar un estudio de impacto ambiental. En este caso, no hay mayor necesidad de investigar si el terreno está cerca a poblaciones, ya que no producimos gran contaminación ambiental ni tenemos residuos químicos ni tóxicos.

La planta debe tener control sobre el desprendimiento de gases, pero en este caso no hay ningún problema con lo que se refiere a contaminación del aire. Únicamente el ruido que generan las máquinas puede llegar a ser bastante molesto, sin embargo pensamos poner jebes en lugares estratégicos de las máquinas para amortiguar el ruido y las vibraciones.

Durante la etapa de descascarado, el aire puede contaminarse de partículas de polvo de las cascaras de la semilla, no es gran contaminación ambiental, sin embargo no es bueno que nuestros operarios aspires este aire cargado, para esto se ha planeado darles mascarillas a los empleado que realicen este proceso, así como poner un sistema de ventilación que los ayude a filtrar este aire.

Muchas de las máquinas y equipos necesitarán de combustibles fósiles (aceites lubricantes, gasolina, gas, etc.) que serán utilizados para la producción del aceite de Sacha Inchi.

Estos combustibles, en el proceso de combustión, producen compuestos de azufre y nitrógeno, cenizas, metano, monóxido y dióxido de carbono, etc. Estas sustancias se expanden a través del medio ambiente y afecta la salud de las personas, causando afecciones pulmonares e incluso cáncer.

Los residuos sólidos que genera nuestra empresa, son principalmente cascaras de la semilla de Sacha Inchi, la cual, funciona muy bien como fertilizante, por lo tanto la donaremos a 
agricultores de la zona. Los residuos sólidos serán guardados en un almacén de residuos sólidos hasta que sean recogidos.

Actualmente muchas organizaciones y países se interesan por la gestión ambiental y la contaminación, en Perú la empresa que regulo la Gestión ambiental es la ISO 14000.

A continuación se adjunta un detalle del impacto ambiental que podría llegar a generar nuestra empresa.

Tabla 5.14.

Aspectos e Impactos ambientales

\begin{tabular}{|c|c|c|c|c|}
\hline $\begin{array}{c}\text { Etapas del } \\
\text { Proceso }\end{array}$ & Salidas & Aspecto Ambiental & Impacto Ambiental & Medidas Correctoras \\
\hline \multirow{3}{*}{ Descascarado } & \multirow{2}{*}{$\begin{array}{l}\text { Sonido del } \\
\text { descascarado }\end{array}$} & \multirow{2}{*}{$\begin{array}{l}\text { Ruido generado por la } \\
\text { maquina y el contacto con } \\
\text { las semillas }\end{array}$} & $\begin{array}{l}\text { Puede afectar de manera } \\
\text { psicologica a los trabajadores } \\
\text { (estrés, malestar, mal humor) }\end{array}$ & \multirow{2}{*}{$\begin{array}{l}\text { Uso de tapones y jebes al } \\
\text { momento de utilizar las } \\
\text { maquinas }\end{array}$} \\
\hline & & & \begin{tabular}{|l|} 
La exposicion prolongada \\
puede afectar los oidos de los \\
trabajdores
\end{tabular} & \\
\hline & Residuos & $\begin{array}{l}\text { Residuos solidos pueden } \\
\text { ser desechados sin cuidado }\end{array}$ & $\begin{array}{l}\text { Puede contaminar el suelo } \\
\text { cercano a la planta }\end{array}$ & $\begin{array}{l}\text { Realizar una buena limpieza y } \\
\text { controlar el desechado de los } \\
\text { desperdicios }\end{array}$ \\
\hline $\begin{array}{l}\text { Etiquetado } \\
\text { envasado }\end{array}$ & Restos de botellas & $\begin{array}{l}\text { Restos de solidos de } \\
\text { botellas }\end{array}$ & $\begin{array}{l}\text { Peligro de que contaminen los } \\
\text { espacios exteriores de la zona. } \\
\text { Pueden causar daño a } \\
\text { personas }\end{array}$ & $\begin{array}{l}\text { Cuidar el traslado de las } \\
\text { botellas y realizar limpiezas } \\
\text { regulares }\end{array}$ \\
\hline Distribucion & $\begin{array}{l}\text { Humo de los } \\
\text { camiones }\end{array}$ & $\begin{array}{l}\text { Emisión de CO2 producido } \\
\text { por los camiones }\end{array}$ & $\begin{array}{l}\text { Contaminacion de la zona } \\
\text { donde se encuentra la planta. } \\
\text { Puede afectar a los vecino }\end{array}$ & $\begin{array}{l}\text { Solicitar a proveedores de } \\
\text { transportes certificados de } \\
\text { camiones en buen estado }\end{array}$ \\
\hline
\end{tabular}

Elaboración propia 
Tabla 5.15.

Matriz EIA

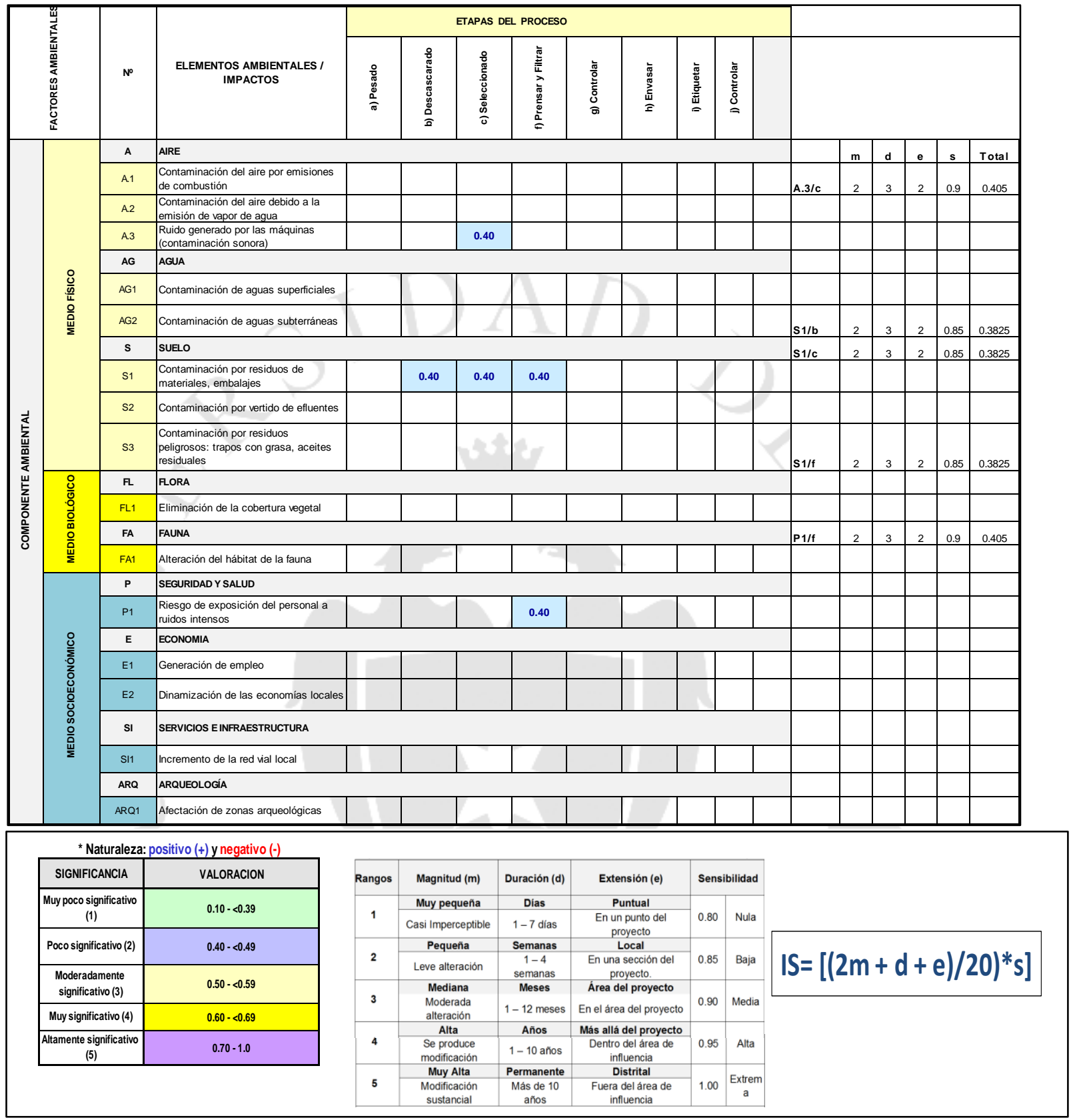

\section{Elaboración propia}


En la matriz EIA analiza los impactos ambientales a lo largo del proceso. En este caso hemos tomado como impacto el ruido generado por las maquinas en el seleccionado de las semillas. La contaminación que pueden causar los residuos en el descascarado, seleccionado, prensado y filtrado. Y por último la exposición del personal a los ruidos en el prensado. Luego de analizar los impactos y tomar en cuenta los factores como magnitud del impacto, duración de exposición, entre otros. Concluimos que los tres impactos son poco significantes. Esto se debe a que obtuvimos una valoración de entre 0.38 y 0.4 luego del análisis.

\section{Seguridad y salud ocupacional}

La Seguridad en nuestra planta y en el proceso de producción es sumamente importante ya que no queremos perjudicar la salud de nuestros trabajadores y tampoco poner en riesgo su vida.

Se deben establecer políticas de seguridad que prevengan cualquier accidente. Políticas relacionadas al manejo de materiales y maquinaria.

En el cuadro de la Matriz IPER se analizan los procesos que pueden presentar algún riesgo en la seguridad ocupacional. Luego del análisis se concluye que los riesgos son bajos o moderados. Estos pueden ser solucionados con medidas correctivas como capacitaciones y el uso de EPP (equipo de protección personal) como gafas o guantes. 
Tabla 5.16.

Matriz IPER

\begin{tabular}{|c|c|c|c|c|c|c|c|c|c|c|c|c|c|c|}
\hline \multirow{3}{*}{ PROCESO } & \multirow{3}{*}{$\begin{array}{l}\text { ACTIVIDAD } \\
\text { (Rutinaria - No } \\
\text { Rutinaria) }\end{array}$} & \multirow{3}{*}{ 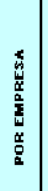 } & \multirow{3}{*}{ 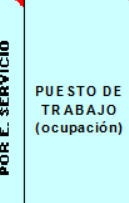 } & \multirow{3}{*}{. } & \multicolumn{2}{|c|}{ PEIGROS } & \multirow{3}{*}{ INCIDENTES SOTENCIAL } & \multirow{3}{*}{$\begin{array}{l}\text { MEDINA DE } \\
\text { CONTROL }\end{array}$} & \multicolumn{6}{|c|}{ EVALUACIÓN DE RIESGOS } \\
\hline & & & & & \multirow[b]{2}{*}{$\begin{array}{l}\text { FUENTE, } \\
\text { SITUACIÓN }\end{array}$} & \multirow[b]{2}{*}{ Асто } & & & \multicolumn{4}{|c|}{ SEGURIDAD } & \multicolumn{2}{|c|}{ HIGIENE OCUPACIOI } \\
\hline & & & & & & & & & $\begin{array}{l}\text { Probabilidad } \\
\text { (P) }\end{array}$ & $\begin{array}{l}\text { Severidad } \\
\text { (S) }\end{array}$ & $\begin{array}{c}\text { Evaluación del } \\
\text { Riesgo }\end{array}$ & \begin{tabular}{ll|l} 
Nivel de Riesgo Exis & \\
\end{tabular} & $\begin{array}{l}\text { xiste Evaluación de } \\
\text { Riesgo }\end{array}$ & Nivel de \\
\hline s Prensado & Rutinaria & & Operador & 1 & & $\mid \begin{array}{c}\text { Colocar extremidad } \\
\text { dentro de maquina }\end{array}$ & Lesion por aplastamiento & Manejo cuidadoso & 3 & 8 & 24 & Moderado & & \\
\hline s Descascarado & - Rutinaria & & Operador & 1 & & $\begin{array}{l}\text { Colocar la cabeza } \\
\text { cerca a la maquina }\end{array}$ & $\begin{array}{l}\text { esion al salir disparada } \\
\text { na cascara }\end{array}$ & Utilizar gafas & 3 & 4 & 12 & Bajo & & \\
\hline s Prensado & Rutinaria & & Operador & 1 & & $\begin{array}{c}\text { Colocar extremidad } \\
\text { dentro de maquina }\end{array}$ & esion por aplastamiento & Manejo cuidadoso & 3 & 8 & 24 & Moderado & & \\
\hline \begin{tabular}{l|l} 
s & Envasado
\end{tabular} & Rutinaria & & Operador & 1 & & \begin{tabular}{l|l} 
Manipular material & $\begin{array}{l}\mathrm{C} \\
\text { peligroso }\end{array}$ \\
da
\end{tabular} & $\begin{array}{l}\text { orte por alguna botella } \\
\text { añada }\end{array}$ & Utilizar guantes & 3 & 4 & 12 & Bajo & & \\
\hline Clasificación & \multicolumn{4}{|c|}{ Probabilidad de ocurrencia } & Puntaje & Clasificación & \multicolumn{2}{|c|}{ Severidad o Gravedad } & Puntaje & Severidad & \multirow{2}{*}{$\begin{array}{l}\text { LIGERAMENTE } \\
\text { DAÑINO (4) }\end{array}$} & \multirow{2}{*}{ DAÑINO (6) } & \multicolumn{2}{|c|}{ EXTREMADAMEN } \\
\hline \multirow{2}{*}{ BAJA } & \multirow{2}{*}{\multicolumn{4}{|c|}{$\begin{array}{l}\text { El incidente potencial se ha presentado una vez o } \\
\text { nunca en el área, en el período de un año. }\end{array}$}} & \multirow{2}{*}{3} & \multirow{2}{*}{$\begin{array}{l}\text { LIGERAMENTE } \\
\text { DANNNONO }\end{array}$} & \multirow{2}{*}{\multicolumn{2}{|c|}{$\begin{array}{c}\text { Primeros Auxilios Menores, Rasguños, } \\
\text { Contusiones, Polvo en los Ojos, Erosiones Leves. }\end{array}$}} & \multirow[t]{2}{*}{4} & Probabilidad & & & TE DAÑINO & \\
\hline & & & & & & & & & & $P \wedge(\Omega)$ & 12 a 20 & 12 a 20 & 24 a 36 & \\
\hline \multirow{2}{*}{ MEDIA } & \multirow{2}{*}{\multicolumn{4}{|c|}{$\begin{array}{l}\text { El incidente potencial se ha presentado } 2 \text { a } 11 \\
\text { veces en el área, en el período de un año. }\end{array}$}} & \multirow[b]{2}{*}{5} & & Lesiones que requieren & tratamiento medico, & & 年 & Riesgo Bajo & Riesgo Bajo & Riesgo Mode & \\
\hline & & & & & & DANINO & $\begin{array}{r}\text { Dislocación, Laceración c } \\
\text { erosiones pr }\end{array}$ & $\begin{array}{l}\text { que requiere suturas, } \\
\text { rofundas. }\end{array}$ & 6 & MEDIA (5) & $\begin{array}{l}12 \text { a } 20 \\
\text { Riesgo Bajo }\end{array}$ & $\begin{array}{l}24 \text { a } 36 \\
\text { Riesgo Moderado }\end{array}$ & $\begin{array}{r}40 \text { a } 54 \\
\text { Riesgo Import }\end{array}$ & \\
\hline ALTA & $\begin{array}{l}\text { El incidente potenci } \\
\text { veces en el áre }\end{array}$ & $\begin{array}{l}\text { l se hap } \\
\text {, en el p }\end{array}$ & $\begin{array}{l}\text { presentado } 12 \\
\text { eríodo de un }\end{array}$ & $\begin{array}{l}0 \text { más } \\
\text { ño. }\end{array}$ & 9 & $\begin{array}{l}\text { EXTREMADAMENTE } \\
\text { DAÑNINO }\end{array}$ & $\begin{array}{r}\text { Fatalidad - Para / Cuad } \\
\text { Incapacidad permanente, a }\end{array}$ & $\begin{array}{l}\text { driplejia - Ceguera. } \\
\text { amputación, mutilación, }\end{array}$ & 8 & ALTA (9) & $\begin{array}{c}24 \text { a } 36 \\
\text { Riesgo Moderado }\end{array}$ & $\begin{array}{c}40 \text { a } 54 \\
\text { Riesgo Importante }\end{array}$ & $\begin{array}{r}60 \text { a } 72 \\
\text { Riesgo Criti }\end{array}$ & \\
\hline
\end{tabular}

Elaboración propia 


\section{Sistema de mantenimiento}

Para el sistema de mantenimiento, escogimos el sistema de mantenimiento predictivo, que es una técnica para pronosticar el punto futuro de falla de un componente de una máquina, para que pueda remplazarse justo antes de que falle. Así, el tiempo muerto del equipo se minimiza y el tiempo de vida del componente se maximiza. Es un Mantenimiento Planificado.

A continuación, detallamos un cuadro que explica gráficamente el funcionamiento del sistema de mantenimiento predictivo.

Figura 5.17.

Sistema de Mantenimiento

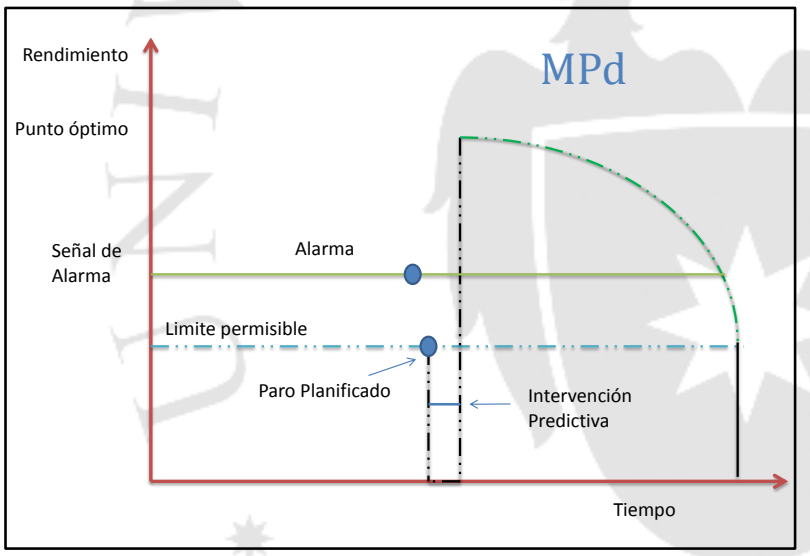

Elaboración propia

\section{Programa de producción para la vida útil del proyecto}

El programa de producción para la vida del proyecto está basado en la proyección de la demanda hallada anteriormente. Se va a considerar un stock de seguridad anual de 10,000 botellas de aceite. 
Tabla 5.18.

Proyección de la producción para la vida útil del proyecto

\begin{tabular}{|c|c|c|c|c|c|c|c|c|c|c|}
\hline Año & 2014 & 2015 & 2016 & 2017 & 2018 & 2019 & 2020 & 2021 & 2022 & 2023 \\
\hline Plan Vts Anuales & $67,759.36$ & $70,245.44$ & $72,731.52$ & $75,217.60$ & $77,703.68$ & $80,189.76$ & $82,675.84$ & $85,161.93$ & $87,648.01$ & $90,134.09$ \\
\hline Total Disponible & $77,759.36$ & $80,245.44$ & $82,731.52$ & $85,217.60$ & $87,703.68$ & $90,189.76$ & $92,675.84$ & $95,161.93$ & $97,648.01$ & $100,134.09$ \\
\hline Produccion & $77,759.36$ & $80,245.44$ & $82,731.52$ & $85,217.60$ & $87,703.68$ & $90,189.76$ & $92,675.84$ & $95,161.93$ & $97,648.01$ & $100,134.09$ \\
\hline Stock & - & $10,000.00$ & $10,000.00$ & $10,000.00$ & $10,000.00$ & $10,000.00$ & $10,000.00$ & $10,000.00$ & $10,000.00$ & $10,000.00$ \\
\hline
\end{tabular}

Elaboración propia

\section{Requerimiento de insumos, personal y servicios}

\section{Materia prima, insumos y otros materiales}

En lo que respecta a materia prima e insumos, se trabajará con terceros que nos faciliten estos elementos. Se trabajará directamente con productores de semilla de sacha Inchi, los cuales nos proporcionaran semillas de buena calidad.

Además también compraremos las botellas y tapas ya listas para colocarlos en nuestra maquinaria. La etiqueta nos la entregaran ya lista para colocarla en el envase.

Tabla 5.19.

Requerimiento de insumos para la producción

\begin{tabular}{|l|r|r|r|r|r|r|r|r|r|r|}
\hline \multicolumn{1}{|c|}{ Año } & \multicolumn{1}{|c|}{2014} & \multicolumn{1}{c|}{2015} & \multicolumn{1}{c|}{2016} & \multicolumn{1}{c|}{2017} & \multicolumn{1}{c|}{2018} & \multicolumn{1}{c|}{2019} & \multicolumn{1}{c|}{2020} & \multicolumn{1}{c|}{2021} & \multicolumn{1}{c|}{2022} & \multicolumn{1}{c|}{2023} \\
\hline Aceite en litros & $19,439.84$ & $20,061.36$ & $20,682.88$ & $21,304.40$ & $21,925.92$ & $22,547.44$ & $23,168.96$ & $23,790.48$ & $24,412.00$ & $25,033.52$ \\
\hline Semilla de Sacha Inchi kg & $86,079.61$ & $88,831.70$ & $91,583.79$ & $94,335.89$ & $97,087.98$ & $99,840.07$ & $102,592.16$ & $105,344.25$ & $108,096.34$ & $110,848.44$ \\
\hline Botellas und & 77,759 & 80,245 & 82,732 & 85,218 & 87,704 & 90,190 & 92,676 & 95,162 & 97,648 & 100,134 \\
\hline Tapas und & 77,759 & 80,245 & 82,732 & 85,218 & 87,704 & 90,190 & 92,676 & 95,162 & 97,648 & 100,134 \\
\hline Etiquetas und & 77,759 & 80,245 & 82,732 & 85,218 & 87,704 & 90,190 & 92,676 & 95,162 & 97,648 & 100,134 \\
\hline
\end{tabular}

Elaboración propia

2. Determinación del número de operarios y trabajadores indirectos

Para poder realizar un buen trabajo y obtener un producto de calidad se necesita de personas capacitadas que puedan realizar un trabajo eficiente. Además, necesitan profesionales que manejen la empresa de manera comercial.

Una ventaja que tenemos de ubicar nuestra planta en Lima, es que la disponibilidad de profesionales y técnicos especializados es grande. 
Los principales puestos que se necesita en nuestra empresa son:

- Producción (operarios, jefe de operarios)

- Comercial (promotor de ventas, analista de marketing, gerente comercial)

- Legal (Asesor legal)

- Planeamiento (analista de distribución y planeación)

\section{Servicios de terceros}

Los servicios que necesitaríamos cubrir por parte de terceros serían los siguientes:

- Energía eléctrica.

- Agua y desagüe

- Teléfono

- Revisión técnica

- Mantenimiento

- Transporte

- Capacitaciones

- Vigilancia

- Limpieza e Higiene

- Combustibles

- Alimentación 


\section{Características físicas del proyecto}

La planta de producción debe de ser diseñada específicamente para el proyecto que se está desarrollando. Por ello se analizará los espacios necesitados para las máquinas y trabajadores. El área más grande de la planta será enfocada en la producción del aceite y en la maquinaria. Además, se colocará una cafetería en donde los operarios podrán almorzar y se colocará los servicios higiénicos necesarios.

Para el área de oficinas tomaremos en cuenta el número de trabajadores que necesitemos. Tomaremos en cuenta de que los trabajadores comerciales no interfieran en el trabajo de los operarios y viceversa.

\section{Factor edificio}

La infraestructura de la planta será construida de material prefabricado. Este trabajo será encargado a un tercero, empresa constructora, que nos dará el servicio. Ellos ayudarán a tomar en cuenta todos los criterios de seguridad en la construcción y para que la estructura de la planta sea la adecuada.

\section{Factor servicio}

Antes de realizar la construcción de la planta, se debe de tener en cuenta todos los factores servicio que influyen en la labor de los trabajadores.

Los puntos a tomar en cuenta son:

- Vías de acceso

- Oficinas

- Servicios Higiénicos

- Servicios de alimentación 


\section{$\underline{\text { Vías de acceso }}$}

Este punto depende de la distribución de espacios que otorguemos a nuestra planta. Debemos de tomar en cuenta que el acceso debe de ser rápido y debe de poseer todas las medidas de seguridad necesarias. Además, debe de facilitar las movilizaciones de los trabajadores haciendo su trabajo más eficiente y no perjudicándolo.

\section{$\underline{\text { Oficinas }}$}

Las oficinas deben ser diseñadas siguiendo con los parámetros establecidos para ello. Se debe de tomar en cuenta el siguiente cuadro dependiendo de la cantidad de trabajadores que tengamos. Según Stephan Konz (2012) tomaremos en cuenta lo siguiente:

- Ejecutivo principal: de 23 a $46 \mathrm{~m} 2$ (250 a 500 pies cuadrados)

- Ejecutivo: de 18 a $37 \mathrm{~m} 2$ (200 a 400 pies cuadrados)

- Ejecutivo junior: de 10 a $23 \mathrm{~m} 2$ (199 a 250 pies cuadrados)

- Mando medio (ingeniero, programador): de 7.5 a $14 \mathrm{~m} 2$ (80 a 150 pies cuadrados)

- Oficinista: de 4.5 a $9 \mathrm{~m} 2$ (50 a 100 pies cuadrados)

- Estación de trabajo mínima: 4.5 m2 (50 pies cuadrados)

\section{$\underline{\text { Servicios Higiénicos }}$}

La distribución de los baños también será diseñada siguiendo con los parámetros mostrados en el cuadro siguiente. Colocaremos dos servicios higiénicos, uno para los obreros y otro para el personal de oficina. 
Figura 5.20.

Distribución de servicios higiénicos

\begin{tabular}{cc}
\hline Número de empleados & Número mínimo de retretes \\
\hline $1-15$ & 1 \\
$16-35$ & 2 \\
$36-55$ & 3 \\
$56-80$ & 4 \\
$81-110$ & 5 \\
$110-150$ & 6 \\
Más de 150 & 1 conjunto adicional por cada 40 \\
& empleados adicionales \\
\hline
\end{tabular}

Fuente: Konz, S. 2012.

$\underline{\text { Servicios de alimentación }}$

Para la distribución de la cafetería se otorgará $1.58 \mathrm{~m} 2$ por trabajador que almuerce en el lugar. Se debe de dar cierto espacio adicional para que pueda también ser usado como un espacio de recreación y descanso durante el tiempo de refrigerio.

Figura 5.21.

Distribución de cafetería

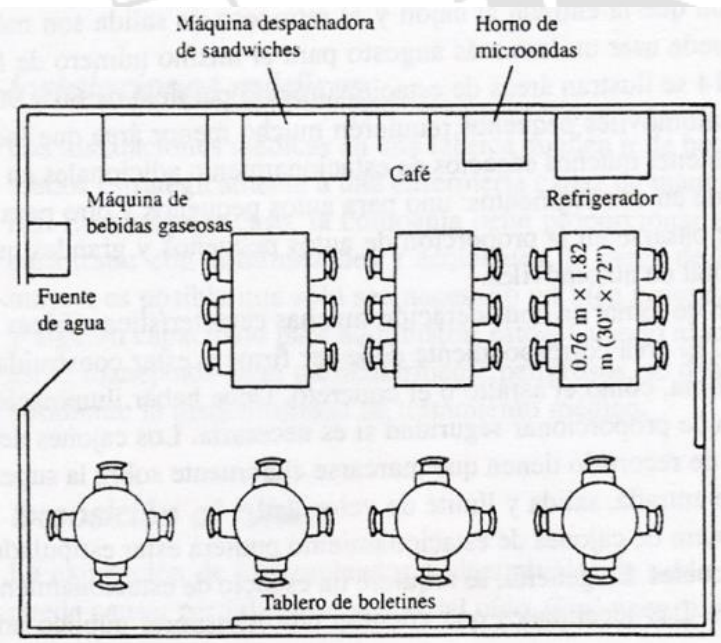

Fuente: Konz, S. 2012.

Imagen referencial 


\section{Disposición de planta}

\section{Disposición general}

Para poder realizar una buena disposición de planta se deben plantear como objetivos maximizar la eficiencia de la producción. Para ello debemos de tomar en cuenta el trabajo y la comodidad de los trabajadores, como se va a distribuir nuestra planta, si lo hacemos de una manera eficiente y si estamos minimizando los costos de transportes y del proyecto en general.

Por ello se va a desarrollar los siguientes puntos que nos ayudarán a elegir mejor la disposición de la planta.

- Método de Guerchet: Para calcular las áreas de las maquinas

- Tabla y Diagrama relacional: Para poder relacionar las áreas más importantes entre si

- Disposición de planta: Para obtener un plano basado en todos los factores que debemos de tomar en cuenta.

\section{Diagrama Relacional}

Este Método permite observar todas las actividades según su grado de proximidad entre ellas. Se permitirá desarrollar una propuesta para la distribución tomando en cuenta la importancia de la cercanía entre las áreas presentes.

Primero, se debe de tomar en cuenta y enumerar las áreas que vamos a analizar. Estas áreas serán las presentes en el plano. 
1. Almacén de Materia Prima

2. Pesado

3. Descascarado

4. Seleccionado

5. Prensado

6. Filtrado

7. Control de Calidad

8. Envasado

9. Etiquetado

10. Almacén de Producto terminado

11. Cuarto de limpieza

12. Oficinas

13. Servicios Higiénicos

14. Comedor

También debemos de tomar en cuenta los motivos de relación entre áreas. Estos motivos ayudarán a especificar si las áreas son importantes entre ellas o no.

1. Mejor control de Materia Prima

2. Mejor traslado

3. Cercanía a instalaciones

4. Control de actividades

5. Mejor manipulación

6. Sin razón aparente.

7. Mismas instalaciones 
El siguiente cuadro nos muestra como analizaremos estas áreas y motivos de relación mediante una codificación de líneas y colores.

Tabla 5.22.

Código de Proximidades

\begin{tabular}{|l|l|l|l|}
\hline Código & Proximidad & Color & $\mathrm{N}^{\circ}$ de líneas \\
\hline A & Absolutamente necesario & Rojo & 4 recta \\
\hline E & Especialmente importante & Amarillo & 3 recta \\
\hline I & Importante & Verde & 2 recta \\
\hline $\mathrm{O}$ & Normal & Azul & 1 recta \\
\hline $\mathrm{U}$ & Sin importancia & & \\
\hline $\mathrm{X}$ & No deseable & Plomo & 1 zigzag \\
\hline
\end{tabular}

Elaboración propia

Luego realizaremos la tabla relacional la cual comparará cada una de las áreas que se están tomando en cuenta.

Para ello, se utilizará un cuadro en donde por medio de rombos colocaremos letras y números para relacionar las áreas.

Figura 5.23.

Representación de la tabla

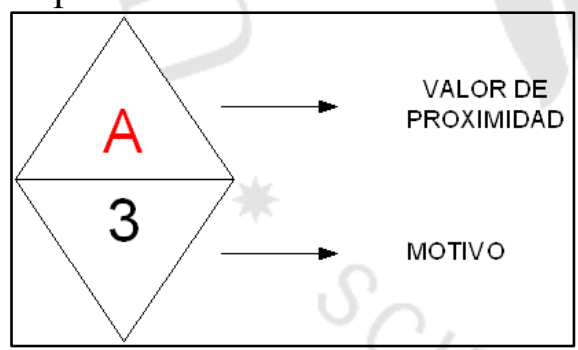

Fuente: Konz, S. 2012. 
Figura 5.24.

Tabla relacional

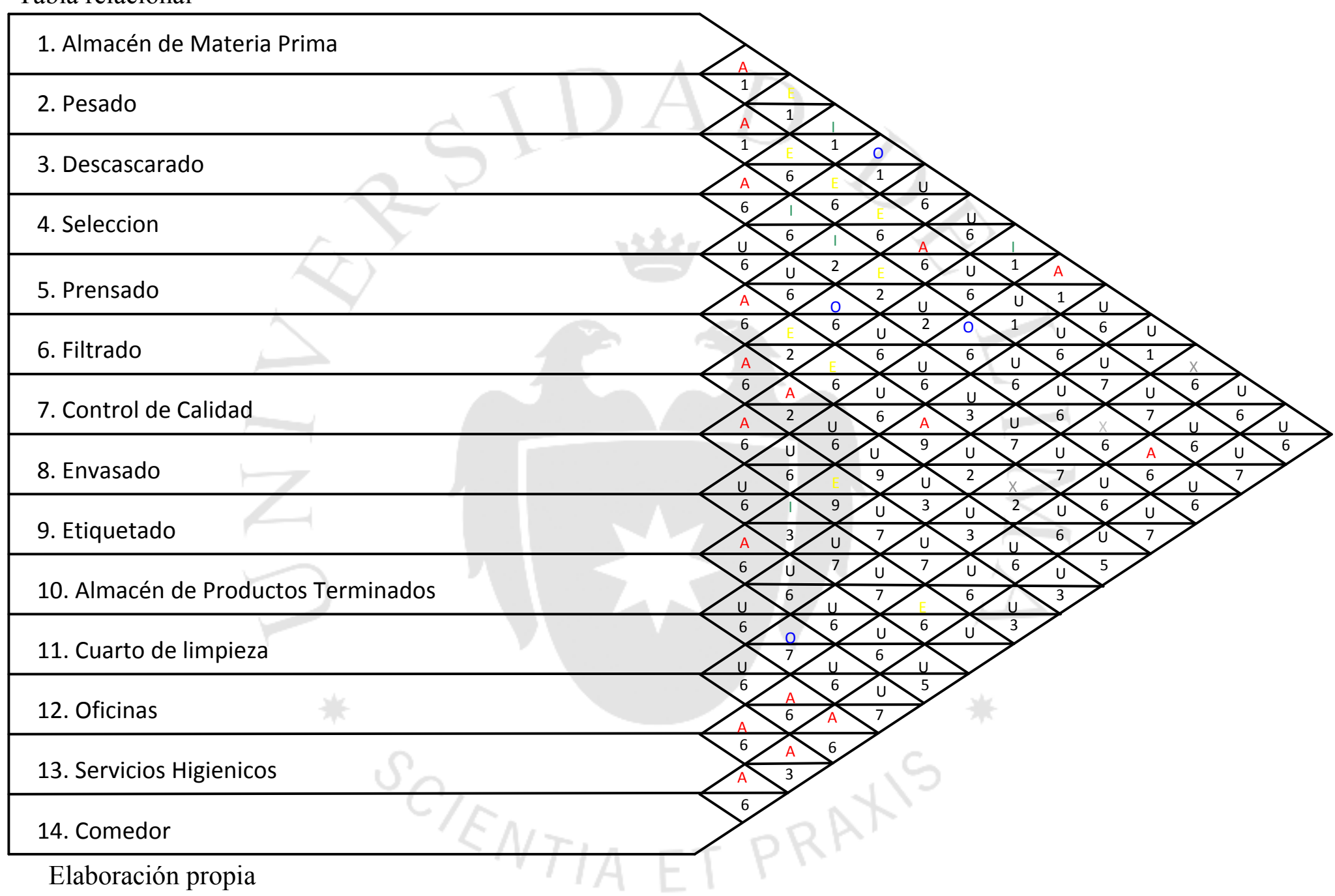


Luego de realizar la tabla relacional, resumimos los valores comparados según el código de proximidad.

A $\quad(1,2)(1,9)(2,3)(2,7)(3,4)(3,13)(5,6)(5,10)(6,7)(6,8)(7,8)(9,10)(11,13)(11,14)$ $(12,13)(12,14)(13,14)$

$(1,3)(2,4)(2,5)(2,6)(3,7)(5,7)(5,8)(7,10)(8,13)$

I $\quad(1,4)(1,8)(3,5)(3,6)(8,10)$

O $\quad(1,5)(3,9)(4,7)(10,12)$

$\mathbf{U} \quad(1,6)(1,7)(1,10)(1,11)(1,13)(1,14)(2,8)(2,9)(2,10)(2,11)(2,12)(2,13)(2,14)(3,8)$ $(3,10)(3,11)(3,14)(4,1)(4,2)(4,4)(4,5)(4,6)(4,7)(4,8)(4,9)(4,10)(4,11)(4,12)(4,13)$ $(4,14)(5,9)(5,11)(5,13)(5,14)(6,9)(6,10)(6,11)(6,12)(6,13)(6,14)(7,9)(7,11)(7,12)$ $(7,13)(7,14)(8,9)(8,11)(8,12)(8,14)(9,11)(9,12)(9,13)(9,14)(10,11)(10,13)(10,14)$ $(11,12)$

X $(1,12)(3,12)(5,12)$

Para poder relación el diagrama relacional de actividades debemos de tomar en cuenta la siguiente simbología.

Tabla 5.25.

Simbología diagrama relacional

\begin{tabular}{|c|c|c|}
\hline SIMBOLO & COLOR & AC TVIDAD \\
\hline 0 & Rojo & Operación (montaje o submontaje) \\
\hline 0 & verde & Operación, processo o tabicicación \\
\hline$\Rightarrow$ & Amarillo & Transporte \\
\hline$\nabla$ & Naranja & Almacenaje \\
\hline$\square$ & Azul & Contol \\
\hline$\Omega$ & Azul & Sevicios \\
\hline 今 & Pardo & Administración \\
\hline
\end{tabular}

Elaboración propia 
Figura 5.26.

Diagrama relacional de actividades

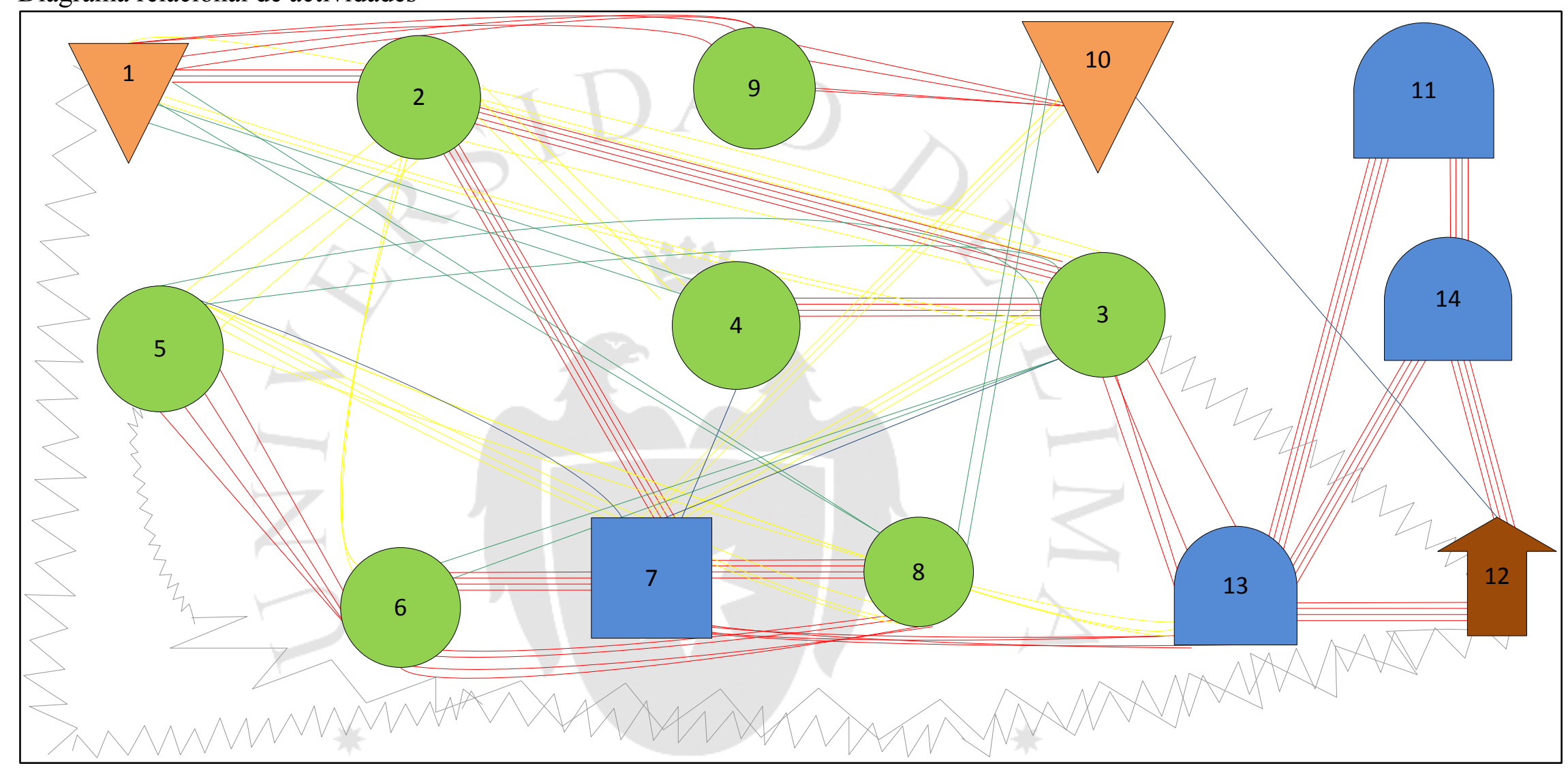

Elaboración propia

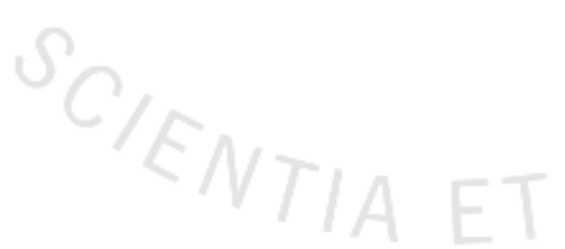




\section{Disposición de detalle}

Para encontrar el detalle de la disposición de planta utilizamos el Método de Guerchet. Este método nos ayudara a calcular las áreas específicas de cada máquina para poder realizar una propuesta más exacta del área de nuestra planta.

Para los cálculos, utilizamos fórmulas que han sido especificadas en el mismo cuadro de cálculos. Además de las siguientes formulas, las cuales son utilizadas para hallar valores necesarios en el método.

Figura 5.27.

Formulas Guerchet 1

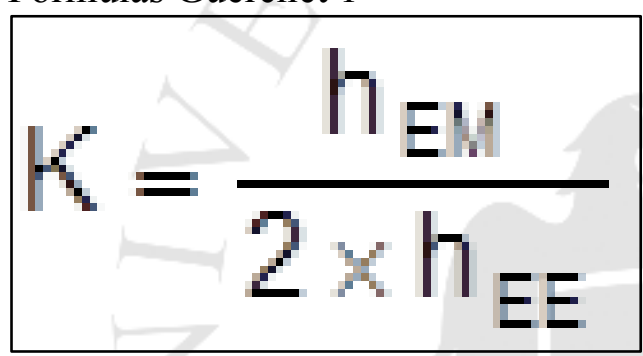

Fuente: Konz, S. 2012.

Figura 5.28.

Formulas Guerchet 2

$\mathrm{h}_{\mathrm{EM}}=\frac{\sum_{i=0}^{\mathrm{r}} \mathrm{S}_{s} \times \mathrm{n} \times \mathrm{h}}{\sum_{i=0}^{r} \mathrm{~S}_{\mathrm{S}} \times \mathrm{n}} ; \mathrm{r}=$ variedad de elementos móviles
$\mathrm{h}_{\mathrm{EE}}=\frac{\sum_{j=0}^{t} \mathrm{~S}_{\mathrm{s}} \times \mathrm{n} \times \mathrm{h}}{\sum_{j=0}^{t} \mathrm{~S}_{\mathrm{S}} \times \mathrm{n}} ; \mathrm{t}=$ variedad de elementos estáticos

Fuente: Konz, S. 2012. 
Figura 5.29.

Método de Guerchet

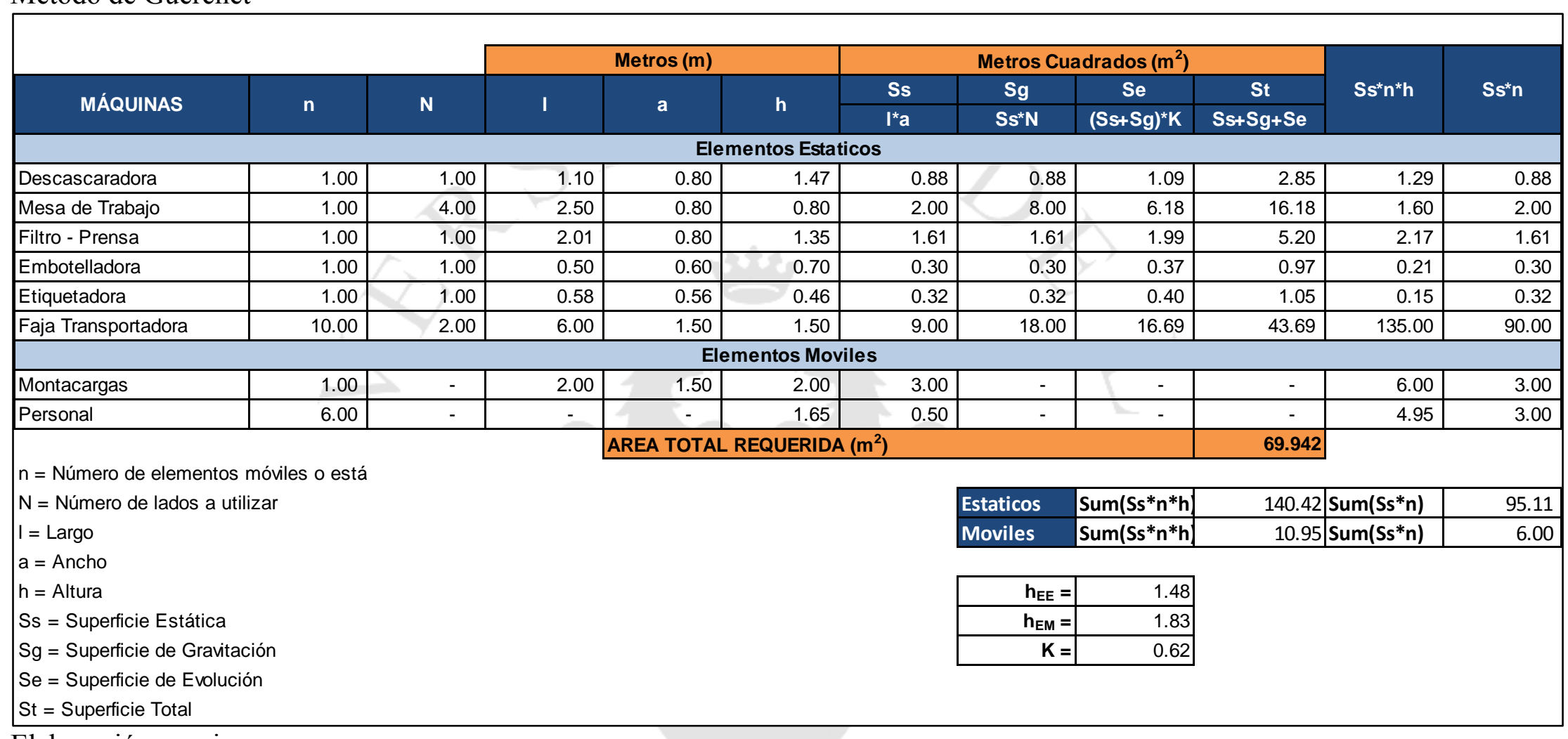

Elaboración propia 
Figura 5.30.

Plano de planta

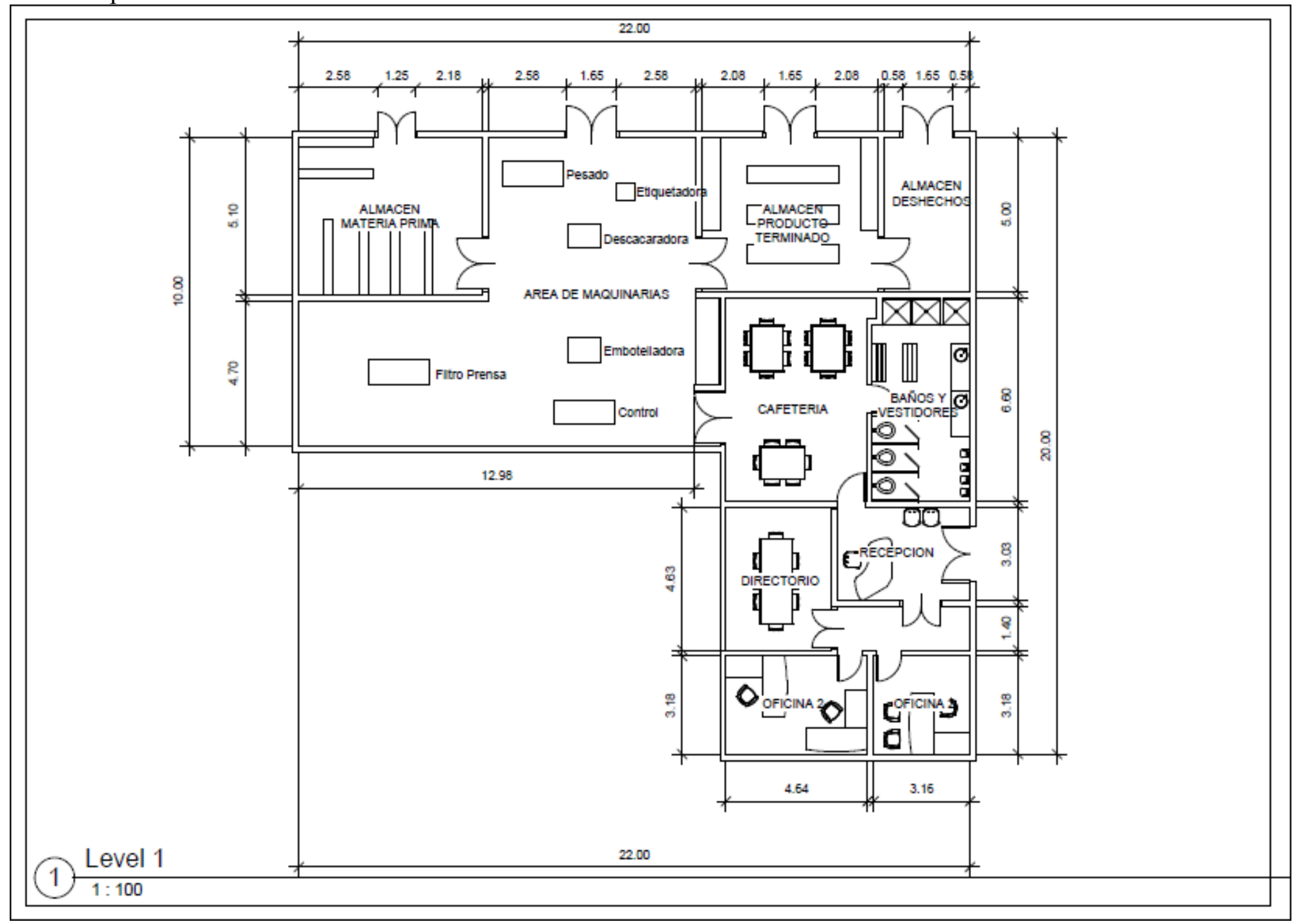

Elaboración propia 


\section{Cronograma de implementación del proyecto}

El proyecto será implementando en el plazo de un año. Dentro de este lapso de tiempo se harán las investigaciones correspondientes para que nuestra planta sea eficiente y podamos alcanzar las metas económicas que queremos. Además, se deberá de analizar todos estos factores para poder hacer un aproximado de gastos e inversiones a realizar.

Figura 5.31.

Cronograma de implementación

\begin{tabular}{|c|c|c|c|c|c|c|c|c|c|c|c|c|}
\hline \multirow{2}{*}{ DESCRIPCIÓN } & \multicolumn{12}{|c|}{ MESES } \\
\hline & . & 2 & 3 & 4 & ( & 6 & 7 & 8 & 9 & 10 & 11 & 12 \\
\hline \multicolumn{13}{|l|}{ Estudios, Investigación y Desarrollo } \\
\hline \multicolumn{13}{|l|}{ Gastos Administrativos pre-operativos } \\
\hline \multicolumn{13}{|l|}{ Gastos de Organización y Constitución } \\
\hline \multicolumn{13}{|l|}{ Compra de terreno } \\
\hline \multicolumn{13}{|l|}{ Obras civiles, de construcción } \\
\hline \multirow{2}{*}{\multicolumn{13}{|c|}{ Compra de maquinaria para la planta }} \\
\hline \multicolumn{5}{|c|}{ Gastos Financieros pre-operativos } & & & & & & & & \\
\hline \multirow{2}{*}{\multicolumn{13}{|c|}{$\begin{array}{l}\text { Compra e instalación de mobiliario de oficina } \\
\text { Instalación de maquinaria y equipos }\end{array}$}} \\
\hline & & & & & & & & & & & & \\
\hline \multicolumn{13}{|l|}{ Gastos de entrenamiento de personal } \\
\hline Puesta en marcha de la maquinaria & & & & & & & & & & & & \\
\hline
\end{tabular}

Elaboración propia 


\section{CAPÍTULO VI. ASPECTOS ECONÓMICOS Y}

\section{FINANCIEROS}

\section{Inversiones}

\section{Estimación de las inversiones}

Para la estimación de las inversiones estamos tomando en cuenta todos los aspectos que afectarán los gastos en el primer año de nuestro proyecto. Se debe tomar en cuenta desde la implementación de una red de cableado para la electricidad hasta cualquier problema que se pueda presentar como contingencia.

Estos costos de inversión solo afectarán nuestro balance en el primer año del proyecto, luego se explicará cuáles son los demás costos que afectaran año por año.

Tabla 6.1.

Costos de inversión

\begin{tabular}{|c|c|}
\hline \multicolumn{2}{|l|}{ Soles } \\
\hline \multicolumn{2}{|c|}{ Activos Fijos Tangibles } \\
\hline Terreno & $1,088,000.00$ \\
\hline Obra civil (Edificios+contratistas) & $85,000.00$ \\
\hline Maquinaria y Equipos & $131,960.00$ \\
\hline Instalaciones electricas y sanitarias & $15,000.00$ \\
\hline Total Activo Fijo Tangible & $1,319,960.00$ \\
\hline \multicolumn{2}{|l|}{ Activos Fijos Intangibles } \\
\hline Ingeniería y Supervisión & $20,000.00$ \\
\hline Permisos y Licencias & $118,475.71$ \\
\hline Contingencias & $50,000.00$ \\
\hline Total Activos Fijos Intangibles & $188,475.71$ \\
\hline TOTAL ACTIVOS FIJOS & $1,508,435.71$ \\
\hline CAPITAL DE TRABAJO & $142,503.99$ \\
\hline INVERSIÓN TOTAL & $1,650,939.70$ \\
\hline
\end{tabular}

Elaboración propia

- Terreno: Costo del lugar en donde instalaremos nuestra planta en el distrito de Ate

- Obra civil: La mano de obra en la construcción del edificio y el pago a la empresa que nos brindará el servicio y equipos de construcción. 
- Maquinaria y equipos: Costo de la maquinaria que nos ayudará en nuestro proceso de producción.

- Instalaciones eléctricas y sanitarias: Todos los elementos que nos permitirán que el local sea apto para trabajo.

- Ingeniería y supervisión: Necesitamos personal especializado en la construcción y diseño de plantas.

- Permisos y Licencias: Pago por los permisos municipales y trámites relacionados a la construcción y funcionamiento de la planta.

- Contingencias: Dinero disponible para cualquier contingencia que se presente a lo largo de la construcción.

\section{Capital de trabajo}

El capital de trabajo está basado en poder cubrir los tres primeros meses de producción de nuestra planta. Luego ya tendremos ingresos para poder continuar normalmente la actividad de nuestra planta. Se considera un capital de trabajo de S/. 142,503.99. El cual se ha obtenido de calcular el costo de producción para el año 2016, desagregarlo por mes y hallar lo necesario para los tres primeros meses. Costo de producción 2016: S/. 570016 y por mes: S/. 47 501.33. Este monto será utilizado para la compra de la materia prima, pago de servicios y mano de obra.

Esta decisión la estamos tomando ya que los supermercados tienen un tiempo de pago a 90 días.

\section{Costos de producción}

\section{Costos de materias primas, insumos y otros materiales}


Para el siguiente cuadro estamos analizando como insumos directos las semillas de sacha Inchi, las botellas y tapas. Existen muchos proveedores de semillas de Sacha Inchi que las traen directamente a Lima para ser producidas. Las botellas y tapas serán compradas al mismo proveedor ya que se venden en conjunto. Estamos considerando 3 soles por $\mathrm{kg}$ de Sacha Inchi para la compra de las semillas y 2 soles para la compra de botellas (incluida tapa).

Los costos de agua y luz han sido obtenidos de Sedapal y Luz del Sur tomando en cuenta nuestros requerimientos de estos servicios para la producción.

Tabla 6.2.

Requerimientos (Lt, Kg, Un)

\begin{tabular}{|c|c|c|c|c|c|c|c|c|c|c|}
\hline Año & 2014 & 2015 & 2016 & 2017 & 2018 & 2019 & 2020 & 2021 & 2022 & 2023 \\
\hline Aceite en litros & $19,439.84$ & $20,061.36$ & $20,682.88$ & $21,304.40$ & $21,925.92$ & $22,547.44$ & $23,168.96$ & $23,790.48$ & $24,412.00$ & $25,033.52$ \\
\hline Semilla de Sacha Inchi kg & $86,079.61$ & $88,831.70$ & $91,583.79$ & $94,335.89$ & $97,087.98$ & $99,840.07$ & $102,592.16$ & $105,344.25$ & $108,096.34$ & $110,848.44$ \\
\hline Botellas und & 77,759 & 80,245 & 82,732 & 85,218 & 87,704 & 90,190 & 92,676 & 95,162 & 97,648 & 100,134 \\
\hline Tapas und & 77,759 & 80,245 & 82,732 & 85,218 & 87,704 & 90,190 & 92,676 & 95,162 & 97,648 & 100,134 \\
\hline Etiquetas und & 77,759 & 80,245 & 82,732 & 85,218 & 87,704 & 90,190 & 92,676 & 95,162 & 97,648 & 100,134 \\
\hline
\end{tabular}

Elaboración propia

Tabla 6.3.

Costos de insumos Soles

\begin{tabular}{|c|c|c|c|c|c|c|c|c|c|c|}
\hline \multicolumn{11}{|c|}{ Soles Peruanos } \\
\hline AÑ̃O & 2014 & 2015 & 2016 & 2017 & 2018 & 2019 & 2020 & 2021 & 2022 & 2023 \\
\hline \multicolumn{11}{|c|}{ DIRECTOS } \\
\hline Semillas de Sacha Inchi & $258,238.83$ & $266,495.10$ & $274,751.38$ & $283,007.66$ & $291,263.93$ & $299,520.21$ & $307,776.48$ & $316,032.76$ & $324,289.03$ & $332,545.31$ \\
\hline Botellas+tapa & $155,518.72$ & $160,490.88$ & $165,463.04$ & $170,435.20$ & $175,407.37$ & $180,379.53$ & $185,351.69$ & $190,323.85$ & $195,296.01$ & $200,268.18$ \\
\hline Costos Directos & $413,757.55$ & $426,985.98$ & $440,214.42$ & $453,442.86$ & $466,671.30$ & $479,899.73$ & $493,128.17$ & $506,356.61$ & $519,585.05$ & $532,813.48$ \\
\hline \multicolumn{11}{|c|}{ INDIRECTOS } \\
\hline Agua & $9,315.00$ & $9,324.32$ & $9,333.64$ & $9,342.97$ & $9,352.32$ & $9,361.67$ & $9,371.03$ & $9,380.40$ & $9,389.78$ & $9,399.17$ \\
\hline Luz & $7,247.42$ & $7,254.67$ & $7,261.93$ & $7,269.19$ & $7,276.46$ & $7,283.73$ & $7,291.02$ & $7,298.31$ & $7,305.61$ & $7,312.91$ \\
\hline Costos Indirectos & $16,562.42$ & $16,578.99$ & $16,595.56$ & $16,612.16$ & $16,628.77$ & $16,645.40$ & $16,662.05$ & $16,678.71$ & $16,695.39$ & $16,712.08$ \\
\hline TOTAL COSTOS & $430,319.97$ & $443,564.97$ & $456,809.99$ & $470,055.02$ & $483,300.07$ & $496,545.13$ & $509,790.22$ & $523,035.32$ & $536,280.43$ & $549,525.57$ \\
\hline
\end{tabular}

Elaboración propia

\section{Costo de los servicios}

Para poder calcular los costos de servicios hemos investigado en las empresas más conocidas que ofrecen cada uno de ellos. Sedapal, Luz del Sur y Movistar son las empresas 
que nos van a proveedor los servicios de agua, luz, alcantarillado, internet y teléfono. El cuadro lo podemos analizar en la siguiente página.

Tabla 6.4.

Costos de servicios

\begin{tabular}{|c|c|c|c|c|c|c|c|c|c|c|}
\hline \multicolumn{11}{|c|}{ Soles Peruanos } \\
\hline AÑ̃ & 2014 & 2015 & 2016 & 2017 & 2018 & 2019 & 2020 & 2021 & 2022 & 2023 \\
\hline Agua & $9,315.00$ & $9,324.32$ & $9,333.64$ & $9,342.97$ & $9,352.32$ & $9,361.67$ & $9,371.03$ & $9,380.40$ & $9,389.78$ & 9,399.17 \\
\hline Alcantarillado & $6,920.00$ & $6,920.00$ & $6,920.00$ & $6,920.00$ & $6,920.00$ & $6,920.00$ & $6,920.00$ & $6,920.00$ & $6,920.00$ & $6,920.00$ \\
\hline Luz & $7,247.42$ & $7,254.67$ & $7,261.93$ & $7,269.19$ & $7,276.46$ & $7,283.73$ & $7,291.02$ & $7,298.31$ & $7,305.61$ & $7,312.91$ \\
\hline Internet & 400.00 & 400.00 & 400.00 & 400.00 & 400.00 & 400.00 & 400.00 & 400.00 & 400.00 & 400.00 \\
\hline Telefono & 80.00 & 80.00 & 80.00 & 80.00 & 80.00 & 80.00 & 80.00 & 80.00 & 80.00 & 80.00 \\
\hline TOTAL & $23,962.42$ & $23,978.99$ & $23,995.56$ & $24,012.16$ & $24,028.77$ & $24,045.40$ & $24,062.05$ & $24,078.71$ & $24,095.39$ & $24,112.08$ \\
\hline
\end{tabular}

Elaboración propia

\section{Costo de la mano de obra}

\section{a. Mano de obra directa}

Para poder realizar un mejor manejo de la producción debemos de tener un jefe de operaciones. Esta persona se encargara de dirigir y supervisar las labores de los operarios y que su trabajo justifique la remuneración que les estamos dando.

Tabla 6.5.

Costo de Mano de obra directa

\begin{tabular}{|l|c|r|r|r|}
\hline $\begin{array}{c}\text { DETALLE DE } \\
\text { OPERACIONES }\end{array}$ & CALIFICADO & $\begin{array}{c}\text { NO } \\
\text { CALIFICADO }\end{array}$ & $\begin{array}{c}\text { COSTO (S/.) } \\
\text { (mensual) }\end{array}$ & $\begin{array}{c}\text { COSTO (S/.) } \\
\text { (anual) }\end{array}$ \\
\hline Pesado de MP & $\mathrm{x}$ & & 800 & 12,000 \\
\hline Selección de granos & $\mathrm{x}$ & & 800 & 12,000 \\
\hline Control de calidad 1 & $\mathrm{x}$ & & 800 & 12,000 \\
\hline Control de calidad 2 & $\mathrm{x}$ & & 800 & 12,000 \\
\hline Carga y superisión & $\mathrm{x}$ & & 800 & 12,000 \\
\hline Carga y supervisión & $\mathrm{x}$ & & 800 & 12,000 \\
\hline Jefe de operaciones & $\mathrm{x}$ & & 2,500 & 37,500 \\
\hline Limpieza y mantenimiento & $\mathrm{x}$ & & 800 & 12,000 \\
\hline TOTAL & & & $\mathbf{8 , 1 0 0}$ & $\mathbf{1 2 1 , 5 0 0}$ \\
\hline
\end{tabular}

Elaboración propia

\section{b. Mano de obra indirecta}


La mano de obra indirecta se encargará de manejar la parte comercial de la compañía.

Hemos decidido elegir dos practicantes envés de dos asistentes ya que sería un ahorro en sus remuneraciones.

Tabla 6.6.

Costo de Mano de obra Indirecta

\begin{tabular}{|l|c|c|r|r|r|}
\hline $\begin{array}{l}\text { DETALLE DEL PERSONAL } \\
\text { REQUERIDO }\end{array}$ & $\begin{array}{c}\text { ESTUDIOS } \\
\text { UNIVERSITARIOS }\end{array}$ & $\begin{array}{c}\text { ESTUDIOS } \\
\text { TÉCNICOS }\end{array}$ & $\begin{array}{c}\text { NO } \\
\text { CALIFICADO }\end{array}$ & $\begin{array}{c}\text { COSTO (S/.) } \\
\text { (mensual) }\end{array}$ & $\begin{array}{r}\text { COSTO (S/.) } \\
\text { (anual) }\end{array}$ \\
\hline Gerente general & $\mathrm{x}$ & & & 15,000 & 225,000 \\
\hline Analista de Administración & $\mathrm{x}$ & & & 3,000 & 45,000 \\
\hline Analista comercial & $\mathrm{x}$ & $\mathrm{x}$ & 3,000 & 45,000 \\
\hline $\begin{array}{l}\text { Community Manager } \\
\text { (Manejo redes sociales) }\end{array}$ & & & $\mathrm{x}$ & 2,000 & 30,000 \\
\hline Practicante & & $\mathrm{x}$ & 800 & 12,000 \\
\hline Practicante & & $\mathrm{x}$ & 800 & 12,000 \\
\hline Vigilante & & & 750 & 11,250 \\
\hline TOTAL & & & $\mathbf{2 5 , 3 5 0}$ & $\mathbf{3 8 0 , 2 5 0}$ \\
\hline
\end{tabular}

Elaboración propia

\section{Presupuesto de ingresos y egresos}

\section{Presupuesto de ingreso por ventas}

Tabla 6.7.

Presupuesto de Ingresos

\begin{tabular}{|c|c|c|c|c|c|c|c|c|c|c|c|}
\hline \multicolumn{12}{|c|}{ VENTAS (SOLES) } \\
\hline RUBRO & 2015 & 2016 & 2017 & 2018 & 2019 & 2020 & 2021 & 2022 & 2023 & 2024 & 2025 \\
\hline PRECIO & & 18.50 & 18.50 & 18.50 & 18.50 & 18.50 & 18.50 & 18.50 & 18.50 & 18.50 & \\
\hline CANTIDAD & & \begin{tabular}{|l|}
$77,759.36$ \\
\end{tabular} & $80,245.44$ & \begin{tabular}{|l|}
$82,731.52$ \\
\end{tabular} & $85,217.60$ & $87,703.68$ & \begin{tabular}{|c|}
$90,189.76$ \\
\end{tabular} & 92,675.84 & \begin{tabular}{|l|l|}
$95,161.93$ \\
\end{tabular} & $97,648.01$ & \begin{tabular}{|l|l|}
$100,134.09$ \\
\end{tabular} \\
\hline TOTAL & & $1,438,548$ & $1,484,541$ & $1,530,533$ & $1,576,526$ & $1,622,518$ & $1,668,511$ & $1,714,503$ & $1,760,496$ & $1,806,488$ & $1,852,481$ \\
\hline
\end{tabular}

Elaboración Propia

2. Presupuesto operativo de costos de materias primas (mano de obra directa, depreciación, costos indirectos de fabricación, costo de producción)

Tabla 6.8.

Presupuesto de depreciación fabril

\begin{tabular}{|c|c|c|c|c|c|c|c|c|c|c|c|}
\hline \multicolumn{12}{|l|}{ DEPRECIACIÓN ANUAL FABRIL (SOLES) } \\
\hline RUBRO & 2015 & 2016 & 2017 & 2018 & 2019 & 2020 & 2021 & 2022 & 2023 & 2024 & 2025 \\
\hline MAQUINARIA (10 años) & 131960 & 13196 & 13196 & 13196 & 13196 & 13196 & 13196 & 13196 & 13196 & 13196 & 13196 \\
\hline INSTALACIONES ELECT Y SAN (20 años & 15000 & 750 & 750 & 750 & 750 & 750 & 750 & 750 & 750 & 750 & 750 \\
\hline OBRA CIVIL (EDF+CONT) (20 años) & 85000 & 4250 & 4250 & 4250 & 4250 & 4250 & 4250 & 4250 & 4250 & 4250 & 4250 \\
\hline TOTAL & 231960 & 18196 & 18196 & 18196 & 18196 & 18196 & 18196 & 18196 & 18196 & 18196 & 18196 \\
\hline
\end{tabular}

Elaboración propia 
Tabla 6.9.

Presupuesto de depreciación no fabril

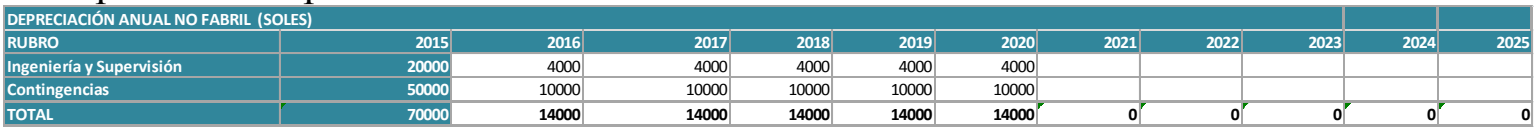

Elaboración propia

Tabla 6.10.

Presupuesto de costos de producción

\begin{tabular}{|c|c|c|c|c|c|c|c|c|c|c|c|}
\hline \multicolumn{12}{|l|}{ RESUPUESTO DE COSTO DE PRODUCCIÓ } \\
\hline RUBRO & 2015 & 2016 & 2017 & 2018 & 2019 & 2020 & 2021 & 2022 & 2023 & 2024 & 2025 \\
\hline TOTAL COSTOS DIRECTOS & & 413,758 & 426,986 & 440,214 & 453,443 & 466,671 & 479,900 & 493,128 & 506,357 & 519,585 & 532,813 \\
\hline TOTAL COSTOS INDIRECTOS & & 16,562 & 16,579 & 16,596 & 16,612 & 16,629 & 16,645 & 16,662 & 16,679 & 16,695 & 16,712 \\
\hline TOTAL COSTO MOD & & 121,500 & 121,500 & 121,500 & 121,500 & 121,500 & 121,500 & 121,500 & 121,500 & 121,500 & 121,500 \\
\hline COSTO DE PRODUCCIÓN (SOLES) & & 551,820 & 565,065 & 578,310 & 591,555 & 604,800 & 618,045 & 631,290 & 644,535 & 657,780 & 671,026 \\
\hline DEPRECIACIÓN ANUAL FABRIL (SOLES) & & 18196 & 18196 & 18196 & 18196 & 18196 & 18196 & 18196 & 18196 & 18196 & 18196 \\
\hline TOTAL & & 570,016 & 583,261 & 596,506 & 609,751 & 622,996 & 636,241 & 649,486 & 662,731 & 675,976 & 689,222 \\
\hline
\end{tabular}

Elaboración propia

3. Presupuesto operativo de gastos administrativos (ventas, marketing, distribución, atención a clientes y gastos generales)

Tabla 6.11.

Presupuesto de gastos generales

\begin{tabular}{|c|c|c|c|c|c|c|c|c|c|c|c|}
\hline \multicolumn{12}{|l|}{ PRESUPUESTO DE GASTOS GENERAL } \\
\hline RUBRO & 2015 & 2016 & 2017 & 2018 & 2019 & 2020 & 2021 & 2022 & 2023 & 2024 & 2025 \\
\hline GASTOS ADM Y VTAS & & 20,000 & 20,000 & 20,000 & 20,000 & 20,000 & 20,000 & 20,000 & 20,000 & 20,000 & 20,000 \\
\hline TOTAL COSTO MOI & & 380,250 & 380,250 & 380,250 & 380,250 & 380,250 & 380,250 & 380,250 & 380,250 & 380,250 & 380,250 \\
\hline DEPRECIACIÓN ANUAL NO FABRIL & & 14000 & 14000 & 14000 & 14000 & 14000 & 0 & 0 & 0 & 0 & 0 \\
\hline TOTAL & & 414,250 & 414,250 & 414,250 & 414,250 & 414,250 & 400,250 & 400,250 & 400,250 & 400,250 & 400,250 \\
\hline
\end{tabular}

Elaboración propia

\section{Flujo de fondos netos}

Debido a que no se cuenta con todo el dinero necesario para completar la inversión por parte de los socios, se deberá pedir financiamiento al Banco del $60 \%$ del total de la inversión, ya que sólo se cuenta como capital propio con el 40\%. Para poder realizar los flujos económicos y financieros se calculará el servicio de la deuda a la que se va a acceder. El banco nos proporciona una tasa de interés anual del 12\% con 5 cuotas fijas anuales y un año de gracia. 
Tabla 6.12.

Flujo de la deuda

SERVICIO DE LA DEUDA

INVERSIÓN TOTAL

DEUDA

1 AÑO GRACIA PARCIAL

CAPITAL

$1,650,940100 \%$

INTERÉS ANUAL

AÑo

$990,56460 \%$

$660,37640 \%$

\begin{tabular}{|c|c|c|c|c|c|}
\hline DEUDA & 990,564 & $60 \%$ & & & \\
\hline CAPITAL & 660,376 & $40 \%$ & & & \\
\hline INTERÉS ANUAL & $12 \%$ & & & & \\
\hline AÑo & SALDO CAPITAL & AMORTIZACIÓN & INTERÉS & CUOTA & SALDO \\
\hline 2016 & 990,564 & - & 118,868 & - & 990,564 \\
\hline 2017 & $1,109,431$ & 174,635 & 133,132 & 307,767 & 934,796 \\
\hline 2018 & 934,796 & 195,592 & $112,175.54$ & 307,767 & 739,205 \\
\hline 2019 & 739,205 & 219,063 & $88,704.55$ & 307,767 & 520,142 \\
\hline 2020 & 520,142 & 245,350 & $62,417.05$ & 307,767 & 274,792 \\
\hline 2021 & 274,792 & 274,792 & $32,975.05$ & 307,767 & - \\
\hline
\end{tabular}

Elaboración propia

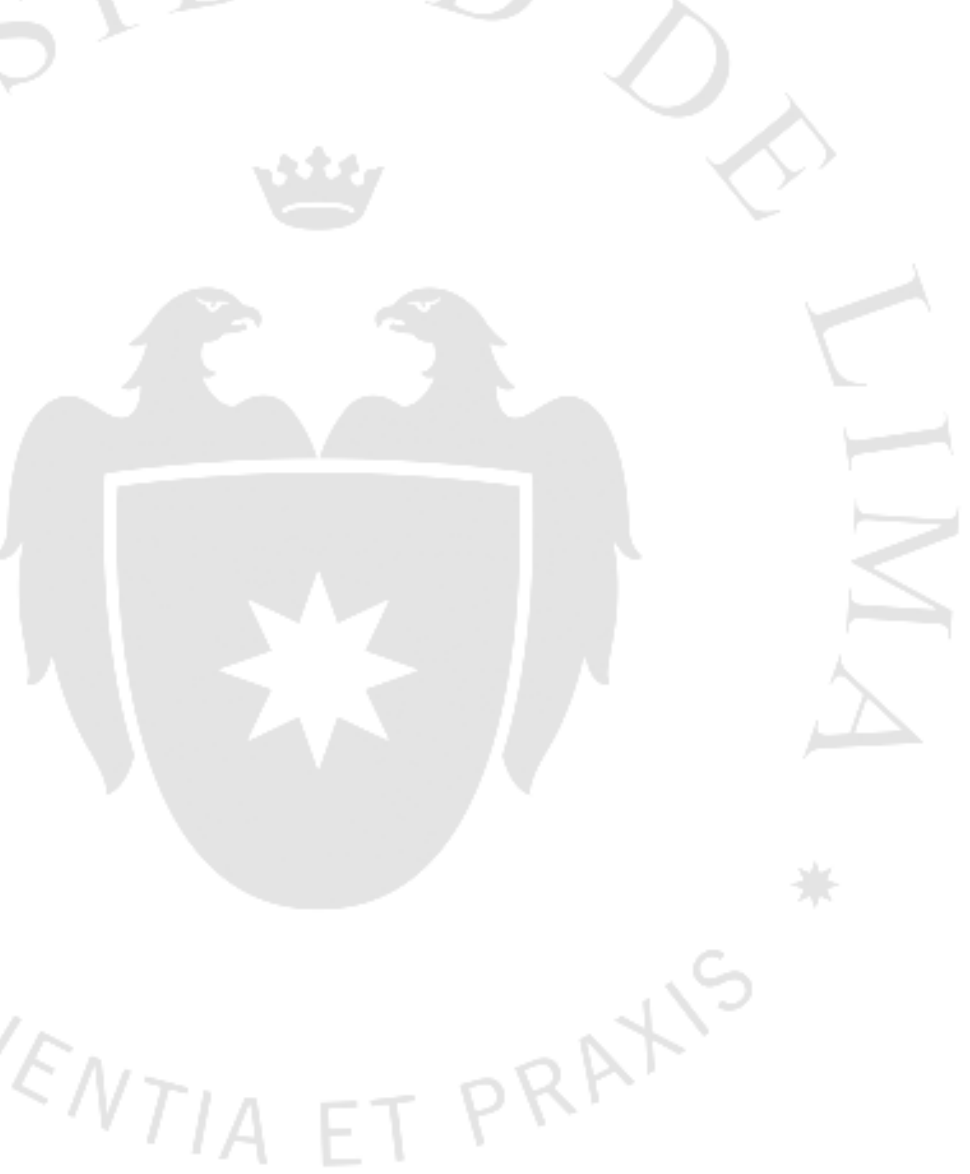




\section{Flujo de fondos económico}

Tabla 6.13.

Flujo Económico

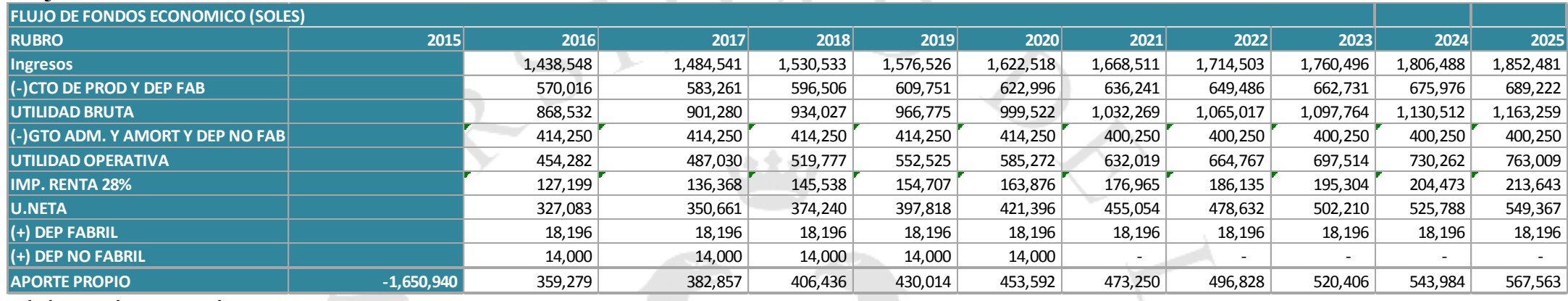

Elaboración propia

\section{Flujo de fondos Financiero}

Tabla 6.14.

Flujo financiero

\begin{tabular}{|c|c|c|c|c|c|c|c|c|c|c|c|}
\hline \multicolumn{12}{|c|}{ Flujo de fondos Financiero } \\
\hline \multicolumn{12}{|l|}{ FLUJO DE FONDOS FINANCIERO (SOLES) } \\
\hline INVERSIÓN & 1650939.7 & & & & 10 & & & & & & \\
\hline Ingresos & & $1,438,548$ & $1,484,541$ & $1,530,533$ & $1,576,526$ & $1,622,518$ & $1,668,511$ & $1,714,503$ & $1,760,496$ & $1,806,488$ & $1,852,481$ \\
\hline (-)CTO DE PROD Y DEP FAB & & 570,016 & 583,261 & 596,506 & 609,751 & 622,996 & 636,241 & 649,486 & 662,731 & 675,976 & 689,222 \\
\hline UTILIDAD BRUTA & & 868,532 & 901,280 & 934,027 & 966,775 & 999,522 & $1,032,269$ & $1,065,017$ & $1,097,764$ & $1,130,512$ & $1,163,259$ \\
\hline (-)GTO ADM. Y AMORT Y DEP NO FAB & & 414,250 & 414,250 & $414,250^{\circ}$ & 414,250 & 414,250 & 400,250 & 400,250 & 400,250 & 400,250 & 400,250 \\
\hline UTILIDAD OPERATIVA & & 454,282 & 487,030 & 519,777 & 552,525 & 585,272 & 632,019 & 664,767 & 697,514 & 730,262 & 763,009 \\
\hline (-)GASTOS FINANC & & 118,868 & 133,132 & 112,176 & 88,705 & 62,417 & 32,975 & - & - & - & - \\
\hline U.A.I.R & & 335,415 & 353,898 & 407,602 & 463,820 & 522,855 & 599,044 & 664,767 & 697,514 & 730,262 & 763,009 \\
\hline IMP. RENTA $28 \%$ & & 93,916 & 99,091 & $114,128^{\prime}$ & 129,870 & 146,399 & 167,732 & $186,135^{\prime}$ & 195,304 & $204,473^{\prime}$ & 213,643 \\
\hline U.NETA & & 241,498 & 254,806 & 293,473 & 333,950 & 376,456 & 431,312 & 478,632 & 502,210 & 525,788 & 549,367 \\
\hline (+) DEP NO FABRIL & & 14,000 & 14,000 & $-14,000$ & 14,000 & 14,000 & - & - & - & - & - \\
\hline (-)AMORT PREST & & - & 174,635 & 195,592 & 219,063 & 245,350 & 274,792 & - & - & - & - \\
\hline APORTE PROPIO & $-660,376$ & 273,694 & 112,367 & 130,078 & 147,084 & 163,302 & 174,716 & 496,828 & 520,406 & 543,984 & 567,563 \\
\hline
\end{tabular}

Elaboración propia 


\section{CAPÍTULO VII. EVALUACIÓN ECONÓMICA Y}

\section{FINANCIERA DEL PROYECTO}

\section{Evaluación económica: VAN, TIR, B/C, PR}

Para hallar el Valor actual neto, se utilizó la siguiente fórmula:

$$
\mathbf{V A N}=-\mathbf{A}+\mathbf{Q 1} /(1+\mathbf{i})+\mathbf{Q} 2 /\left((1+\mathbf{i})^{\wedge} 2\right)+\ldots . .+\mathbf{Q n} /\left((1+\mathbf{i})^{\wedge} \mathbf{n}\right)
$$

Dónde:

A: Inversión inicial

Q: Flujos de caja

$\mathrm{N}$ : número de años

I: tasa de descuento

Concluimos que:

Sí VAN > 0, el proyecto es rentable.

$\mathrm{Si} \mathrm{VAN}=0$, el proyecto es postergado

Si $\mathrm{VAN}<0$, el proyecto no es rentable.

Entonces concluimos, teniendo como datos A: S/.1 650253 N: 10 e i: $12.58 \%$

$\mathrm{VAN}=\mathrm{S} / .785300 .89$ con lo que determinamos que el proyecto es viable.

Para hallar la Tasa Interna de Retorno, se utilizó la siguiente fórmula:

$$
\mathrm{TIR}=-\mathrm{A}+\mathrm{Q1} /(1+\mathbf{r})+\mathrm{Q} 2 /(1+r) \wedge 2+\ldots .+\mathrm{Qn} /(1+\mathbf{r})^{\wedge} \mathbf{n}=\mathbf{0}
$$

Dónde:
A: Inversión inicial
Q: Flujos de caja
N: número de años
r: tasa de descuento 
Concluimos que:

Sí TIR > tasa de descuento, el proyecto es aceptable.

Si TIR = tasa de descuento, el proyecto es postergado.

Si TIR $<$ tasa de descuento, el proyecto no es rentable.

Entonces concluimos, teniendo como datos A: S/.1 650253 N: 10 e i: $12.58 \%$

TIR $=22.48 \%$ que es mayor a la tasa de descuento, con lo que determinamos que el proyecto es viable.

Para hallar el Beneficio/ Costo, se utilizó la siguiente metodología:

Se obtiene con los datos del VAN; cuando se divide la sumatoria de todos los beneficios entre la sumatoria de los costos.

Si $\mathrm{BC}>1$ : El proyecto es aceptable.

Si $\mathrm{BC}=0$ cercano a 1 : El proyecto es postergado.

Si BC $<1$ : El proyecto no es aceptable.

Entonces concluimos, teniendo como datos VAN= S/. 785300.89 tasa: $12.58 \%$ que el $\mathrm{B} / \mathrm{C}=1.48$ que es mayor a 1 , con lo que determinamos que el proyecto es viable.

Tabla 7.1. Evaluación económica

\begin{tabular}{|l|r|}
\hline VAN ECONOMICO & $\mathrm{S} / .785,300.89$ \\
\hline TIR ECONOMICO & $22.48 \%$ \\
\hline B/C ECONOMICO & 1.48 \\
\hline COK & $12.58 \%$ \\
\hline
\end{tabular}

Elaboración propia 


\section{Evaluación financiera: VAN, TIR, B/C, PR}

Para hallar los datos del VAN y el TIR financiero se utilizó el mismo procedimiento que para hallar el económico, sólo que se utilizaron los datos del flujo Financiero.

Tabla 7.2.

Evaluación financiero

\begin{tabular}{|l|r|}
\hline VAN FINANCIERO & S/. 809,464.58 \\
\hline TIR FINANCIERO & $31.90 \%$ \\
\hline B/C FINANCIERO & 2.23 \\
\hline COK & $12.58 \%$ \\
\hline
\end{tabular}

Elaboración propia

\section{Análisis de los resultados económicos y financieros del proyecto}

Para poder determinar si el proyecto es viables, se determinará el VAN, TIR y B/C para poder tomar una decisión.

Primero debemos hallar el valor del COK utilizando el Método CAMP (Capital Asset

Pricing Model). CAPM $=\mathrm{t}($ libre riesgo $)+\mathrm{B}(\mathrm{t}($ mercado $)-\mathrm{t}($ riesgo $)+\mathrm{t}($ riesgo país $))$

Datos:

- Tasa de libre riesgo: 5.78 (Reporte Financiero Centrum La Católica)

- Tasa de riesgo país: 2.30 (La Republica)

- Tasa de riesgo LATAM: 4.19 (La Republica)

- Tasa de riesgo mercado: 8.43 (Reporte Financiero Centrum La Católica)

- Beta: 1.04 (Empresa de consumo masivo Alicorp)

$\mathrm{CAPM}=5.78+1.04(8.43-4.19+2.3)=12.58$ 
Luego de evaluar el VAN económico, se pudo ver que el valor que nos da es positivo, lo cual nos dice que el proyecto es viable. Al evaluar el TIR económico y que el valor que obtuvimos es mayor al valor del COK que se determinó (12.58\%), concluimos que el proyecto también es viable. Y finalmente, al evaluar el ratio B/C económico nos da un valor mayor a 1 con el que se concluirá también que el proyecto es viable.

Al igual que en la evaluación económico, cuando se realizó la financiera también todos los ratios nos salieron positivos, lo cual nos da la satisfacción de saber que nuestro proyecto es viable.

\section{Análisis de Sensibilidad}

El análisis de sensibilidad lo realizamos para medir como reaccionaria nuestro modelo frente a un decrecimiento en nuestras ventas. Esto se puede ocasionar por una recesión en la economía, cambio de hábitos de consumo, entre otros.

Hemos realizado los cálculos frente a un posible decrecimiento del 10\% de las ventas.

Los resultados obtenidos son favorables ya que podemos afrontar una caída de esta magnitud en nuestras ventas. 
Tabla 7.3.

Flujo Económico (análisis sensibilidad)

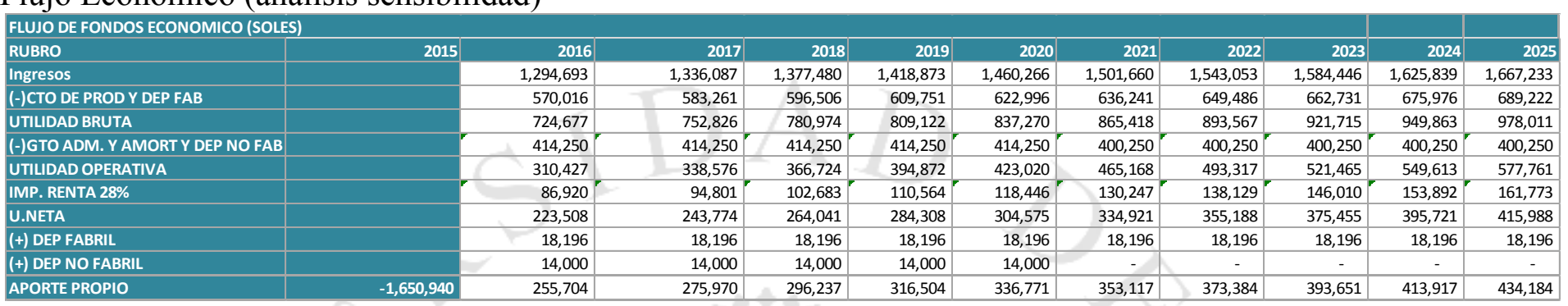

\section{Elaboración propia}

Tabla 7.4.

Flujo financiero (análisis sensibilidad)

\begin{tabular}{|c|c|c|c|c|c|c|c|c|c|c|c|}
\hline \multicolumn{12}{|l|}{ FLUJO DE FONDOS FINANCIERO (SOLES) } \\
\hline INVERSIÓN & 1650939.7 & & & & & & & & & & \\
\hline Ingresos & & $1,294,693$ & $1,336,087$ & $1,377,480$ & $1,418,873$ & $1,460,266$ & $1,501,660$ & $1,543,053$ & $1,584,446$ & $1,625,839$ & $1,667,233$ \\
\hline (-)CTO DE PROD Y DEP FAB & & 570,016 & 583,261 & 596,506 & 609,751 & 622,996 & 636,241 & 649,486 & 662,731 & 675,976 & 689,222 \\
\hline (-)GTO ADM. Y AMORT Y DEP NO FAB & & $414,250^{\circ}$ & 414,250 & $414,250^{\prime}$ & $414,250^{\circ}$ & $414,250^{\circ}$ & $400,250^{\prime \prime}$ & 400,250 & 400,250 & 400,250 & 400,250 \\
\hline UTILLDAD OPERATIVA & & 310,427 & 338,576 & 366,724 & 394,872 & 423,020 & 465,168 & 493,317 & 521,465 & 549,613 & 577,761 \\
\hline (-)GASTOS FINANC & & 118,868 & 133,132 & 112,176 & 88,705 & 62,417 & 32,975 & - & - & - & \\
\hline U.A.I.R & & 191,560 & 205,444 & 254,548 & 306,167 & 360,603 & 432,193 & 493,317 & 521,465 & 549,613 & 577,761 \\
\hline IMP. RENTA $28 \%$ & & $53,637^{\prime \prime}$ & 57,524 & 71,274 & 85,727 & $100,969^{\prime \prime}$ & $121,014^{\prime}$ & 138,129 & 146,010 & 153,892 & 161,773 \\
\hline (+) DEP NO FABRIL & & 14,000 & 14,000 & 14,000 & 14,000 & 14,000 & - & - & - & - & - \\
\hline (-)AMORT PREST & & - & 174,635 & 195,592 & 219,063 & 245,350 & 274,792 & - & - & - & \\
\hline APORTE PROPIO & $-660,376$ & 170,119 & 5,480 & 19,879 & 33,574 & 46,480 & 54,583 & 373,384 & 393,651 & 413,917 & 434,184 \\
\hline
\end{tabular}

Elaboración propia

Tabla 7.5.

Evaluación económica (análisis sensibilidad)

VAN ECONOMICO

TIR ECONOMICO

B/C ECONOMICO

COK

Elaboración propia
Tabla 7.6.

Evaluación financiera (análisis sensibilidad) VAN FINANCIERO

TIR FINANCIERO S/. $173,097.76$

B/C FINANCIERO $16.70 \%$

COK

1.26

Elaboración propia 


\section{CONCLUSIONES Y RECOMENDACIONES}

- Con respecto al proceso de producción, no se está considerando los procesos de triturado y de tamizado ya que la semilla de sacha Inchi no requiere de excesiva presión para poder obtener aceite. Solo es necesario el prensado.

- El aceite de Sacha Inchi no puede ser expuesto a altas temperaturas ya que pierde sus principales características nutricionales. Por ello se debe de tener cuidado en el proceso de producción en etapas como la del prensado.

- Para poder determinar un demanda realista y adecuada al mercado meta, se debe enfocar puntualmente a los clientes a los que queremos llegar, es necesario realizar una segmentación adecuada del mercado, investigando arduamente las bases de datos y realizando encuestas orientadas al consumo del producto, para poder obtener datos reales que se puedan aplicar a nuestro trabajo.

- Para poder realizar un plano adecuado, optimizar los espacios de trabajo y a su vez, minimizar los costos del proyecto y la producción, se debe realizar un estudio adecuado, incluyendo los análisis del Guerchet, diagrama relacional, DOP y los ratios hallados en el manual de distribución de planta para determinar el tamaño necesario de planta y su distribución.

- Al momento de realizar la elección de proveedores, se debe hacer un arduo estudio de proveedores para determinar cuál nos ofrece el mejor precio, mayor disponibilidad de producto y mejor calidad en las semillas.

- Para poder realizar un flujo de fondos financiero y económico, se debe realizar un estudio detallado de los costos, tomando en cuenta todos los factores importantes 
que pueden influir en el precio del producto, los insumos y los activos de la empresa.

- Al momento de comercializar nuestro producto, se debe de enfocar en los valores agregados que este posee como su alto valor nutricional, calidad y beneficios. Esto ayudará a diferenciar este producto de la competencia y poder incrementar las ventas.

- No existe gran variedad de aceite de Sacha Inchi en los supermercados, esto nos da una gran ventaja frente a los demás competidores. Por ello estamos ingresando directamente a este canal de venta. La mayoría de proveedores de este producto se enfoca en tiendas naturistas y en boticas.

- Para localizar adecuadamente nuestra planta se deberá de analizar todos los factores importantes que pueden influenciar en los costos de nuestro proyecto. El agua, electricidad, costos de terreno, entre otros, son algunos de los puntos que pueden afectar de manera importante nuestra decisión.

- Al momento de elegir nuestra maquinaria, debemos de considerar la demanda que vamos a satisfacer. Con este análisis podemos evaluar mejor la capacidad necesaria en cada máquina para no producir en exceso e incrementar nuestros costos.

- Al finalizar el proyecto debemos realizar un análisis de sensibilidad para analizar como reaccionaríamos frente a alguna variación en el mercado y en la venta del producto. 


\section{REFERENCIAS}

- Agroindustrias

Amazónicas

SAC.

Recuperado

de:

http://www.incainchi.com.pe/index.htm

- Catalogo Virtual Santa Natura. Recuperado de: http://santanatura.com.pe/tiendavirtual/index.php?option=com_frontpage\&Item $\mathrm{id}=1$

- Catalogo Virtual Tienda Wong. Recuperado de: http://www.ewong.com/

- Chang Cornejo, Christian Benjamín.(2008). "Estudio preliminar para la instalación de una empresa productora de aceite de semilla de la vid". (Seminario de investigación). Universidad de Lima

- Conroy Ferrecio, Alessandra.(2008). "Estudio preliminar para la implementación de una planta productora de crema anti envejecimiento a base de sacha Inchi". (Seminario de investigación). Universidad de Lima

- Escudero Asin, Andrea.(2010). "Estudio preliminar para la instalación de una planta productora de chocolate con sacha Inchi". (Seminario de investigación). Universidad de Lima.

- Ficha Técnica Sacha Inchi

○ http://www.incainchi.es/pdf/ficha.pdf

O http://tienda.wong.com.pe

- Información acerca de las enfermedades que previene el aceite

○ http://radio.rpp.com.pe/saludenrpp/el-sacha-inchi-y-sus-propiedades/

- Información inmobiliaria

○ http://peru.inmobiliaria.com/ 
○ http://www.colliers.com/es-pe/peru

- Información Maquinaria para el proceso

○ http://www.grippo.com/post/436709/Maquinas\%20para\%20extraer\%20 aceite $\% 20$ de\%20Olivo\%20directo\%20desde\%20china.html

○ http://spanish.alibaba.com/product-gs/sunflower-seed-kernel-machineseed-huller-730156979.html

○ http://spanish.alibaba.com/product-gs/oil-seeds-flaker-crusher285965389.html

○ www.ajonjoli-peru.com

○ http://www.gx.com.ar/?gclid=CP6BprSPurcCFc4DOgodjSsA3Q

- Investigación de Mercados. APEIM.

○ http://www.apeim.com.pe/wp-content/themes/apeim/docs/nse/APEIMNSE-2013.pdf

- Investigación de Niveles socioeconómicos 2013. Asociación Peruana de La exportación de aceite de oliva cae un $12,5 \%$ en los tres últimos meses por la crisis

○ http://www.elconfidencial.com/mercados/archivo/2009/02/25/56_expor tacion_aceite_oliva_ultimos_meses_crisis.html

- Nancy Chasquibol, M.Carmen Pérez-Camino, Wenceslao Moreda, M. Angeles Garín, Juan C. Yácono. Caracterización química y autenticación del aceite de tres ecotipos de las semillas del Sacha Inchi (Plunkenetia volubilis L.), cultivados en la región del Departamento de San Martín, Facultad de Ingeniería 
Industrial, Instituto de Investigación Científica (IDIC), Universidad de Lima, 2012

- Publicación sobre el dia mundial de la población. Instituto Nacional de Estadística e Informática. INEI.

○ http://www.inei.gob.pe/media/MenuRecursivo/publicaciones_digitales/ Est/Lib1157/libro.pdf

- Sacha Inchi

O http://www.inkanat.com/es/infosalud/sacha-inchi.html

- Sacha Inchi. Prevención.

○ http://afrontarelcancerjuntoalafamilia.ning.com/profiles/blogs/losbeneficios-del-aceite-sach

\section{- Bases de Datos}

- INEI

- Ipsos Apoyo
- Euromonitor

- Data Trade 


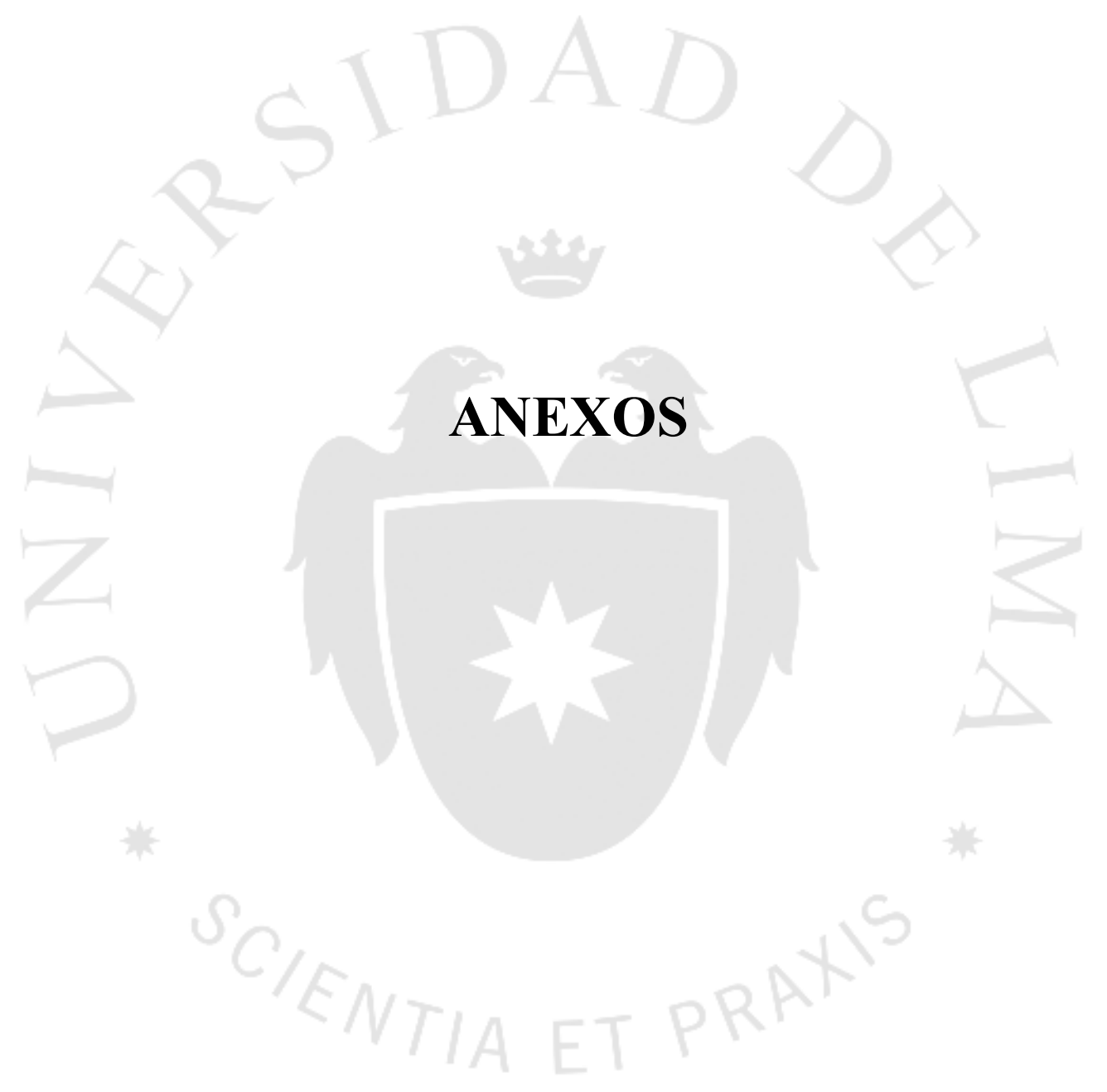




\section{ANEXO 1: PBI per cápita}

Producto Interno Bruto (PIB) per capita (US\$)

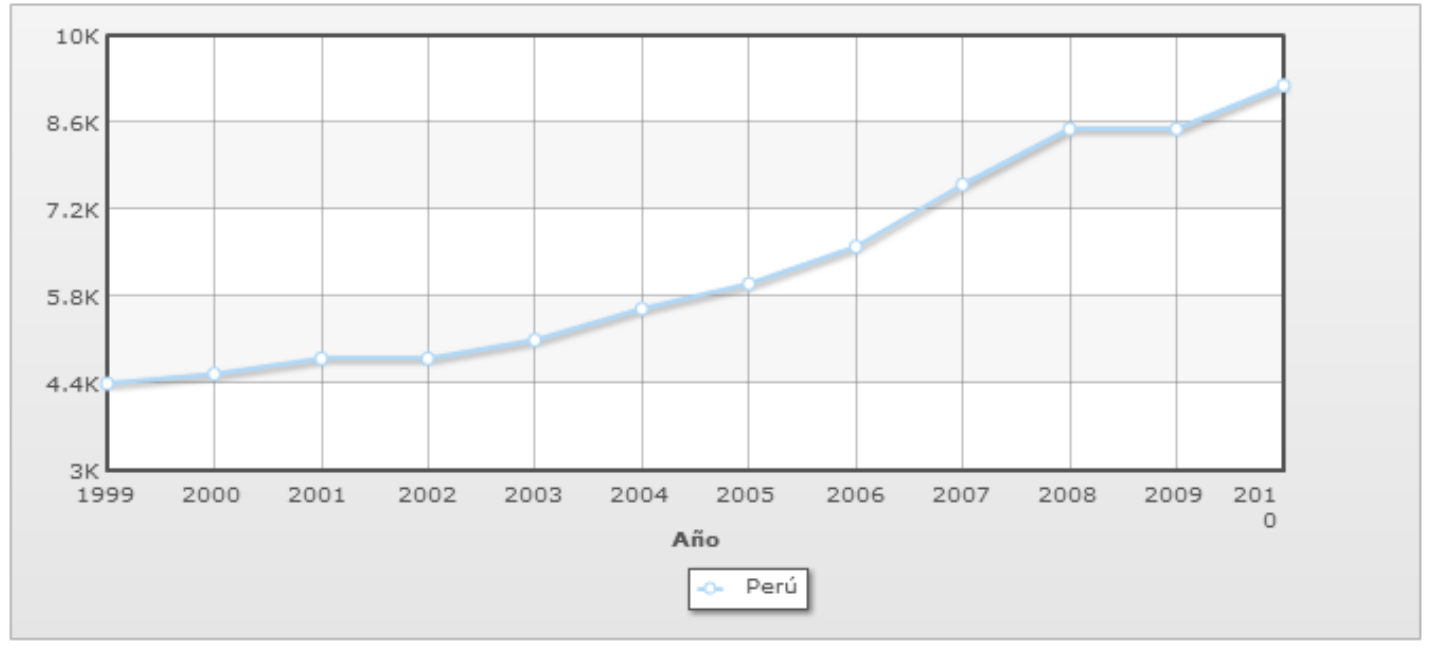

Waiting

\begin{tabular}{|l|c|c|c|c|c|c|c|c|c|c|c|c|}
\hline Country & 1999 & 2000 & 2001 & 2002 & 2003 & 2004 & 2005 & 2006 & 2007 & 2008 & 2009 & 2010 \\
\hline Perú & 4.400 & 4.550 & 4.800 & 4.800 & 5.100 & 5.600 & 6.000 & 6.600 & 7.600 & 8.500 & 8.500 & 9.200 \\
\hline
\end{tabular}

- Fuente: http://www.indexmundi.com/g/g.aspx?c=pe\&v=67\&l=es 


\section{ANEXO 2: Encuesta}

1. ¿Consume aceites vegetales?
a. $\mathrm{Si}$
b. No

3. ¿Compran aceites diferentes a los comerciales? Por ejemplo: Soja, Sacha Inchi, Oliva
a. Si
b. No

2. ¿Con que frecuencia los consume?
a. Diario
b. Semanal
c. Cada dos semanas
d. Mensual

4. ¿Compraría aceite de Sacha Inchi sabiendo los valores nutritivos y ventajas que posee?
a. $\mathrm{Si}$
b. No

5. Señale el grado de intensidad de su posible compra.
a. Poco Probable
b. Probable
c. Muy Probable
d. De todas maneras

6. ¿Cuánto estaría dispuesto a pagar por una botella de vidrio de $250 \mathrm{ml}$ ?
a. 10 soles
b. 15 soles
c. 20 soles
d. 25 soles 
7. ¿En qué momento consumiría el producto?
b. Desayunos
c. Almuerzos
d. Cena
e. Aperitivos

a. Preparación de comidas

8. ¿Dónde le gustaría encontrarlo?
a. Bodega
b. Autoservicios (Grifos)
c. Supermercado
d. Mercado

9. Edad
a. Menor de 18 años
b. De 18 a 30 años
c. De 30 a 50 años
d. Mayor de 50 años

10. Distrito en el que vive
a. Surco, La Molina, San Isidro, Miraflores, San Borja
b. Jesús María, Lince, Pueblo Libre, Magdalena
c. Surquillo, Barranco, Chorrillos, Cercado, La Victoria, Independencia
d. Otros 


\section{ANEXO 3: Población peruana y nivel de educación}

\begin{tabular}{|c|c|c|c|c|c|c|c|c|c|}
\hline \multicolumn{10}{|c|}{$\begin{array}{l}\text { CUADRO N² } 2.3 \\
\text { PROVINCIA DE LIMA: POBLACIÓN CENSADA DE } 15 \text { Y MÁS AÑOS DE EDAD POR NIVEL DE EDUCACIÓN } \\
\text { ALCANZADO, SEGÚN DISTRITO, } 2007 \\
\text { (Porcentaje) }\end{array}$} \\
\hline \multirow{3}{*}{ Distrito } & \multirow{3}{*}{ Total } & \multicolumn{8}{|c|}{ Nivel de educación } \\
\hline & & \multicolumn{4}{|c|}{ A lo más primaria } & \multirow[b]{2}{*}{ Secundaria } & \multicolumn{3}{|c|}{ Superior } \\
\hline & & $\begin{array}{l}\text { Sub } \\
\text { total }\end{array}$ & $\begin{array}{r}\text { Sin } \\
\text { nivel }\end{array}$ & Inicial & Primaria & & $\begin{array}{l}\text { Sub } \\
\text { total }\end{array}$ & $\begin{array}{l}\text { Superior no } \\
\text { universitaria }\end{array}$ & $\begin{array}{r}\text { Superior } \\
\text { universitaria }\end{array}$ \\
\hline Total & 5702643 & 14,2 & 2,3 & 0,1 & 11,8 & 42,9 & 42,9 & 20,0 & 22,9 \\
\hline Lima & 235656 & 12,8 & 1,5 & 0,1 & 11,2 & 44,3 & 42,9 & 18,5 & 24,4 \\
\hline Ancón & 23239 & 18,8 & 2,0 & 0,2 & 16,6 & 55,4 & 25,8 & 15,6 & 10,2 \\
\hline Ate & 344954 & 17,1 & 2,4 & 0,1 & 14,6 & 51,7 & 31,2 & 15,0 & 16,2 \\
\hline Barranco & 27664 & 9,0 & 0,8 & 0,1 & 8,1 & 37,0 & 54,0 & 20,0 & 34,0 \\
\hline Breña & 65455 & 9,8 & 0,8 & 0,1 & 8,9 & 38,8 & 51,4 & 22,6 & 28,8 \\
\hline Carabayllo & 149751 & 19,1 & 2,8 & 0,1 & 16,2 & 51,5 & 29,4 & 16,7 & 12,7 \\
\hline Chaclacayo & 31087 & 14,3 & 2,4 & 0,1 & 11,8 & 41,7 & 44,0 & 18,6 & 25,4 \\
\hline Chorrillos & 214549 & 14,8 & 1,9 & 0,1 & 12,8 & 46,4 & 38,8 & 19,5 & 19,3 \\
\hline Cieneguilla & 19467 & 21,7 & 6,4 & 0,1 & 15,2 & 43,3 & 35,0 & 20,7 & 14,3 \\
\hline Comas & 360143 & 15,1 & 2,9 & 0,1 & 12,1 & 42,4 & 42,5 & 23,1 & 19,4 \\
\hline El Agustino & 132212 & 18,9 & 2,7 & 0,1 & 16,1 & 53,8 & 27,3 & 14,6 & 12,7 \\
\hline Independencia & 154176 & 16,9 & 3,6 & 0,1 & 13,2 & 42,8 & 40,3 & 22,5 & 17,8 \\
\hline Jesús María & 55747 & 6,3 & 0,6 & 0,0 & 5,7 & 27,1 & 66,6 & 19,9 & 46,7 \\
\hline La Molina & $10 \overline{7} \overline{713}$ & $\overline{5}, \overline{7}$ & $\overline{0,7}$ & 0,0 & 5,0 & 25,4 & 68,9 & 15,8 & 53,1 \\
\hline La Victoria & 149849 & 14,3 & 1,5 & 0,1 & 12,7 & 48,0 & 37,7 & 16,8 & 20,9 \\
\hline Lince & 46173 & 7,4 & 0,6 & 0,0 & 6,8 & 32,8 & 59,8 & 21,2 & 38,6 \\
\hline Los Olivos & 241202 & 12,3 & 1,4 & 0,1 & 10,8 & 43,1 & 44,6 & 20,7 & 23,9 \\
\hline Lurigancho & 121184 & 18,6 & 4,5 & 0,2 & 13,9 & 42,2 & 39,2 & 17,9 & 21,3 \\
\hline Lurín & 44152 & 19,8 & 2,6 & 0,1 & 17,1 & 54,2 & 26,0 & 15,3 & 10,7 \\
\hline Magdalena del Mar & 41646 & 7,4 & 0,9 & 0,1 & 6,4 & 31,3 & 61,3 & 20,9 & 40,4 \\
\hline Magdalena Vieja & 61483 & 6,7 & 0,6 & 0,0 & 6,1 & 28,3 & 65,0 & 20,2 & 44,8 \\
\hline Miraflores & 73660 & 4,3 & 0,4 & 0,0 & 3,9 & 23,8 & 71,9 & 17,0 & 54,9 \\
\hline Pachacamac & 46589 & 21,6 & 4,9 & 0,2 & 16,5 & 48,8 & 29,6 & 18,6 & 11,0 \\
\hline Pucusana & 7239 & 21,4 & 2,1 & 0,2 & 19,1 & 55,6 & 23,0 & 14,7 & 8,3 \\
\hline Puente Piedra & 163109 & 19,5 & 4,2 & 0,1 & 15,2 & 47,3 & 33,2 & 20,4 & 12,8 \\
\hline Punta Hermosa & 4276 & 14,3 & 2,0 & 0,0 & 12,3 & 47,7 & 38,0 & 19,1 & 18,9 \\
\hline Punta Negra & 3848 & 14,6 & 1,9 & 0,1 & 12,6 & 47,9 & 37,5 & 19,5 & 18,0 \\
\hline Rimac & 135111 & 14,7 & 1,7 & 0,1 & 12,9 & 47,8 & 37,5 & 18,2 & 19,3 \\
\hline San Bartolo & 4306 & 14,4 & 3,2 & 0,0 & 11,2 & 47,0 & 38,6 & 21,1 & 17,5 \\
\hline San Borja & 87635 & 4,8 & 0,6 & 0,0 & 4,2 & 23,8 & 71,4 & 16,2 & 55,2 \\
\hline San Isidro & 49722 & 4,5 & 0,5 & 0,0 & 4,0 & 24,4 & 71,1 & 15,6 & 55,5 \\
\hline San Juan de Lurigancho & 655707 & 16,1 & 3,0 & 0,2 & 12,9 & 45,9 & 38,0 & 20,5 & 17,5 \\
\hline San Juan de Miraflores & 269590 & 15,7 & 3,4 & 0,1 & 12,2 & 41,5 & 42,8 & 24,6 & 18,2 \\
\hline San Luis & 42838 & 10,5 & 1,0 & 0,1 & 9,4 & 39,4 & 50,1 & 19,2 & 30,9 \\
\hline San Martin de Porres & 435279 & 11,8 & 1,9 & 0,1 & 9,8 & 38,5 & 49,7 & 25,1 & 24,6 \\
\hline San Miguel & 104346 & 7,2 & 0,7 & 0,0 & 6,5 & 31,0 & 61,8 & 21,2 & 40,6 \\
\hline Santa Anita & 137563 & 15,8 & 2,2 & 0,1 & 13,5 & 50,0 & 34,2 & 16,7 & 17,5 \\
\hline Santa Maria del Mar & 569 & 19,5 & 2,5 & 0,0 & 17,0 & 47,6 & 32,9 & 19,0 & 13,9 \\
\hline Santa Rosa & 7675 & 13,7 & 1,6 & 0,0 & 12,1 & 48,9 & 37,4 & 22,2 & 15,2 \\
\hline Santiago de Surco & 231571 & 6,2 & 0,6 & 0,1 & 5,5 & 28,4 & 65,4 & 19,9 & 45,5 \\
\hline Surquillo & 71566 & 9,6 & 0,9 & 0,1 & 8,6 & 36,7 & 53,7 & 20,8 & 32,9 \\
\hline Villa El Salvador & 271780 & 16,2 & 3,1 & 0,1 & 13,0 & 46,9 & 36,9 & 23,8 & 13,1 \\
\hline Villa Maria del Triunfo & 273162 & 19,3 & 2,4 & 0,1 & 16,8 & 52,7 & 28,0 & 18,0 & 10,0 \\
\hline
\end{tabular}




\section{ANEXO 4: Términos nutritivos relacionados al aceite de Sacha Inchi}

Omega 3: Es un ácido graso esencial poliinsaturado, que no lo puede producir el cuerpo humano.

Ayuda a incrementar el tiempo de coagulación de la sangre, que sirve para prevenir la incidencia de enfermedades cardiovasculares. También ayuda a regular la presión arterial aumentando la elasticidad de las arterias, tiene efectos benéficos en el cerebro, ayuda a la artritis reumatoide disminuyendo el dolor, la colitis ulcerosa con disminución de la inflamación, ayuda a los dolores de la menstruación, reducen los eritemas de la soriasis, ayuda en la dermatitis, mejora los síntomas de la esquizofrenia, retardan la pérdida de masa ósea (osteoporosis) y da una buena influencia al bebé durante la gestación. Administrado en altas cantidades podría disminuir los efectos de la depresión y ayuda a prevenir el cáncer colorectal.

Omega 6: Es un ácido graso insaturado que no lo puede producir el cuerpo humano. Tienes propiedades antiinflamatorias y ayuda a fluidificar la sangre reduciendo el riesgo de enfermedades cardiovasculares. Se debe llevar una dieta equilibrada en omega-3 y omega-6, ambas pueden trabajar en conjunto para beneficio de la salud. El consumo de estos ácidos sin un correcto equilibrio y de ácidos grasos omega-6 en forma excesiva produce inflamación y puede contribuir al desarrollo de enfermedades; por ejemplo, de índole coronaria, cáncer y artritis. En una dieta saludable la proporción de ácidos omega-6 debería ser aproximadamente de 1:1 a 2:4 veces mayor que la de omega-3. (Tengo que explicarte unas cosas que he leído sobre esto de omega 6 y 3, la cosa es q el omega 6 está en casi todo lo q comemos (tiene colesterol y engorda cuando 
lo comes en exceso), en carnes en comidas en todos los aceites, etc.... Pero el 3 no está en muchos lugares, la cosa es que el omega 3 es el que te regula y las cantidades de omega 6 y ayuda a que se utilice y el metabolismo lo absorba como grasa buena, por eso es que también ayuda a bajar de peso.)

Omega 9: Es un ácido graso insaturado. Ayuda a prevenir el cáncer de mama, sus efectos biológicos son generalmente mediados por sus interacciones con el omega 3 y 6. Tiene efectos antioxidantes, mejora la artritis, aftas, psoriasis, hernia de hiato, gastritis, úlceras digestivas, estreñimiento y ayuda a regular la presión arterial. También es recomendado para las enfermedades neurodegenerativas. Ayuda a disminuir la ingesta de Omega 6 y ayuda a optimizar la ingesta del Omega 3.

Vitamina A: Es un nutriente esencial para el cuerpo humano. Desarrolla un papel importante en el desarrollo de una buena visión., especialmente ante una luz tenue. También se puede requerir para la reproducción y la lactancia. Tiene propiedades antioxidantes que ayudan a prevenir el envejecimiento celular. Es necesaria para el crecimiento y desarrollo de los huesos, evita afecciones al sistema respiratorio.

Vitamina E: Ayuda al sistema circulatorio, tiene propiedades antioxidantes, oculares, previene la enfermedad de Parkinson, regula el colesterol, ayuda al crecimiento del cabello y evita la demencia en la vejez.

\section{Ácidos grasos insaturados (93\%):}

Tienen un punto de fusión (Sólido->líquido) más bajo que los ácidos saturados. Tienden a ser líquidas a temperatura ambiente. 


\section{Ácidos grasos saturados (7\%):}

Es la más baja en comparación a cualquier otra semilla oleaginosa. Tienden a ser sólidas a temperatura ambiente. Se relacionan con una mayor probabilidad de tener enfermedades cardiovasculares.

Digestibilidad alta (96\%): Que se aprovecha todo el alimento, los desperdicios que el cuerpo elimina son mínimos comparados con la cantidad de materia ingerida. 